\title{
PATIENT EXPERIENCE OF JOINT REPLACEMENT EDUCATION: A JOINT VENTURE
}

\author{
by \\ Lynda Sheree Gare
}

A thesis submitted to the Victoria University of Wellington

in partial fulfilment of the

requirements for the degree of

Master of Nursing (Clinical)

Victoria University of Wellington

2006 


\section{Abstract}

Purpose: To explore patients' educational experiences and the usefulness and benefits of this health education in the rehabilitation period, when undertaking a total joint replacement.

Design \& Method: An exploratory, qualitative descriptive study, describing patients’ experiences of health education. Five participants, convenience sampled, were interviewed eight to twelve weeks post surgery following unilateral total joint replacement in a tertiary hospital.

Findings: Participants valued the education they received pre operatively, which included written material, video and individual interaction with varied health professionals. Although this was provided in a timely manner, evidence showed limited post operative reinforcement and follow up of given education and preparation for discharge. Three 'partnership' themes were identified from data, Communicative, Subservient and Knowledge. 'Communicative Partnership' conceptualised the participants' experiences of the nurse-patient relationship, whilst 'Subservient Partnership’ captured the participants' experiences of 'being' patients. 'Knowledge Partnership' combined the participants' ideas about knowledge and their retention of this knowledge to assist with their rehabilitation post surgery.

Conclusion: The needs and experiences of patients after total joint replacement reflect on transitional change - changes in roles, behaviour, abilities and relationships. Educational contents need to reflect a realistic recovery process to assist with this transitional period, delivered by health care professionals in a manner best suited for patients. This study provides a descriptive study of patients' perspectives of their journey undergoing a total joint replacement, making the process and their experiences more visible for health professionals. Careful pre and post operative education and planning can facilitate patients' optimism and motivation in their rehabilitation.

Key Words: Joint replacement, health education, patients’ experiences 


\section{Acknowledgements}

This thesis has been a journey of a life time in which I have grown both personally and professionally. This journey would not have been possible without the assistance and help of others, with which I would like to acknowledge.

To my 'study buddies' Diane and Ross - thank you for sharing the highs and lows during my journey and for being there when needed. Our supervision sessions were both fun and informative. By sharing and openly discussing our work, the process became much more interesting and far less tedious.

To all the Masters students who have journeyed before me, I thank you for being able to share your 'master' pieces. The help and understanding it has given me in my own personal journey has made the road to completion a little less windy and rough. I hope, too, that this project will help future students as they strive to achieve their goals.

To the participants I am truly grateful for sharing their experiences and enabling me to share them with you all.

To my supervisor, Cheryle Moss. Thank you so very much for the wonderful words of wisdom, the support and guidance throughout this journey. This relationship started as a professional affiliation, but along the way changed to a valued friendship that will long be treasured. Thank you Cheryle, for letting me be me, and letting me discover myself as a person, without any pressure.

Thanks to the Ministry of Health, NZ, for the Orthopaedic Initiative scholarship to assist with my studies over the past three years. 
To David Clews, I thank you for believing in me and supporting me as I ventured in my academic journey and advancing clinical practice. Your gentle, yet admirable leadership qualities have given me inspiration and have allowed me to realise that no dream is ever unachievable. You have taught me, and many others, so much during your short life span and to this I am truly indebted. You have given hope to many underprivileged children and have taught me that there is always hope and achievement, no matter what life throws at us. May you forever fly freely, Dave.

And last of all, my heartfelt thanks goes to my husband, Jerome and son, Hayden. Without their loving support and understanding, my journey would never have been completed.

\section{I dedicate this, my 'master' piece to them both.}




\section{Table of Contents}

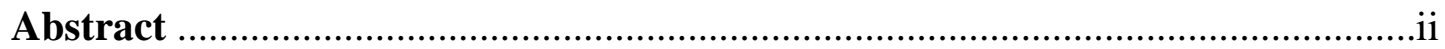

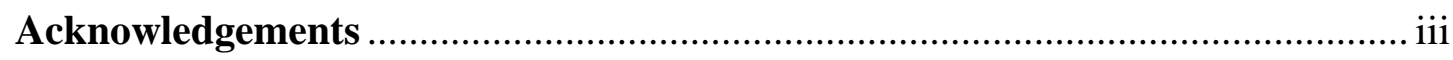

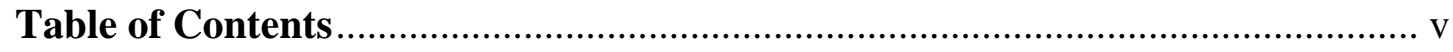

List of Tables ................................................................................................. vii

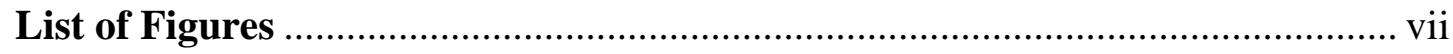

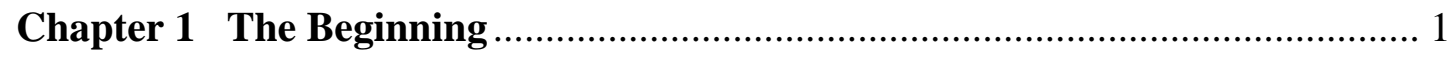

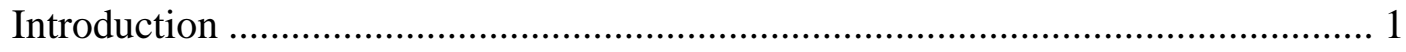

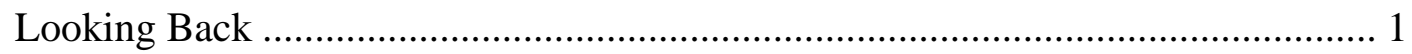

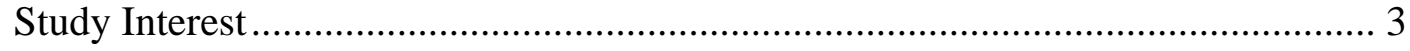

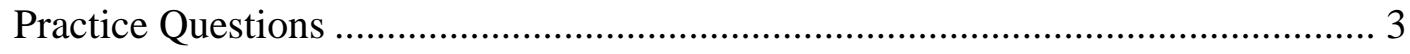

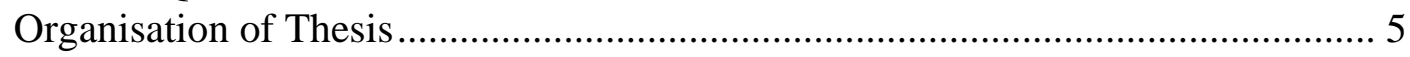

Chapter 2 Background: Demands for Joint Surgery ….................................. 7

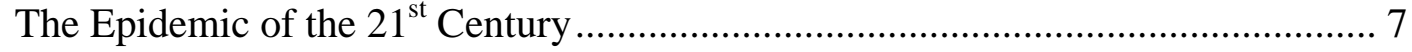

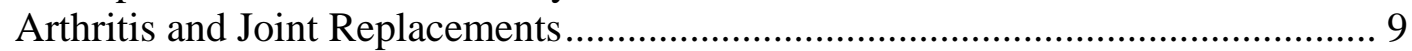

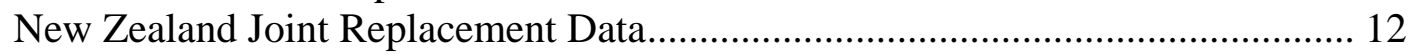

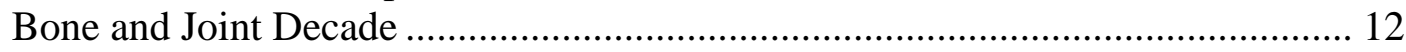

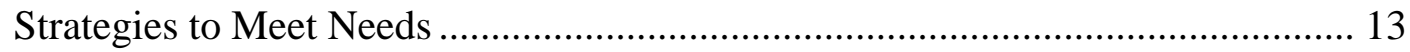

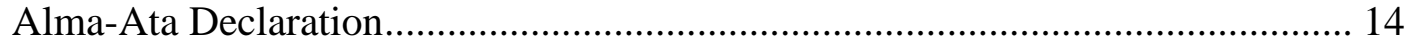

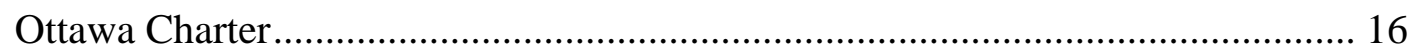

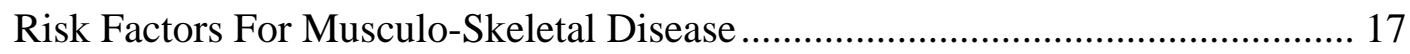

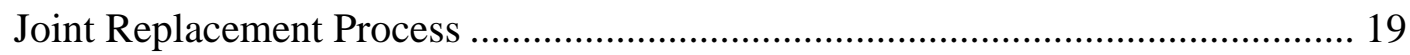

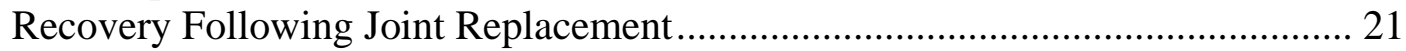

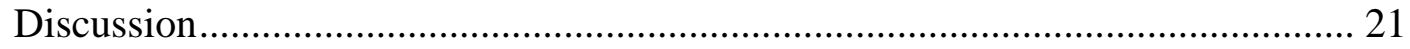

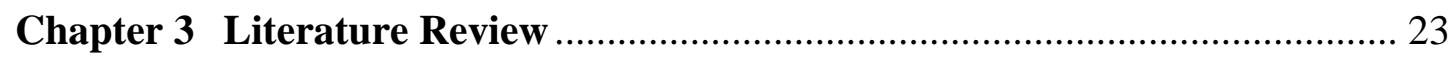

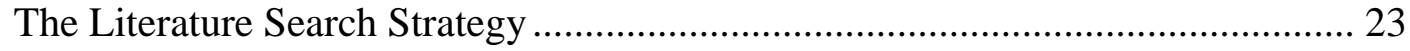

Pre Operative Education: A Systematic Review …........................................... 24

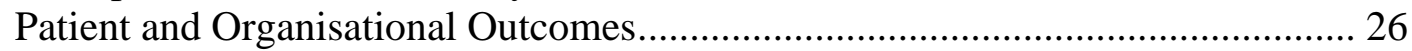

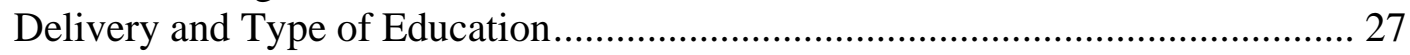

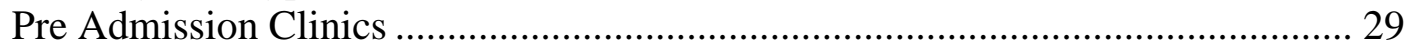

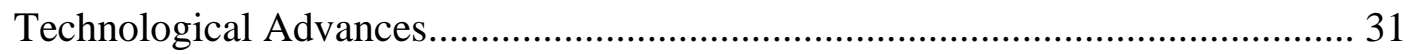

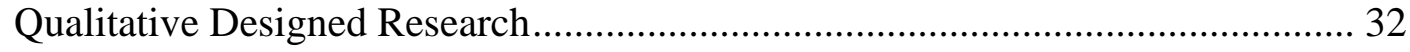

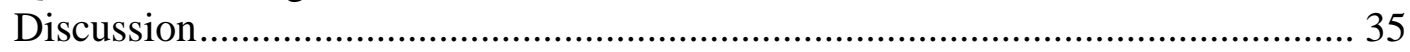

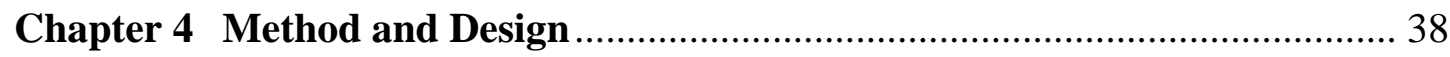

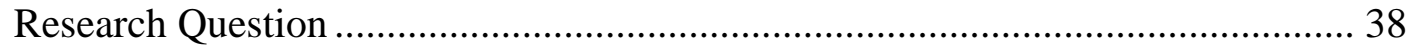

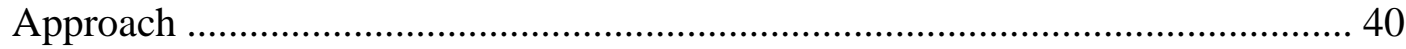




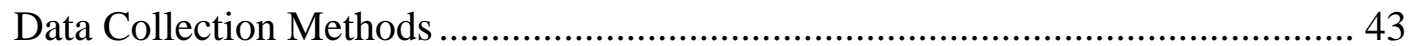

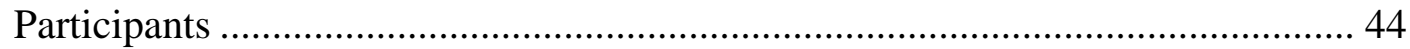

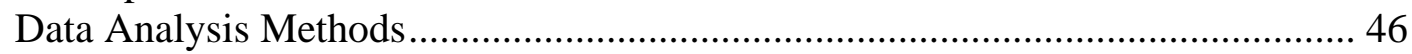

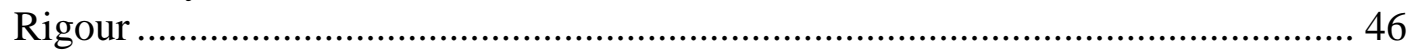

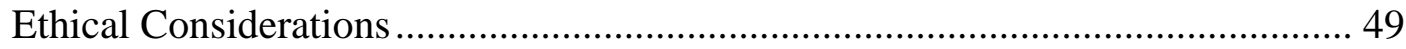

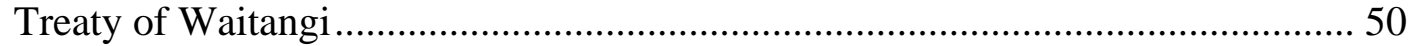

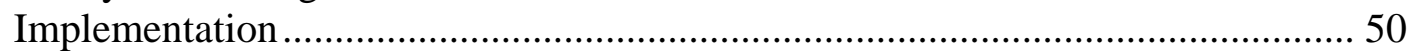

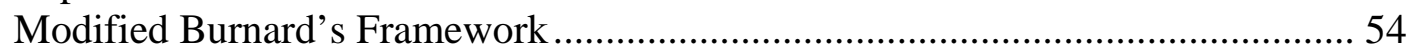

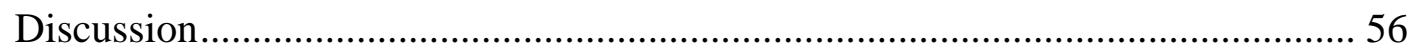

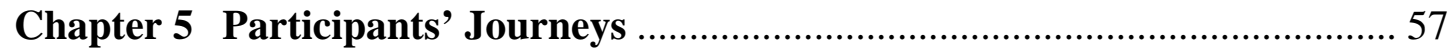

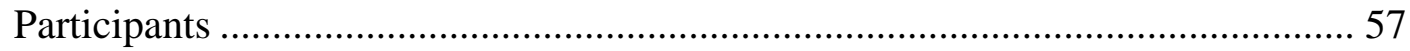

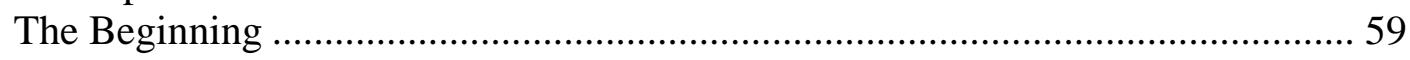

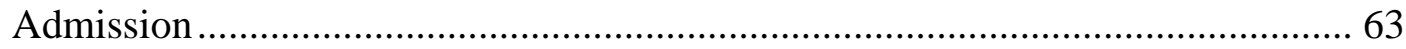

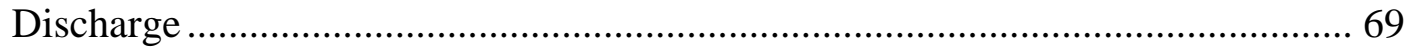

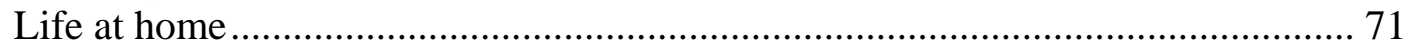

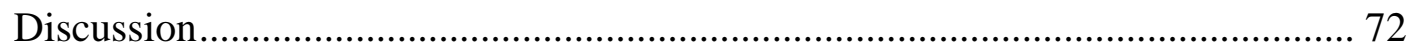

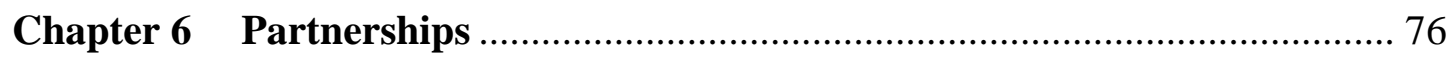

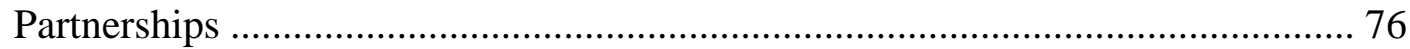

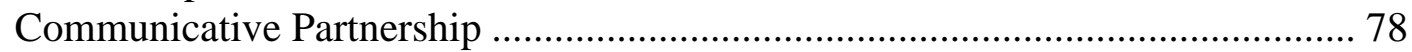

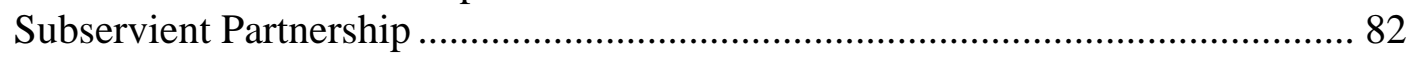

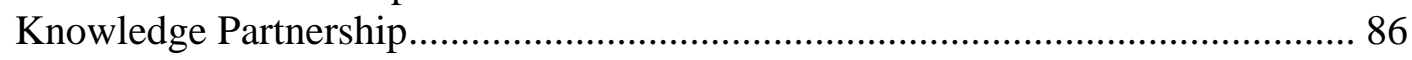

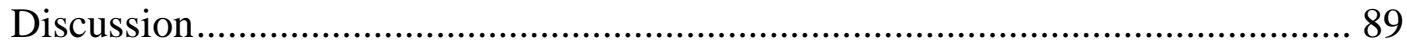

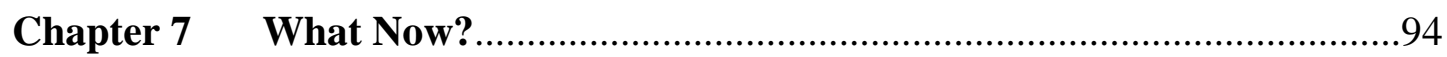

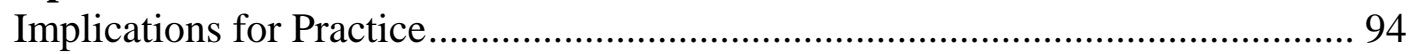

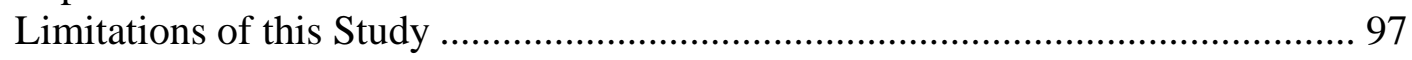

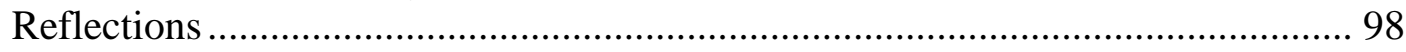

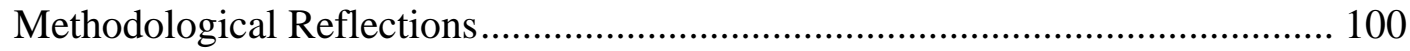

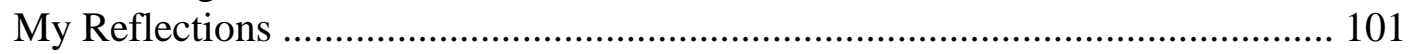

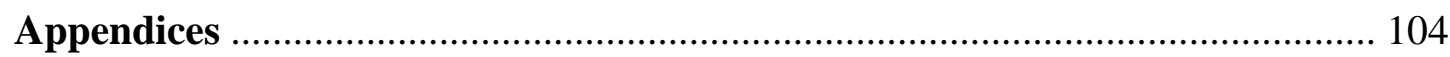

Appendix 1 Transcriber's Statement of Confidentiality. ................................... 104

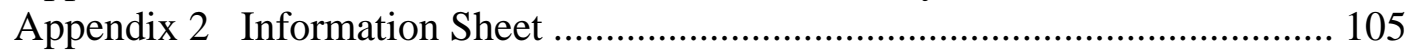

Appendix 3 Consent Form.......................................................................... 107

Appendix 4 A Health Equity Assessment Tool (HEAT) ................................. 109

Appendix 5 Maori Health Approval ................................................................. 110

Appendix 6 Northern Y Ethics Committee Approval ...................................... 112

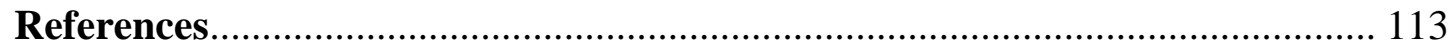




\section{List of Tables}

Table 1 Overview of Method and Design.......................................39

Table 2 Framework of Questions used as ‘Aide Memoire'........................45

Table 3 Modified Burnard's Analysis Tool.....................................46

Table 4 Reoccurring Sub Themes from Data................................. 76

\section{List of Figures}

Figure 1 Theme Relationships................................................77 


\section{Chapter 1 The Beginning}

\section{Introduction}

Health education and informed patients are important aspects of health care delivery. The interest of this thesis is education given to patients undergoing total joint replacement, and the usefulness and benefits in their rehabilitation. This study will explore participants' educational experiences through their joint replacement journey, commencing from their pre admission appointment through to the transition to their home environment. Participants will share their experiences of the education and care they received throughout their journey.

In my clinical practice as the Orthopaedic Pre Admission Nurse Specialist, my role entails completing in depth health assessments and the preparation of patients for their pending joint surgery. This includes preparation for surgery, explanations of actual surgery, expectations following surgery, and effectively preparing them for going home. Health education is a large proportion of this role, teaching both patients and their families about joint replacements and the processes that occur during the journey. Personally, I believe that patients need to be fully aware of the procedures and what is expected from them following their surgery. Developing a partnership between the patient and the health carers plays a very important role within the journey and also has some bearings to the way patients take control of their recovery period post operatively.

\section{Looking Back}

Like all things, there is always a beginning. The journey towards this research interest began in the early nineteen eighties as I progressed through my nursing education. Right from an early stage, I remember taking an interest in patients’ abilities to gain knowledge about their conditions and their planned treatments. During those years consultants performed ward rounds, often talking amongst the doctors and barely acknowledging the patient. Then off they would proceed to the 
next bed. I would watch, in utter bewilderment, as, back then, as a student I did not ever dream of speaking to the consultant. In my experiences the nursing model was definitely subservient to the medical profession (Rolfe, 1996; Turnbull, 1994). However, as I experienced this type of behaviour more frequently I began to realize that health care needed to become a partnership - a partnership between the health professionals and the patient.

My early realisation of the vulnerability of patients in this era was overwhelming. Patients seemed to have very little knowledge and there was often an understanding that the 'doctor knew best' and that even if they did not know what was happening, they were in good hands (Rolfe, 1996; Simons \& Ewing, 2001). Erlen (2006) discusses how vulnerable patients can experience lack of confidence, feel threatened, have knowledge deficits and power inequalities. Despite changes occurring in the healthcare sector that support patients becoming more involved with decision making, it is still evident that disparate relationships continue (Baldwin, 2003). I became acutely aware of the need for a 'voice' for the patient following these experiences, someone who would speak up and ask questions and ensure that the patient did fully understand their situation. I felt very sensitive to patients' needs and became an advocate to support or represent the patient as required. Those that take the role as an advocate are frequently described as 'activists', and some colleagues have some difficulties in the full understanding of this action, as I have experienced in my meandering pathway.

Many times in my nursing career, I have been left to give the necessary health information in a way that the patient understands. Following these experiences I believe that patients need to be fully informed and educated about their treatment and care. I believe that health education will empower people and allow them informed consent, and gain back a partnership in health care. Looking back, I can feel proud and justified as I utilised my skills and knowledge to support those in a vulnerable position.

Over the last 26 years, I have focused my career in the public health arena. At times, it has become evident that private and public services to health care 
consumers has differed vastly, despite performing similar elective surgery. This has encouraged an inner curiosity within me and has initiated me to reflect on current practices that occur for patients receiving joint replacement surgery. It has raised several issues. Is it beneficial to patients to have health education when proceeding with joint replacement? What benefits do patients receive? How does health education assist them as they return to normal, everyday life? These reflective questions have emerged as I think more seriously about my own practices within my educator's role in regard to health education.

\section{Study Interest}

Surgical treatment for osteo arthritic joints is a major health intervention; the frequency of which will undoubtedly increase due to the increase in the elderly population. In my clinical role, I am very passionate about patient education and strive to explore ways in which I can improve the delivery and understanding of this. However, there is very little research that has been published on patients' perspectives of health education associated with joint replacement. Exploring their experiences and stories will assist the development of evidence. I strongly believe that patients and their families need to be fully aware of what to expect during their hospitalisation and their rehabilitation, and this study will allow me to reflect on their perspectives of current practice and improvements that may be made.

\section{Practice Questions}

The method in which the health education is delivered is important. Is it delivered in a manner that is easy to understand and how well do patients interpret it? Remembering that a majority of those receiving joint replacements are in the elderly population, it is important for them to be fully conversant and understand the procedures. As people get older, their senses are not always as astute. They may take longer to interpret and understand information. They also are from the era where they put complete faith and trust into the medical profession and do not ask questions. Were patients given written material that they perhaps could not read? Or was the volume and tone of the video they viewed not easily picked up 
due to hearing loss? These are all issues that need to be considered. Part of any pre operative education is to prepare the patient for discharge from hospital. Did the patients feel adequately prepared for that transition and for the following few weeks of recuperation in their own homes? What were the issues that arose during their joint journey that may not have been covered in the education? The aim of all joint replacement patients is to reduce pain and return to their desired functional activities. This requires a person to have clear expectations of the recovery process and the knowledge to continue with the rehabilitation plan in their own home. It is my belief, along with Loft, McWilliam and Ward-Griffin (2003), that to allow this to occur, the patient must be empowered with essential knowledge and a working partnership relationship with the health carers.

This piece of research supports me to explore what I am very passionate about. That is, to hear the patients talk about their experiences and their perceptions of the health education they received. They are the consumers and if I and my health professional colleagues are to make a difference in care and treatment, it is important that the patients' voices are heard. Empowerment and partnership are important issues in my clinical practice and hearing the participants' experiences will allow me to identify and enable these to occur. Too often in my own clinical practice, I hear that health professionals may listen, but they do not actually hear. Partnership will be described in further details in Chapter Six.

This project explores patients' educational experiences and the usefulness and benefit in rehabilitation when patients undergo their first total joint replacement. As New Zealand's aging population increases, so does the incidence of musculo skeletal diseases, in particular, the debilitating effects and pain of arthritis. Not only is the increased aging population affecting the incidence of joint replacements, but risk factors such as obesity are now playing a significant part also. For those people affected by this disease, the only long term relief is joint replacement for which, as discussed previously, demand will increase in the future. 


\section{Organisation of Thesis}

The epidemic of the $21^{\text {st }}$ century, as described by the New Zealand Orthopaedic Association (2003), of the need for increased joint replacements, will be explored in Chapter 2 and will examine how that affects both the individual and society as a whole. The physiology of arthritis will be overviewed and exploration of potential risk factors will be identified. The Ottawa Charter and the Alma-Ata Declaration will be discussed in relation to this epidemic, and strategies put in place by the New Zealand government will be discussed.

Exploration of the literature surrounding health education in the orthopaedic field will be presented in Chapter 3, exploring the different ways that health education has been researched. It will identify the different methods used in disseminating education to patients and will explore findings from these studies. It will also identify the absence of research around health education from a patient's perspective in regard to joint replacements.

An insight into the choice of methodology to allow the exploration of patients' experiences and their perspectives of the given health education will be explained in Chapter 4. Within this chapter two tenses will be utilised to describe the processes involved with this study. Inclusion criteria and recruitment methods will be discussed. Reviews of ethical considerations and the Maori Health consultation process will be clarified as appropriate to this study.

The next chapter will be constructed as a woven piece of narrative, detailing the participants' journeys, using quotations and interwoven with supportive literature, starting at the pre admission clinic through until discharge. Chapter Five will give an insight into patients' experiences of the health education that they received throughout this joint replacement journey and describe the patients' preparedness for their surgery. Sub themes will be identified, discussed and supported by current literature.

Partnership will be discussed within Chapter 6, identifying the relationship with communication, subservience and knowledge, whilst Chapter 7 provides a 
conclusion to this study and will discuss the implications, limitations and further research that may be initiated. 


\section{Chapter 2 Background: Demands for Joint Surgery}

In New Zealand, an average of 10,000 knee and hip joint replacements occur every year. This figure is expected to dramatically increase as the population ages, obesity continues to rise, musculo-skeletal disease increases and sporting injuries continue to occur. With the contractual commitments of joint replacements being increased by the Ministry of Health, district health boards need to meet the government's and the consumer's needs. Both are important issues that health professionals need to consider. Health education is one aspect of joint care that is important for consumers when undertaking a joint replacement and it is this topic where my interests lay. This chapter will provide some background orthopaedic information concerned with musculo-skeletal disease and why joint replacements are undertaken, with the risks and benefits discussed. National and international strategies will be identified and discussed in relation to musculo-skeletal disease and joint replacements, and current practices will be explored.

\section{The Epidemic of the $21^{\text {st }}$ Century}

New Zealand's aging population has been identified by the New Zealand Orthopaedic Association (NZOA) (2003) as an epidemic which will have a major impact on the health system. For society, this will impact on future health care. It is predicted that by the year 2051, 31.6\% of the population will be over the age of sixty years. This increase in proportion of older persons is attributed to today's advanced technology, health management and prolonged life expectancy. Population aging has not developed as far in New Zealand as it has in many other developed countries and there is now an opportunity to observe and learn from others’ experiences (Kinsella \& Velkoff, 2001).

In relation to this study, the increasing aging population suggests that a concomitant increase in the amount of joint replacements will also occur in future years. It will also represent more challenges for health professionals when they provide care. Issues such as increased morbidity and mortality, increased risk of 
post operative complications, increased challenges for knowledge retention, higher input for discharge planning, increases of social services, to name but a few (Cornwall \& Davey, 2004).

The aging population needs to be considered, both now and in the future, for planning and policy development (Cornwall \& Davey, 2004; Health of Older People Strategy, 2002; Poutasi, 2004; Tak, 2006). Significant factors that will need to be considered are health, housing, transport, and community services to meet their needs. It is known that older people are high consumers of publicly funded health services and demand is driven by trends in age-related diseases, mortality and disability. In terms of fiscal pressure, it is important to consider such effects early (Access Economics, 2005).

In the future, the aged population will be different to today's elderly, due to dissimilar educational, lifestyle and workforce experiences. It will also have greater ethnic diversity and regional differences in the aging pattern, and a higher proportion of the female gender which is already becoming evident. Although the aging population has been identified as an epidemic in relation to age-related disease trends (New Zealand Orthopaedic Association, 2003; Poutasi, 2004), there are some positive aspects that need acknowledgement. Longer life is a testimony to social and economic progress and the ability for this age to contribute to society is a significant achievement (Cornwall \& Davey, 2004). It is greatly important that those suffering from the debilitating effects of arthritis be treated within a timely manner and returned to their normal activities as quick as possible. This may even mean returning to paid employment, as the population continues to work for longer.

Analysis of age-related diseases suggests an increase of incidence in musculoskeletal disease (Health of Older People Strategy, 2002; Poutasi, 2004; Tak, 2006). There are over one hundred and fifty diseases and syndromes that can affect the musculo-skeletal system and these are usually associated with pain and/or inflammation, debilitation and reduced ability to maintain daily living needs. Arthritis, osteoporosis, spinal disorders and increased fragility leading to 
increased falls and injuries, are the common ones which have been identified as a leading cause of morbidity and disability in the older population.

Access Economics (2005) states that in 2005, “almost 522,000 New Zealanders aged 15 or over are living with at least one type of arthritis” (p.1). That equates to approximately one in every six people or $16.2 \%$ of the total population. Little information is available through clinical studies measuring the prevalence of arthritis in New Zealand. This would provide useful information to policy makers in relation to risk factors, impacts and the cost effectiveness of interventions and preventative activities (Arthritis New Zealand, n.d.).

It is not only the aged population that will create a demand for an increased number of joints to be undertaken in the future years. Other risk factors are on the increase within New Zealand's population. Physical inactivity, heredity and social indicators, and the increasing weight and body mass index will put more demands on New Zealand's health service in the future (King, 2004; Poutasi, 2004). These risk factors will be discussed later in this chapter.

\section{Arthritis and Joint Replacements}

The most common type of arthritis is osteoarthritis, which is prevalent in the elderly age group. Osteoarthritis has been commonly called the "wear and tear" or “degenerative” arthritis, but there is a growing understanding that it may be an inflammatory arthritis (Arthritis New Zealand, n.d.). It occurs more commonly in the weight bearing joints - hips, knees and spine. For years, osteoarthritis was considered only in the elderly population, it has now been detected in some people before they reach the age of 21 years.

With the increase of research being undertaken, there is now an understanding that it may be an inflammatory arthritis, resulting in the mechanical breakdown of the structures affecting the joint. New Zealand research is leading the world in researching the cells within cartilage which first breaks down (Arthritis New Zealand, n.d.). Despite the size and economics of New Zealand, there are scientists that are researching and uncovering new knowledge which in the future years will help many people. It is known that arthritis is not caused by bacteria or 
poisons in the blood, acids in the body, diet deficiencies or excesses, gland abnormalities, the weather, exercise or sudden shock, although some of these may influence the pain once osteoarthritis is established.

In the normal joint, the cartilage that covers the end of the bones acts as a shock absorber, with tendons and ligaments holding the joint in position, enclosed within a capsule. The thin synovial membrane releases fluid to enable the joint to function smoothly. In osteoarthritis, the cartilage starts to wear away and leaves the bone unprotected. The joints become painful and difficult to move, and often loses its shape as the bone underneath thickens and grows out at the sides. This further reduces the smooth movements of the joint and increases the pain and difficulty in movement (American Academy of Orthopaedic Surgeons, 2006a; 2006b).

Total joint replacement is the removal of the damaged or diseased joint with the replacement of an artificial joint which is commonly known as a prosthesis or implant. It is a surgical intervention that is undertaken for arthritic joints and is commonly done after an initial trial of conservative treatment.

Hip joint replacements were first performed back in 1960 (American Academy of Orthopaedic Surgeons, 2006a), with knee joint replacements following in 1968 (American Academy of Orthopaedic Surgeons, 2006b). Since then, surgical techniques have advanced and surgical materials have much improved, greatly increasing the effectiveness of joint replacements. There are also many varying types of joint surgeries performed today. For example a knee joint replacement can now be a total or a unicompartmental (replacing just one compartment) joint replacement. Joint replacements are not limited to hips and knees today. With increased knowledge and advancing techniques, there are now several other joint replacements that are being carried out by orthopaedic surgeons - shoulders, elbows and ankles.

The decision to perform a joint replacement is not taken lightly. Conservative treatment including physiotherapy, pain management, non-steroidal antiinflammatory drugs and the use of walking aids, are usually trialled initially. Conservative treatment for osteoarthritis is done in collaboration with health 
professionals that may include physiotherapists, occupational therapists, alternative practitioners, doctors, and nurses. Treatment will not reverse the changes which have already occurred in the joint, but symptoms can be managed. Surgical consideration occurs when the joint becomes increasingly damaged, which causes an increase in pain and decrease in mobility and the person's ability to maintain a normal lifestyle is considerably reduced (Arthritis New Zealand, n.d.). There are several factors that must be considered prior to joint replacement surgery. Orthopaedic consultation for a thorough evaluation including medical history, functional activities, physical examination and x-rays are undertaken.

A major goal for joint surgery is that patients will get relief of the severe pain that limits their everyday activities such as walking, sitting and standing, and climbing stairs. Often pain can be present even at rest and in well advanced arthritis, this is difficult to manage conservatively. There is no guarantee that all pain will be alleviated following surgery, however, joint stiffness and mobility can be much improved following joint replacement (Arthritis NZ, n.d.; New Zealand Orthopaedic Association, 2003). However, intensive physiotherapy and hard work is often required by the patient, particularly for knee replacements. Joint deformities that often occur due to the loss of cartilage within the joint can often be improved also with surgery. This greatly reduces the stress placed on other joints and parts of the body. Patients can often return to activities that they have previously found too painful or difficult. There are risks associated with any surgical procedure and joint replacements are not excluded. The main risks specifically pertaining to joint replacements is infection, dislocation and loosening. If any of these occur, the impact on both the person and the health care can be colossal - financially, physically, mentally and socially (New Zealand Orthopaedic Association, 2005).

Joint replacement surgery is considered to be major surgery. The resources needed to perform such surgery are large and involve a large team of health professionals. The impact of an increase in joint replacement surgery will definitely impact on the health dollar and on health service provisions to the New Zealand population. It is therefore imperative that risk factors, such as weight and social indicators, be addressed early. 


\section{New Zealand Joint Replacement Data}

The NZOA has developed a national joint replacement register to collect data about joint replacements. The database was initially set up back in 1998 and provides data for future research, patient satisfaction assessments, survivorship of different implants, and auditing for individual surgeons, hospitals and regions (New Zealand Orthopaedic Association, 2005). This register will be used in monitoring and auditing in the future years.

In the year ending December 2005, there were 11,888 knee and hip joint replacements documented to have been undertaken within New Zealand. Back in 1999, the total number of hip and knee joints was 6597 (New Zealand Orthopaedic Association, 2006). That is an increase of 5291 in just five years. In a media release by the New Zealand Orthopaedic Association in April 2005, it was revealed that more than 100 New Zealanders over 90 years of age, received joint replacements over the past five years (New Zealand Orthopaedic Association, 2005). This supports the prediction of the trend of the elderly population with the increasing demand for joint replacements in the future.

\section{Bone and Joint Decade}

In light of the aging population and the increased incidence of age-related musculo-skeletal disease, Swedish orthopaedists conceived the idea of dedicating a decade devoted to musculo-skeletal disease - Decade of Bone and Joint 20002010. As a result an International Steering Committee was initiated (Bone and Joint Decade Joint Motion 2000-2010; New Zealand Orthopaedic Association, 2005). This has been developed on the perceived success of the Decade of the Brain in terms of fostering interest and promoting research and awareness of musculo-skeletal diseases. This initiative was keenly taken up in New Zealand by health professionals and lay groups such as Arthritis New Zealand and Osteoporosis New Zealand. Their aims, whilst taking the global objectives into account, were to identify major operational working projects. These included actually measuring the extent of the musculo-skeletal disease burden in New 
Zealand and raising the awareness and emphasizing the preventative measures that can assist with reducing it. It also included the education of the public surrounding specific musculo-skeletal diseases and improving the access and consistency of treatment for these disorders. The other main project is ensuring that new treatments for such disorders were available to all New Zealanders (Arthritis NZ, n.d.; Access Economics, 2005). The 'Bone and Joint Decade' project has the endorsement of the United Nations, the World Bank and the World Health Organisation (WHO) and have had the overwhelming support of more than 750 organisations and institutions from all over the world (WHO and the Bone and Joint Decade, 2001).

\section{Strategies to Meet Needs}

The increased demand to provide joint replacements is placing an increasing amount of pressure on district health boards across New Zealand. Services and procedures are being evaluated to provide timely, effective joint care. Patient education is an important aspect of this care and considerable time is spent ensuring the patient is fully informed about their impending joint surgery. There is little published research surrounding the perceived benefits and advantages of this education from the patients' perspective. With the government investing heavily in joint surgery to increase the numbers to meet demands, this research project will enlighten health professionals on the patients' perceived benefits of education that was given.

The Ministry of Health developed the “Orthopaedic Initiative” in 2004, whereby funding was increased to district health boards. This initiative is set to double the number of major knee and hip joint replacement operations until 2008 (King, 2004; Poutasi, 2004). This will enable those that have been waiting for a considerable time to finally have their surgery undertaken. Not only has the government provided more funding for district health boards to perform more operations, it has also provided extra funding to assist health professionals with further studies, research, and projects. This is enabling nurses to advance their orthopaedic knowledge and skills to provide more effective joint care. University studies are being undertaken by nurses, whilst district health boards are initiating 
new positions and pilot projects to assist with the ever increasing number of joint replacements and facilitating an improved health care system for all New Zealanders. The position that I am currently employed in as an Orthopaedic Pre Admission Nurse Specialist has been developed in conjunction with the Joint Initiative Strategy.

Despite this initiative being announced before the 2005 general election, with possible political tones, it can only be a positive move, for the population, to improve the quality of life of many New Zealanders. With the district health boards increasing the number of joint replacements, people will not have to wait so long for their surgery and can be relieved of the chronic pain that so often restricts their daily lives. This will enable them to restore their quality of life and independence. As our population ages and the incidence of arthritis increases from other risk factors, waiting lists in public hospitals continue to grow. District health boards are struggling to balance consumers' needs with the available health dollar, and manage Ministry of Health contracts, despite the extra funding. This has become evident in my role of Clinical Nurse Specialist.

\section{Alma-Ata Declaration}

Back in 1978 the International Conference on Primary Health Care acknowledged the Declaration of Alma-Ata (World Health Organisation, n.d.; Breslow \& Gale, 2002). Those that attended that conference made a plea for governments and communities world wide to protect and promote the health of all people in the world. This declaration still has great importance today and is still often referred to in Primary Health Care.

Social and economic influences play an important role in the Alma-Ata Declaration. The need to reduce the gross health inequalities between the lower and higher socio economic groups remain a high priority (Ministry of Health, 2002). Recently in New Zealand the Primary Health Organisations (PHOs) have been developed with this aim in mind. PHOs work in partnership with the district health boards and identify problems in primary health, develop strategies to assist 
with these problems and then pilot these projects to promote health and well being. Obesity is one of the issues that is being examined currently, which today is a significant health issue for New Zealand's population. It also contributes significantly to symptoms of musculo-skeletal disease (Ministry of Health, 2002).

It is widely recognized that the promotion and protection of peoples' health relates directly to the social and economic development of society and also contributes to a better quality of life (King, 2004). The Alma-Ata Declaration also emphasizes the need for people to be involved with the planning and implementation of the health care (Ministry of Health, 2002). This health care must be delivered at a sustainable cost and be readily accessible to those in need. (World Health Organisation, n.d.). New Zealand Orthopaedic Initiative strategies are attempting to achieve this for joint replacements.

Tobias and Howden-Chapman (2000) suggests significant links between income and health. In New Zealand, there is no official definition of 'poverty', however, in some studies it is defined as the lowest 20 percent of the income distribution. Tobias and Howden-Chapman (2000) argues that ethnic groups, elderly and children are over represented in these figures. It appears that the lower socioeconomic people do not access health care as readily as others. Often this group of the population either cannot afford or do not know how to access the assistance that is required and don't actively seek it until it is often at the extreme. This is seen in orthopaedic outpatient clinics when the elderly present with a fracture due to a fall. It is only when x-rays are completed that osteoporosis is diagnosed. Older people also tend to not seek assistance to manage arthritic pain and symptoms. They tend to struggle with their everyday living activities. These patients often tend to need more health and social service input, such as convalescing care and home help on discharge, when admitted for joint surgery.

Tobias and Howden-Chapman (2000) identify lower income earners are often engaged in the low-skilled manual occupations. For these people, it increases the risks of the 'wear and tear' phenomena on the joints, increasing the chances of osteoarthritis, and also increasing the risk of injury. Studies show a higher mortality rate for manual labourers than professionals and also a higher rate of 
death, major chronic illness and injury (Tobias \& Howden-Chapman, 2000). Due to the affluent members of the population utilizing private insurances and hospitals, it is difficult to assess the utilization of hospital inpatient services. It is recognized that those living in more deprived regions of New Zealand have higher rates of inpatient hospitalization (King 2004).

Today there are many different stakeholders who are involved with the planning and implementation of health care. In New Zealand it has been recognised that Maori and Pacific Islanders have poorer health (King, 2004; Ministry of Health, 2002; Ministry of Health and Public Health Consultancy, 2002). It is important to remember that health promotion in New Zealand needs to consider ethnic issues, such as the implications of the Treaty of Waitangi, and incorporate it into health care planning (Health Promotion Forum of New Zealand, n.d.). Embracing the Maori model of health, including the spiritual, mental, physical, language and family elements is imperative to improve Maori health.

\section{Ottawa Charter}

The Alma-Ata Declaration was followed by the Ottawa Charter, established in 1986 (Breslow \& Gale, 2002). It focuses on health promotion, encouraging people to take control over and improve their health. It emphasizes health as a positive aspect incorporating social and personal resources as well as physical capacities (Health Promotion Forum of New Zealand, n.d.). The key points of the Ottawa Charter are health promotion, maintenance and restoration. It is about building healthy public policies and creating supportive environments to address such issues as culture, social and economics. Strengthening community actions is about providing support and resources for the above to take place. An example of this is the Ministry of Health Referral Guidelines, currently available for health practitioners in general practice. This gives them guidance for management and treatment of conditions such as osteoarthritis, and guides them with a framework for specialist referral.

Education and support assists with developing personal skills to enable the population to make informed life style and health choices. This is assisted by 
health services which must all work in collaboration with the population to achieve these. Re-orientating the health service shares this responsibility (Health Promotion Forum of New Zealand, n.d.; Tobias \& Howden-Chapman, 2000).

The orthopaedic service is involved with all three aspects of the Ottawa Charter promotion, maintenance and restoration. It is important to recognize that the Ottawa Charter must intertwine with the Treaty of Waitangi to offer the best possible outcomes for the Maori population in New Zealand. Some patients who are assessed in the orthopaedic specialty do not require surgery or further intervention from a tertiary service. It is at this stage that conservative treatment is continued, involving the promotion of well health.

Maintenance occurs when surgical intervention is either not indicated or not warranted at this time. It can also occur whilst patients wait for their pending surgery. Maintenance of the patient's condition will then occur in collaboration with the multidisciplinary health teams. This may include setting up equipment in the home with the occupational therapists, providing treatments such as physiotherapy, initiation of further medication management, and home help to assist the person to remain as independent as possible within their own environment.

Restoration occurs both as a primary and a secondary intervention. Primary intervention occurs when the patient who has osteoarthritis, requires a joint to be replaced. The secondary intervention is when the joint needs to be revised due to problems such as loosening. This promotion, maintenance and restoration cycle continually occurs with patients who have osteoarthritis.

\section{Risk Factors For Musculo-Skeletal Disease}

Other than the increased aging population that has already been identified as a factor in increased musculo-skeletal disease, there are several other risk factors identified in the development of osteoarthritis, which in turn will have an effect on the number of people requiring joint replacements. These include biological 
factors, age, joint damage from injury or chronic obesity, physical inactivity, lower education and income and heredity. It is these risk factors that have been identified which will need attention in the future.

As in many developed countries, the average body mass index (BMI) in the New Zealand population has slowly been increasing over the past few decades. Chronic obesity is becoming a major health risk in today's population (Tobias \& HowdenChapman, 2000) and may have a profound affect on musculo-skeletal problems in the future. There have been several studies that link between the increase of obesity and age-prevalance of arthritis (Gill, Taylor, Chittleborough \& Dal Grande, 2003; Oregon Department of Human Services, 2004; Vermont Department of Health, 1999). Following joint replacement surgery, obesity may create further problems with complications of loosening and wear and tear (Donovan, Dingwall \& McChesney, 2006). New Zealand health policy makers are very aware of the impact that this may have in future health care and there has been an emphasis on education of the general public regarding obesity.

Other risk factors are injuries such as fractures and torn cartilage that can result in osteoarthritis at a later stage. It may follow unusual or prolonged strain on a joint either in work or sport. New Zealanders are well known for their love of the outdoors and being keen participants of sporting activities, which increases the risks.

Some forms of arthritis do have a familial tendency especially those affecting the small joints of the hands. However, there is no convincing evidence to state that it is a major reason for having osteoarthritis. Although osteoarthritis is prevalent in the older age group, it can be found in the younger population, as discussed earlier. There is also a prevalence of the female gender being more affected in their later years (New Zealand Orthopaedic Association, 2003).

In this section of the chapter I have highlighted the continual work of district health boards and PHOs to improve the general health and well being of the population. This is being done in conjunction with the extra funding from the government with the “Joint Initiative strategy” (King, 2004). Promotion of well 
health is a very important aspect of health care today, and people need to take ownership of this. Despite the length of time since the Ottawa Charter and the Declaration of the Alma-Ata have been developed, it is still regarded highly and very appropriate in health care today. Increasing the awareness of musculoskeletal disease within the population and promoting all opportunities to advance research and improve health care is the aim of the Bone and Joint Decade. This study will serve to gain further information to inform practice, in regard to patient education, with patients undergoing joint replacements.

\section{Joint Replacement Process}

There is no standardisation of the processes that a patient preparing for a joint replacement transgresses through within the New Zealand health setting. However, district health boards are continually striving to increase the number of joint replacements undertaken in a timely, financial manner. The Joint Initiative has enabled and encouraged health providers to liaise with others in similar settings and evaluate processes being undertaken. It has also encouraged nurses to complete university studies which involve research projects.

The process that occurs in the district health board in which I am currently employed will be explained to give a better understanding of the surgical and joint replacement journey for the patient. Prioritising of joint replacement waiting lists has been undertaken, due to the need for joint replacements outweighing the hospital's ability to meet these needs. Patients requiring hip and knee joint replacements are initially assessed by the orthopaedic consultants and before being placed on the waiting lists, are then reassessed in a specialty clinic by a physiotherapist and nurse. Thresholds for surgery are determined and the patient is then placed on the waiting list, if met. Several issues are assessed in these clinics and the patient's optimum health is a priority. Issues such as obesity, comorbidities and other issues are often highlighted and referrals are sent for further input from the multi disciplinary health team. At this stage in the process, joint education is commenced. Written pamphlets and verbal discussions take place 
with the patient and their supporting family members, if present, in preparation for the pending surgery.

Pre admission clinic is the next stage whereby full health assessments are completed and patients are assessed by the anaesthetists. Pre operative bloods and other required tests are undertaken and followed up. Within this clinic, there is an allocated time for pre operative teaching by the multi disciplinary team physiotherapist, occupational therapist and specialty nurse. A video is viewed by all patients and family members, which reiterates the information in the written booklets. One on one sessions involving each member of the team are completed with full explanations and assessments are carried out. Questions are answered and discharge planning is also discussed, in readiness for surgery and rehabilitation. The objective is to prepare the patient fully for their pending surgery and rehabilitation.

Health professionals involved with education for joint replacement surgery base their practice on what they deem important and what they believe is appropriate and workable within their health settings. The next chapter supports this claim as there is little research to explore education from the patients' perspectives and how they find the relevance and benefits during their rehabilitation. Research to explore patients' experiences will reveal important data for these health professionals to guide their clinical practice.

Knowledge of how well we prepare patients for their surgery and rehabilitation remains elusive. This study seeks to add knowledge to this important area. Patient satisfaction surveys are randomly sent to patients to complete following their discharge from the tertiary hospital in which this study was undertaken. It is a general rating system using a Likert scale to rate from very poor to very good. The topics rated are information on different treatments available, family involvement, permission to treat, choices specific to culture, preparation for discharge, cleanliness of environment, dietary, safety and security issues. There are four extra lines at the end of the form for further comments. There are no questions related to preparedness for surgery, health education received or what was useful or beneficial throughout the patient's journey. 


\section{Recovery Following Joint Replacement}

The optimum recovery for the patient is the main objective throughout the joint replacement journey. To have a patient fully informed about joint surgery and the expectations following in the rehabilitation period will assist the recovery period. I choose to use the 'worse case scenario' when I am educating patients as I firmly believe that patients need to be well informed on how the recovery period may go. If by chance there are problems, patients are more aware that these can happen and it gives them some assistance with coping. It is also important that patients are aware of where to gain further assistance when required, and this is discussed during the teaching period in pre admission clinic.

The average length of stay for patients having had hip replacements is between five to seven days while the knee replacement is six to eight days in the tertiary hospital where I am employed. Management is always seeking ways to reduce this length of stay to further reduce hospital costs. My belief is that if patients are fully informed and aware of expectations, they will progress with their recovery and be able to be discharged to their own homes or alternative arrangements within the expected time frame. Patients have often told me in the past that they prefer to rehabilitate within their own environments, however, are happy to be hospitalised if it is required.

This last section of this chapter gives an insight into the process which patients transgress following the diagnosis of arthritis and being placed on the waiting list for surgical intervention within the district health board I work in. This study may inform current practice, as there is little known about patients' perspectives of the joint education they receive.

\section{Discussion}

In terms of this study, the growing context of joint replacements highlights the need for well-informed patients. This chapter demonstrates significance of orthopaedic demands in the future. It has also highlighted the importance of 
careful, health planning for the future due to the aging population epidemic. It is the ever increasing burden of the effects of musculo-skeletal disease on this population, that will increase the pressure on an already struggling health system. Osteoarthritis and the associated symptoms have been identified and the available treatments explained.

Government strategies to cope with meeting the increased demands for joint surgery have been undertaken under the Joint Initiative and an increase of contractual agreements are in place for district health boards to meet. The importance of the Alma-Ata Declaration and the Ottawa Charter, in regards to orthopaedic patients, have been highlighted with an emphasis on promoting well health and developing a partnership with health professionals.

Having a New Zealand National Joint Register enables data to be collected and stored in one central database which will enable future research to be undertaken. This will provide much needed evidence for the future. The background of the joint journey has been undertaken to provide information for the following chapters. It is important as it offers a concept of epidemiological trends and issues surrounding joint replacement surgery. The kinds of processes that we use have importance for patients undergoing a total joint replacement and their return to their normal daily activities following surgery.

Published literature will be examined in the next chapter. Some of these relate to the different types of health education delivery whilst there are others that relate to the different processes within the education process when patients are undergoing total joint replacement surgery. These will be explored in relation to my chosen topic, patients' perspectives of relevance and helpfulness of education when undergoing a total joint replacement. 


\section{Chapter 3 Literature Review}

With the demand for joint replacements significantly rising each year, it is important that research is undertaken and published to provide health professionals access to evidence based practice. With more information in relation to health education for patients undergoing joint surgery, health professionals can improve the health education delivery and the processes associated with joint surgery. Prior to undertaking any research, it is important to review current literature that may inform and direct research projects and acknowledge supporting work which may provide further evidence.

At present we know little about what might constitute best practice for education of patients undertaking joint replacements. A literature search was undertaken to explore the current evidence and this will be discussed in the following sections. Utilisation of key words, databases and processes will be identified and discussed in relation to this study. Articles found to be relevant to the topic of health education to patients undergoing joint replacements will be critiqued and other literature that has close links with this topic will be examined.

\section{The Literature Search Strategy}

To identify the relevant literature for this study, I initially utilized today's advancing technology. This has made researching on any topic much easier, although it still can take some considerable time (Langford, 2001). I began by searching several health databases including the Cumulative Index of Nursing and Allied Health Review (CINAHL), ProQuest (a search engine that links directly to other bibliographic databases), Medline, Pubmed and The Cochrane Database of Systematic Reviews.

The electronic search became disjointed because of the wide dispersal of material. The databases that I found particularly helpful were Medline and CINAHL. I initially commenced with key words ‘joint replacement' and 'education'. It was also necessary to use the term 'total arthroplasty', as this is often interchanged 
with 'joint replacement'. Many hundreds of published articles were highlighted, and it was necessary to refine the search further. I included 'patients' perspectives'. This resulted in a key reduction of the number of papers. I then returned to the initial large number of hits and started a further systematic process of reading the abstracts. This enabled more relevant articles to be detected. From these studies I was able to explore what literature there was published on my chosen topic of patient education in relation to joint surgery. From this cohort I was able to select key literature, research based studies and those of high relevance. Once I had retrieved the relevant articles, I also used their reference lists to expand the search. This way I was able to gain further articles that were related to the topic of patient education for joint surgery. This literature search is written in relation to the extracted papers and other relevant papers. The Cochrane Database was also searched and one paper retrieved. This is discussed in some detail below.

\section{Pre Operative Education: A Systematic Review}

Although I was focusing this study on patients' experiences, and the chosen method would be qualitative in nature, I chose to search The Cochrane Database of Systematic Reviews which detected one systematic review of pre operative education for hip or knee replacements. McDonald, Green and Hetrick (2004) conducted this review and focused on improved outcomes following joint replacement surgery. A systematic review is classified as the "gold standard" in the quantitative research fields (French, 1995; Hope, 1995; Sackett, Richardson, Rosenberg \& Haynes, 1997; Street, 2001), reviewing several randomized trials of all sizes, both published and unpublished. Systematic reviews focus on quantitative randomized and/or quasi randomized studies.

The aim of this review was to determine whether pre operative education improves post operative outcomes in patients having knee or hip joint replacements. Outcome measures that were assessed were post operative pain, length of stay, occurrence of deep vein thrombosis, range of motion, patient satisfaction, compliance with exercise routine, pre and post operative anxiety and 
post operative mobility (McDonald, Green \& Hetrick, 2004). Nine studies were chosen from a total of seventeen eligible studies, involving 782 participants. Reasons for exclusion included: not relevant to hip/knee joint replacements, not randomised, combined pre and post operative education given, and not investigating post operative outcomes.

From this systematic review there was little evidence to support or refute the use of pre operative education to improve post operative outcomes in patients undergoing knee or hip joint replacements. This needs to be taken into context with the small number of studies examined, the control groups including some pre operative education and the routine post operative protocols likely to limit variation between groups in respect to length of stay and mobility outcomes. Post operative complications may be less likely to be detected due to the small sample sizes in studies.

Length of stay was largely not affected by pre operative education. Rather it depended on when patients were mobilised, and this, in turn, would largely be dependent on protocols and guidelines. One study did show a reduced length of stay, but on further examination, participants had poor social support or were functioning at a low level. These participants received tailored support programmes (Crowe, 2000). Pre operative anxiety was shown to be reduced with pre operative education, however, the effect on post operative anxiety was inconclusive. Post operative teaching and reinforcement of pre operative education showed a more beneficial effect on the post operative outcomes studies in two studies (McDonald et al., 2004).

As discussed, this systematic review showed insufficient evidence to support the use of pre operative education to improve post operative outcomes in patients undergoing hip or knee replacement surgery, over and above the routine care. Considering patients' individual needs and tailoring education according to these may prove to have some benefits. Levels of anxiety, poor social support or disabilities would need to be assessed individually. McDonald et al. (2004), suggests that future research should be undertaken to investigate the incorporation of assessments of patients requirements and tailoring them within the pre and post 
operative care. Recommendation was also given to research the method, or combination of methods, which is best for delivering health education and the follow up reinforcement of patient education in the post operative period.

The focus of this systematic review was on evaluating effectiveness of pre operative education in relation to post operative outcomes. This did not take into account the patients' experiences or their perceived benefits of this education. Patient satisfaction was briefly acknowledged in one article within this systematic review, but on further critiquing this article, minimal information and data was collected. Santavirta et al.'s (1994) study indicated that those in the experimental group of intensified teaching were more satisfied and appeared to significantly adhere to rehabilitation programmes better. Participants in this study knew significantly better when to inform their doctor of potential complications within the post operative period following a total hip joint replacement. Further research was indicated by the authors which supports the undertaking of this descriptive research project to allow the patients' experiences and perceived benefits to be revealed.

\section{Patient and Organisational Outcomes}

Research determining the impacts on patients and organisations were revealed within this current search of the literature. The following literature was not included within the Systematic Review that has been previously discussed. It was the quantitative methodology that was commonly used throughout these studies. Lin, Lin and Lin (1997) compared patients, who were undergoing knee replacements, who had both teaching and written information at pre admission followed by a video on admission. The control group had only the pre admission teaching and booklet. The findings showed no significant difference in the pre operative anxiety, however, the experimental group did show a higher level of knowledge and performed the post operative exercises more regularly and correctly, when compared to the control group. A limitation of this study was the lack of outcome indicators assessed. However, there was evidence to show the use 
of pre operative teaching incorporated with booklet and video did enhance the patients’ learning.

Roach, Tremblay and Bowers (1995) studied the effects of pre operative education in regard to the average length of stay following joint replacement. The aim of this study was to institute measures that would utilise resources appropriately, and increase patient satisfaction, while providing quality care. Their research showed a considerable decrease in the average length of stay, which was then equated to the dollar saving figures. However, little was reported in the way of patient satisfaction. It was very briefly acknowledged in the conclusion that patients verbally commended the programme, but the study design did not actually focus on this.

Other studies using a quantitative design revealed impacts, such as those listed below, on patients undergoing joint replacements (Gahlmer et al., 1996; Spalding, 1995; Santavirta et al., 1994). Using frameworks, issues such as the perceived health and functional status, anxiety level, exercise compliance, and post operative complications were all studied, but no studies included the patients' perspectives of the given education. Organisational impacts remained focused on the average length of stay, to effectively utilise resources.

\section{Delivery and Type of Education}

Several articles that were revealed within the initial search examined the different types and delivery of health education. There are many different ways that health education is delivered to patients who were undergoing total joint replacement. With today's advancing technology it may be a difficult task for health professionals to keep abreast with advances. Interactive DVD programmes, videos and written material, used individually or in combination in the pre operative period, have all been studied and evidence has shown to benefit patients undergoing joint replacements (Fielden, Scott \& Horne, 2003; Lewis, Gunta \& Wong, 2002; Livesley \& Rider, 1993; Pellino et al., 1998; Showalter, Burger \& Salyer, 2000 ). 
Lewis et al. (2002) used an experimental design to compare outcomes of pre operative education in a non interactive manner versus an interactive DVD programme for those patients undergoing joint replacements. Patients who were in the interactive DVD group showed greater knowledge and an increase in physical exercise therapy. These outcomes are positive, however the small sample size and the inability to track other outcomes such as pain behaviour and complications limit this study. The theoretical framework of this study was self-efficacy, based upon Bandura’s theory (Lewis et al., 2002).

Pellino et al.'s (1998) study compared an empowerment model of teaching to the traditional education. This compared historical patient education traditionally based on the medical model versus patient empowerment. The medical model is disease based and the provider evaluates and decides what information and how much detail the patient receives. The empowerment model enables the health care professional to provide knowledge, develop patient skills and identify resources available for patients and enables the patient to take some control. It develops a partnership between the health care professional and the patient within the teaching / learning process. Pellino et al. (1998) hypothesized that patients educated with the empowerment model would report better outcomes. They successfully used the self efficacy model which increased the patients' self confidence to carry out tasks. It was also noted that the same self efficacy model was used as the framework in Lewis et al.'s study. This theory works on the principle of encouraging change by enabling patients to acquire and master new competencies (Lewis et al., 2002). Both Lewis et al.'s (2002) and Pellino et al.’s (1998) studies highlighted the importance of building the patient's self confidence, as in Bandura's social learning theory whereby "what people think, believe and feel affects how they behave” (Bandura Quotable Quotes, 2005).

Livesley and Rider (1993) assessed change in the patients' knowledge and satisfaction during a total joint replacement by comparing results from patients who received printed information booklets pre operatively with the traditional oral education given to the other group of patients. Those given the booklet had a greater understanding of the nature of the joint replacement, and were more aware of possible complications and the rehabilitation. 
The above three studies all compared one type of pre operative education delivery with another. Research has shown beneficial results of pre operative education and outcomes of treatment, patient satisfaction and long term results. Knowledge and preparedness for joint surgery were all improved with the experimental intervention groups, however, there was insignificant differences noted in lengths of stay, pain and complication rate variances.

Written material appears to be a good reference for patients undergoing joint replacements. They can read it at their leisure and as many times as required. In Fielden et al.'s (2003) study, it was found that patients given printed educational pamphlets at their pre admission clinic session two to three weeks pre operatively, enhanced participants' satisfaction with their discharge planning. However, verbal clarification of this material was not often undertaken due to the limited time to read the information during the clinic thus leaving patients with further questions or queries. It was noted in Livesley and Rider's (1993) study, that the written material needed to be well constructed for benefits to be gained.

The above studies all research topics very pertinent for patients undergoing joint replacement surgery. However, there is very little discussed regarding the patients' perspective of the given education. Exploring the patients' experiences of the given education and their perceived benefits will enable health professionals to evaluate timing, methods and modes of delivery. It is for this very reason that I focus on what the patients have to tell about the education they received when undergoing a joint replacement.

\section{Pre Admission Clinics}

Processes within pre admission clinics have been studied by several authors and these have tended to be descriptive in method (Fellows et al., 1998 \& 1999; Lichtenstein, Semaan, \& Marmar, 1993; Roach et al., 1995; Thomas, Burton, Withrow \& Adkisson, 2004). Pre admission clinics were designed as health care costs began to escalate. By implementing patient screening on an outpatient basis, 
the needs for expensive in-hospital care were avoided (Butler, Hurley, Buchanan \& Smith-Van Horne, 1996). It also provided an opportunity for health care professionals to obtain a patient history and complete a physical assessment, and obtain further investigations as required (Messer, 1998). The third aspect of pre admission clinic was to prepare patients both physically and mentally for their impending surgery. This involves providing an environment that patients can feel comfortable in, provide concise, clear education and offer time for questions to be answered. It is well known that good quality pre operative education enhances the patient's knowledge and prepares them for surgery and promotes a relationship between the health professionals and the patients (Messer, 1998).

Roach et al. (1995) describe the pre admission process that was developed to prepare patients for their joint surgery. Prior to this study, there was no pre admission clinic within the project setting of an orthopaedic unit, so the development was an important addition for their joint patients. As discussed previously, the aim was to reduce the length of stay to utilise financial resources better and increase the patients' satisfaction, however, the results only indicated a reduction in the length of stay. No analysis of verbal feedback gained from patients or their families was completed within this study. It appeared that this study focused on organisational benefits rather than on the patients' benefits.

Fellows et al.'s (1998) article on orthopaedic pre admission assessment clinics gave an in depth account of the clinic set up in their project. A full account of the physical, social and psychological assessments were undertaken with good, clear guidelines. They discuss the advantages both for the patients and for the health care providers equally, which is a significant difference to other studies which focus on organisational benefits rather than being patient focused. The paper explores how successful patient education is dependent on the knowledge of adult learning principles. These include being self directed learners, accumulating experiences, readiness to learn depending on developmental and engaged tasks, and problem solving skills. The domains of learning are also another important aspect that needs some consideration - cognitive, affective and psychomotor. Within any programme to educate patients, these all need to be considered. These authors, Fellows et al. (1998), followed up this work with another paper that 
highlighted the benefits of the initiation of advanced nursing practice with nurseled clinics in pre admission clinic.

Malkin (2000) explored the patients' perspectives of pre admission clinic, and undertook unstructured interviews to collect data from eleven participants. Participants were undergoing total joint replacements and spinal surgery. This pre admission clinic appeared to relieve the participants' anxiety by giving them factual information regarding the pending surgery and this was conceptualised as 'given information'. Participants also described experiences from the clinic such as caring environment, individualised care and efficiency which was conceptualised as 'experienced information'. There can be a wide variance in regard to patients' experiences and understanding, and this study showed the importance of the acknowledgement of individual care for patients.

Malkin's (2000) study acknowledged the limitation of only four participants being re-interviewed to evaluate study findings. Validity may have been strengthened if more were re-interviewed. Emerging topics that required further research were highlighted - the reduction of anxiety in relation to the information given, differences in coping mechanisms and the amount of information required to meet individual needs.

\section{Technological Advances}

The internet is a powerful medium for disseminating knowledge and as it becomes more accessible, it could play a bigger role in health education in the future. Tak and Hong (2005) discuss how the internet is commonly used for communication and correspondence rather than for accessing educational information within the elderly group they studied. Brooks (2001), as cited in Fielden et al. (2003), discusses the effectiveness of internet learning and improved patient outcomes when patients are directed to educational material that fits their style of learning patterns. There needs to be careful consideration with this medium as the quality of information and ease of use varies greatly (Labovitch, Bozic \& Hansen, 2006). 
Further research into internet use for health education for patients having joint replacements would be beneficial.

Health care can be critiqued in many different aspects - cost-efficiency, effectiveness, best practice and patient satisfaction (Higgs \& Bithell, 2001). The literature on the development, implementation and impact of such educational programmes reflects on the patients' perspectives of these needs from the provider's point of view. Patient surveys are commonly used to evaluate patient satisfaction. Armitage and Kavanagh (1998) states that these frequently measure “patients' agreement with health professionals' assumptions of patients' needs” (p.68). This often fails to gain constructive critical responses from the patients' perspective (Fielden et al., 2003). Data gained from in depth, open-ended interviews could reveal more pertinent information and give health professionals an insight into the patients' world (Denzin \& Lincoln, 1994; Pontin \& Webb, 1995).

There was no literature to hear the experiences and perspectives from the patients' point of view. It is important in our consumer-focused health care today to determine the needs from the consumers' perspective and develop and/or modify health education programmes according to those needs (Showalter et al., 2000). Consumerism, today, has become quite a significant influence across health care settings over the past decade. Health providers are under pressure from overstretched resources and demands for the highest standards of clinical effectiveness (Higgs \& Bithell, 2001). Need to restructure paragraph!!!!!!!

\section{Qualitative Designed Research}

Seeking out qualitative research was much more difficult to find. It is only in recent years that qualitative methods are being used as it becomes more readily accepted in health research. I was intrigued to discover two qualitative studies in the orthopaedic field from New Zealand. This highlights how New Zealand nurses are advancing the body of knowledge and adding new dimensions to qualitative research. These papers gave me encouragement to continue my quest to hear the 
patients' stories about the joint education they received and to discover their perceptions of what was needed.

Fielden et al. (2003) discuss the ever important consumer-focused health care delivery and the drive to provide evidence-based nursing care. Nurses are more aware of the importance of evaluating the effects of nursing care in relation to patient outcomes (Middleton \& Lumby, 1998). Again, very few research studies ask patients for their perceptions and experiences of the health educational programmes and the usefulness in preparing them for their rehabilitation in the post operative period.

Fielden, et al.'s (2003) study of patient satisfaction of the discharge process following total hip joint replacement surgery was undertaken in two metropolitan hospitals in New Zealand. This study used two groups of patients - the first having being early discharged under five days and the second group being discharged over five days. Differences in their experiences were not identifiable from the data collected. However, identification of three themes that emerged from the data was revealed - 'readying self', 'recovering mobility' and 'transition to wellness'. Readying self involved the process of gaining knowledge during the pre operative period from the multi disciplinary health team and being able to comprehend it. It was found that some patients would have liked in depth verbal explanations to assist with comprehension. It was also indicated, as discussed previously, that patients did not have time to clarify or question further about the written information that they received, as time did not allow during their pre admission clinic visit. Recovering mobility demonstrated the patients' ability to manage their recovery with the appropriate assistance. An aspect that was highlighted was that patients felt their individuality was not recognised in respect to their rehabilitation. Routine procedures were not reassessed for individual patients. Transition to wellness was characterised by uncertainty and hopefulness, with patients generally having realistic expectations about their returning to wellness. Written information was relied upon during their rehabilitation, but it was found that there was some confusion regarding what health professionals said and what the pamphlets had suggested. 
From this study, (Fielden et al., 2003), it was noted that all multi disciplinary health team roles were clearly identified in relation to their expert knowledge, except for the nursing staff. Patients often described the nursing care as of outstanding quality, rather than in terms of the holistic nature of the profession. This raises questions regarding the nurses' role and the relative values in patients' outcomes. Recommendations from this study included the inclusion of appropriate web site information in the info packs with verbal clarification at pre admission clinic. As the web becomes increasingly more available, there is a need to direct patients to the more appropriate sites. Investigations into the nurses' role within discharge planning and also the use of a dedicated discharger planner in larger hospitals could be pivotal and valuable to the nursing profession. Another recommendation is consideration of an individual patient's teaching / coaching plan for use by all multi disciplinary team members at pre admission clinic.

Another qualitative, descriptive study that was identified was Showalter et al.'s (2000) study which described the patients' and their spouses' experiences and needs during hospitalization and rehabilitation following joint replacement. Five patients and their spouses were involved with a focus group interview to collect data.

Patients and their spouses described the transitions they experienced as they progressed through hospitalization and rehabilitation. Situational and role transitions were found by participants to be difficult to cope with. Having unrealistic expectations in their recovery and not being able to return to activities as quick as expected after surgery created some distress for participants. This emphasised the important role that spousal support played within this transitional period. Another transition that was identified in this study was 'health and illness'. This again involved the perceived and actual recovery process, which at times did not correspond. Knowing the 'best case - worse case scenario' (Showalter et al., 2000, p 53) was indicated by the participants as maybe being helpful if progress is more prolonged. Participants felt prepared for hospitalisation and the early recovery period, but felt unsure once they had returned to their home environment. This study highlighted transitional issues that patients and their spouses endeavoured to progress through. Little was mentioned in regard to the 
pre operative education received or the reinforcement in the post operative phase. Hearing patients' stories enlightens health professionals to 'actual' issues that create disruption within the rehabilitation process following joint replacement surgery.

Another New Zealand study by Marcinkowski, Wong and Dignam (2005) described the experiences of adults who have undergone total knee joint arthroplasty for osteoarthritis. The main themes to emerge from this study were 'enduring', 'thinking twice' and 'keeping faith'. 'Enduring' conceptualized the way the participants lived their daily lives, while 'thinking twice' captured the way the participants adapted and problem solved in their every day lives. 'Keeping faith' describes the determination, optimism and trust that the participants sustained as they progressed through their rehabilitation following a total knee joint arthroplasty. This study indicated that patient teaching should reflect a realistic recovery process for patients undergoing knee joint surgery. This education should be continually reinforced during their journey and written material should be re-referred to throughout. Initiation of a follow up home visit or phone call once discharged may assist patients in coping with the transition to their home environment, and allay any fears or doubts they may have.

\section{Discussion}

Continuous quality improvement is a topic that is continually being used in the health field today. Financial benefits to institutions are being identified with improved efficacy of pre admission clinic and identification of medical problems which may cause cancellation of surgery. These cost benefits play an important role in health management plans today. But who else is better at determining the effectiveness of an educational programme but the patients themselves. They are the “definers of quality” (Messer, 1998, p.32).

With government strategies to dramatically increase the number of joint replacements in the next few years in New Zealand, streamlined and effective processes must be underway to improve the delivery of health care. Promotion of 
well health is the starting place with all consumers needing to take some responsibility into looking after ones' self. All health professionals need to be involved with the promotion of healthy living and educate people on ways to reduce risk factors involved with the onset of arthritis. Management of patients awaiting joint replacements must focus on maintaining their independence and conservatively managing symptoms until surgery is undertaken.

Literature reviews reveal little information from the perspective of patients in regards to the health education when undergoing joint replacement surgery. The systematic review indicates that little is known about the benefits of education or what makes it work best for these patients. Much has been detailed around the financial benefits to health care providers in regard to patients' outcomes in the post operative period. Length of stay outcomes are one of the more prevalent topics that has been researched, with pain, anxiety, exercise compliance and post operative complications following. Types of education and how it is delivered have been described in depth and appears that a combination of methods may be the most effective way to provide this. Studies showing the effectiveness of pre admission clinics for both health providers and for patients have been identified and streamlining these processes by health professionals are continual, to improve the quality of care provided.

Patients' experiences of discharge planning, and their experiences and needs during hospitalization and rehabilitation following joint replacement have been undertaken but very little research has been undertaken in regard to the received education when undertaking joint replacement surgery. What do patients need to prepare them for joint replacement surgery? These questions have been identified and discussed in Chapter One. The aim of all joint replacement patients is to reach the desired outcome of return of functional abilities. This requires them to have clear expectations of the recovery process and the knowledge to continue with the rehabilitation plan in their own home.

When researchers use an interpretive approach, the patients tell 'their story', they do not answer questionnaires that are defined by the researchers relating to specific clinic aspects. They do not focus on organizational outcomes. It is the 
patients' stories that enable health professionals to determine the needs of the patients and develop approaches to meet these needs (Showalter et al., 2000; Malkin, 2000). Based on this, it seems important to explore patients' experiences and the perceived benefits throughout the joint journey, and contribute to the field of knowledge that can inform clinical practice.

The gap in the literature suggests that this proposed study would contribute to nursing knowledge about health education associated with joint replacements. Findings can be used to evaluate existing health education and understand the meaning of this from the consumers' view. In addition, the information elicited could be useful to direct future improvement or change to the existing education system. Much of the research is undertaken internationally, so having local research to provide evidence for local change would be an advantage to health services in New Zealand. 


\section{Chapter 4 Method and Design}

The aim of this research study was to explore patients' educational experiences and the usefulness and benefits in relation to their rehabilitation when undertaking joint replacement surgery. The design of a research project is always dependent upon the research question. This chapter will discuss the chosen method, qualitative, exploratory descriptive and the reasons why this approach was used. Table 1 gives an overview of the approach and design which will be discussed in greater depth. This chapter will conclude with the implementation of this design and my journey through the process.

In the writing of this chapter it will become evident that there are two tenses used to describe the planned and actual processes of this project. The planned stage will be conveyed in the present tense and then a transition to the past tense will then describe the implementation of this research project.

\section{Research Question}

As identified previously this research question arises from my clinical practice. What are the patients' educational experiences and the usefulness and benefits in rehabilitation of the health education received when undergoing a total joint replacement? As the previous chapter demonstrated, there is little published regarding this topic. There is a greater emphasis on patient education and empowerment of consumers in the health field today, so it becomes important that health professionals can hear the patients' stories. As Fielden et al. (2003) discusses all too often patient satisfaction surveys are from the health providers' perspectives and very little data is actually collected and correlated from the consumers' experiences. Table 1 highlights features of the research design. In the following section of this chapter, these aspects of the study design and the rationale behind them will be discussed. 


\begin{tabular}{|c|c|}
\hline Research Question & $\begin{array}{l}\text { What are the patients' educational experiences and } \\
\text { the usefulness and benefits in rehabilitation of the } \\
\text { health education received when undergoing a total } \\
\text { joint replacement? }\end{array}$ \\
\hline Approach & $\begin{array}{l}\text { Exploratory, qualitative descriptive study } \\
\text { (Sandelowski, 2000). }\end{array}$ \\
\hline Data Collection Methods & $\begin{array}{l}\text { Open ended individual interviews, one per } \\
\text { participant. }\end{array}$ \\
\hline Participants & $\begin{array}{l}\text { Purposive sampling (Sandelowski, 2000). } \\
\text { Six to eight people. } \\
\text { English speaking who are having first joint } \\
\text { replacement. } \\
\text { Interviews six to twelve weeks post surgery. }\end{array}$ \\
\hline Data Analysis Methods & $\begin{array}{l}\text { Open review of transcribed texts. } \\
\text { Content and thematic analysis. } \\
\text { Modified Burnard's framework. }\end{array}$ \\
\hline Rigour & $\begin{array}{l}\text { Purpose: Discover the basic nature / shape of } \\
\text { experiences (Sandelowsi, 2000). } \\
\text { Decision trail - auditable methods. } \\
\text { Data process - clearly described. } \\
\text { Representative credibility. }\end{array}$ \\
\hline Ethical Considerations & $\begin{array}{l}\text { Human Ethics application. } \\
\text { Special concerns }- \text { researcher / participant } \\
\text { relationship. } \\
\text { Maori Health. }\end{array}$ \\
\hline Treaty of Waitangi & $\begin{array}{l}\text { Maori consultation in early planning. } \\
\text { Consultation prior to Ethics application. } \\
\text { Use of 'HEAT' tool. } \\
\text { Continued Maori support. }\end{array}$ \\
\hline
\end{tabular}

Table 1. Overview of Method and Design 


\section{Approach}

The aim of this study was to gain a clearer understanding of patients' perspectives of the education they had associated with joint replacement. To do this a qualitative approach was needed to generate the needed data of their experiences of the health education. Qualitative research involves an interpretive, naturalistic approach to the world which means the researcher studies things in the natural settings, and relates and interacts with the participants in an effort to understand their experiences and meanings they attribute to them (Denzin \& Lincoln, 2005; Holloway \& Wheeler, 1996). Denzin and Lincoln (2005) suggest that the work of the qualitative researcher can be compared to that of a quilt maker - stitching, editing and putting slices of reality together into a bigger, interpretive experience.

Qualitative research is often difficult to describe as there are no set methods or practices that are clearly defined (Denzin \& Lincoln, 2005; Langford, 2001; Sandelowski, 2000). It can often be many things at one time. Guba and Lincoln (2005) argue that the boundaries of qualitative research are on the move. Today's created texts can push through firm boundaries set in place within the conventional social science and seek to create new social science about human life. The focus can be moved from the centre to the margins and forgo the closed, bounded worlds to look towards the open ended and less encompassed world.

We occupy a historical moment marked by multivocality, contested meanings, paradigmatic controversies and new textual form. This is an age of emancipation, freedom from the confines of a single regime of truth, emancipation from seeing the world in one colour.

Denzin \& Lincoln, 2005 (p.189)

This post modern era is of change and flexibility. Many research methods have remained much the same over time, perhaps being refined with each new generation. However, change is inevitable in today's society. Plummer (2005) compares the changes in society with the parallel changes in research practices. Comparing to the past, today's society is much more provisional and less authorative. It allows individualism, increased self-reflexivity and allows flow and mobility (Bauman, 2000; Beck, 1994; Giddens, 1991; Urry, 2000). 
Research practices need to change as we, as a society, tentatively progress into these new worlds. The tools that are used for theory and research need to be closely examined and overhauled as progression continues. German sociologist, Ulrich Beck, describes some research practices as "zombie categories because they are dead, but somehow go on living, making us blind to the realities of our lives” as cited in Heartfield (2004).

Plummer (2005) pushes many boundaries with his studies associated with sexuality and gender. The use of traditional language symbolizing interactionism, pragmatism, story telling, democratic thinking, justice and citizenship, all come from quite old, traditional ideas with somewhat orthodox claims. These are continually being challenged with the use of more radical language within Plummer's 'Queer Theory' studies. This enquiry does not flow as easily and is often described as more 'messy' and out of order.

It is after reading Plummer's (2005) work that I realise that research approaches are being challenged. With this in mind I try to comprehend the historical theorists and their works in qualitative research. To grasp an understanding of the historical complexity of qualitative research, much reading and question asking must be done. This journey has taken me through the bounds of this only to find that for a relative newcomer to research, it has only made more confusion and complication for this project. There have been many different highly sophisticated and theoretical qualitative methods discussed in publications. Very little has been published regarding qualitative descriptive studies, as Sandelowski describes it as being thought of as the "lowest rung of the quantitative research design hierarchy" (2000, p 334). However, as Sandelowski discusses in her work, it is due to the increasing complexity and the dictatorship of methods used in nursing research that makes it important that qualitative description is used.

Sandelowski (2000) discusses the confusion surrounding qualitative research and how researchers feel obligated to describe their methods as being more than mere description. Sandelowski offers the critique that often studies are described as grounded theory, phenomenology, ethnography or narrative, but on examining the methods more closely, many studies only have used overtones of these methods. 
There is no comprehensive definition in the published literature of qualitative description, despite it being one of the most frequently employed methodological approaches. Professor Sandelowski (2000) appears to be one of a few, who has chosen to acknowledge this methodology as being worthwhile and one which should have equal standings with other qualitative methods. She describes it as "a categorical enquiry” (2000, p.335) - one that hasn't occurred due to adaption of current methods, but as an already unacknowledged existing method. As stated, description is used frequently within other methodologies, however, Sandelowski sees the researcher not requiring to move so far from or into descriptive data as in other methods. The rendering of data can be done in a simplistic, understandable manner and not require a conceptual or highly abstract presentation. This does not belittle or imply that qualitative description is superficial or simple, nor does it imply that it is any less valuable, scientific or desirable. It is the appropriateness and usefulness in each individual situation which needs to be examined (Sandelowski, 2000). It was upon reading Sandelowski’s work that the pieces of fabric started to become woven into the beginnings of my academic quilt.

Interpretation of description is fundamental in all descriptive studies, however, in qualitative description that interpretation is "low-inference" (Sandelowski, 2000, p.335). This often results in researchers agreeing more readily with the 'facts' of the presented work. The presentation of these facts are in everyday language. This differs to studies that use other qualitative methods such as phenomenology, whereby the researcher interprets data in terms of "lifeworld existentials" such as corporeality and temporality (Van Manen, 1990, p.101). Sandelowski (2000) says "language is a vehicle of communication, not itself an interpretation structure that must be read” (p.336). It is the manner in which researchers convey the facts and meanings in a coherent and useful way. Nursing does not have unique research traditions as other disciplines have. It is necessary for nursing scholars to utilise methods already in place within these other disciplines (Parse, Coyne \& Smith, 1985).

To explore patients' perspectives on their experiences of education while undergoing a joint replacement it is necessary to generate data from the patients. To gather the required data, it is imperative that a qualitative design is used. The 
exploratory, descriptive design will enable rich data to be gathered and analysed in a more simplistic manner which is not heavily seeped in theoretical standings. As discussed previously, little is known in relation to patients' perspectives on the education they receive. Exploratory, descriptive qualitative enquiry is the methodology of choice because it will provide foundations for further research.

\section{Data Collection Methods}

On choosing how to collect data, it is important for the researcher to consider flexibility and the best approach for the topic (Grbich, 1999), to gain the optimum, high quality data for analysis. For qualitative studies, interviewing is the most common type of data collection, whether it be individual or in groups (Streubert Speziale \& Carpenter, 2003). Initially focus groups were the chosen method of data collection, whereby a small group of individuals who share common experiences or characteristics can be guided by a facilitator. Focus groups have often been said to be a relatively quick and inexpensive way to collect data (Krueger, 1994; Morgan, 1993; Parsons \& Greenwood, 2000; Webb \& Kevern, 2001). Initially I considered the use of focus groups which initiates participants to discuss, describe and compare their ideas, experiences or thoughts about a pre determined topic and can be used in a variety of settings (McDaniel \& Bach, 1996). Having several participants together discussing their experiences, would generate much discussion regarding the education the participants had received when undergoing a total joint replacement. However, on further consideration, I recognised that this would be impractical for some participants who may offer to be part of this research project, as participants had recently had total joint replacements and may still be experiencing some mobilization difficulties. There may even be some who have not returned to driving and may not accept the invitation to participate due to travelling issues.

The updated plan was to interview participants individually for up to one hour in their own home or a place mutually agreed upon, by using semi-structured interviewing skills. This interview would take place six to twelve weeks after their joint replacement, when the participants will be returning to normal activities. 
Further clarification of data was to be initiated with further conversations or interviews following the initial interview as required.

For the open ended interviewing technique, an 'aide memoire' will be used. This is the use of a framework of questions to commence the interview and to prompt the participant in general direction if required throughout the interview process. This can be useful to probe more deeply into participants' experiences and also to assist with the flow of the interview (Minichiello, Avoni, Timewell, \& Alexander 1990). Table 2 reveals the range of questions used in the aide memoir. Each interview is to be digitally recorded and transcribed verbatim. A confidentiality consent was initiated for the transcriber to protect the participants and the use of pseudonyms were to be used throughout the transcription (See Appendix 1).

\section{Participants}

Consideration was given in regard to sample characteristics and size. The study needed to be realistically accommodated within the specific time frame set for the Masters of Nursing (Clinical) programme and worked within a projected budget. As Sandelowski (2000) reflects, "sample size in qualitative research may refer to numbers of persons, but also to numbers of interviews and observations or number of events sampled" (p.180). She furthers this statement by adding "an adequate sample size in qualitative research is one that permits - by virtue of not being too large - the deep, case-oriented analysis that is a hall mark of all qualitative enquiry, and that results in - by virtue of not being too small - a new and richly textured understanding of experience” (Sandelowski, 1995, p.183). Sandelowski (2000) in her paper 'Whatever happened to qualitative description' suggests that studies using this method use purposive sampling "to locate cases that can be deemed information-rich" (p.338). With this in mind the following recruitment and inclusion criteria were identified. 


\section{Preparation for surgery.}

Can you tell me about your experiences of the health education that you received throughout your journey?

How did you prepare yourself for your pending surgery?

What did you find particularly helpful when you were preparing for your joint surgery?

What part of the pre operative education did you find useful and why?

How do you think that this education has helped you prepare for surgery?

How did you find the time frame of the education before your surgery?

Dealing with pain is quite a major part following your surgery. How do you think pain management was dealt with in the delivered education?

\section{Post surgery.}

Following your surgery, what type of on going education was given to you? How did this assist you with your rehabilitation? Who was involved with the delivery of this education and how well did you understand it?

\section{General and personal experiences of education.}

What were some of the issues you faced before you had your surgery? How did that make you feel? Did the education assist you with dealing with these limitations after your surgery?

\section{Readiness for issues post surgery.}

What sort of issues arose that you weren't prepared for following your joint surgery? Can you tell me how you felt when you were experiencing these issues? What type of strategies helped you cope with these issues? Tell me how these could be incorporated into the health educational package?

\section{General reflections on education.}

Can you describe the different ways the education was given? How effective was this type of delivery for you personally?

What were the aspects that you felt weren't covered well?

How did health professionals make you feel during your joint replacement journey?

What opportunities were there to ask questions or clarify any information that you didn't understand?

Which health professionals did you discuss issues with?

Table 2. Framework of questions used as 'aide memoire'.

For the purpose of this study, I have chosen to interview people who have recently undergone their first total hip or knee joint replacement. It is important that participants have no preceding ideas or expectations from a previous experience of joint surgery, so as not to bias the data collected. It is also important, due to budgetary and time constraints, that participants are English speaking. This enables the transcriber to work through the transcripts with minimal hassles and allow the researcher adequate time to fully immerse in the data. Another criterion to be considered was the distance from the main city centre. As this tertiary 
hospital has a wide catchment area for consumers, it was necessary to limit the participants to those residing within 50-60 km of the city centre for convenience. There was no other distinction on the basis of culture, age or gender.

\section{Data Analysis Methods}

The primary method of data analysis to be used for this study is content analysis. Such an approach is central to the method (Sandelowski, 2000) and well suited to the types of text that participants would generate through open-ended interviews. Content analysis as described by Polit and Beck (2004, p.714) is "the process of organizing and integrating narrative qualitative information according to emerging themes and concepts”. Open review of the transcribed text will be initiated to immerse into the gathered data. On further analysing the data, a method discussed by Burnard (1991) will be utilised. It has been adapted from Glaser and Strauss' 'grounded theory' approach and from various works on content analysis (Babbie, 1979; Berg, 1989; Fox, 1982; Glaser \& Strauss, 1967). Burnard (1991) describes fourteen stages to this analysis method, however, this has been modified for this study. Table 3 describes the different stages utilised. This will be discussed in more detail in the implementation stages.

\begin{tabular}{|rl|}
\hline Stage 1 & Development of notes and memos following interview \\
2 & Immersion into transcribed data \\
3 & Defining emerging themes and describing contents \\
4 & Reduction of themes \\
5 & Review of transcripts for further themes \\
6 & Highlighting categories in each transcript \\
7 & Commencement of writing process \\
\hline
\end{tabular}

Table 3. Modified Burnard’s Analysis Tool

\section{Rigour}

Validity is a concept that has historically been involved with the determination of rigour in quantitative research. However, in the last quarter of a century, rigour in qualitative research has been criticised widely (Emden \& Sandelowski, 1998, 1999; Rolfe, 1996; Sandelowski, 1986; Streubert Speziale \& Carpenter, 2003). 
With all the discussion and debate in regard to defining trustworthy, valid qualitative research, there is still no consensus on establishing appropriate criteria for this to be undertaken (Rolfe, 1996).

There has been much discussion as to whether qualitative research should come under the umbrella of the scientific domain, or whether it should be observed under an artistic approach. As Sandelowski states "qualitative inquiry may also be viewed as blending scientific rules and artistic imagination” (1986, p.29). These rigour and validity test debates are often confounded by the vast diversity of this type of research and the lack of agreement on conforming rules and whether, in fact, it should be comparable to the quantitative types of research at all. With this in mind, there may always be some debates over the validity of qualitative research.

Emden and Sandelowski $(1998 ; 1999)$ explore the debate on 'the good, the bad and the relative' in their two part scholarly paper. This enlightens the reader to the complexity of the topic and the varying ideas that have been muted as the academic quilt gets pieced together in qualitative research. As there is no complete answer to what constitutes goodness in qualitative research, and researchers' backgrounds are so varied, it enables the researcher to piece together the design and patterns within their own projects, to ensure that these are colourfully immersed with the collected data material.

For this study I draw on previous work by Sandelowski (1986) in which she proposed the following criteria for the rigour of qualitative research. Sustaining auditability, fittingness, truth value and confirmability. In particular I hold to three core values in the research process. The focus and purpose of the method was about discovering the basic nature or shape of experiences (Sandelowski, 1986; 2000; Thorne, 1997). The importance of generating an auditable trail from data through analysis to general description and attribution of significance. And the relationship of these to achieving representational credibility.

Sandelowski is well cited in published work regarding the issues of validity in qualitative research (Hilton, 2001; Rolfe, 1996; Sandelowski \& Barroso, 2002). 
She has published several articles to assist the reader to comprehend the dilemma surrounding rigour in qualitative research practice. Sandelowski (1986) discusses the use of factors relating to tests of rigour in scientific research and relates them to research using human subjects. These include truth value, fittingness, auditability and confirmabilty, which have been modified from Guba and Lincoln’s (1981) work.

The truth value of any qualitative research is subject-oriented, and generally resides in the discovery of human experiences as they are perceived by the participants (Morse \& Field, 1996). However, a major threat to the truth value is the “closeness of the investigator-subject relationship” (Sandelowski, 1986, p.30). By describing and interpreting one's own behaviour and experiences in relation to the participants, the researcher can reduce this threat.

It is known that qualitative research is not generalisable, however, the selected participants are considered to represent a specified group. Fittingness relates to when the findings 'fit' into contexts outside the current study situation and when the reader can view the findings as "meaningful and applicable in terms of their own experiences” (Sandelowski, 1986, p.32). Can the study be useful in other settings? From my perspective, I believe that the data and findings from this study may well be useful in all types of elective surgery settings.

Qualitative research emphasises the uniqueness of human phenomena or experiences and these are not always able to be validated. It is not the repetition, but the variations of an experience that the researcher is looking at when undertaking this type of research. Leaving what one may call a 'decision trail' whereby a fellow researcher can clearly follow the study, the processes and its findings is often referred to as auditability (Sandelowski, 1986).

Neutrality, in regards to research, is the absence of bias throughout the study process and findings. Guba and Lincoln (1981), as cited in Sandelowksi (1986), suggests that confirmability be the term used to describe this within qualitative research. This is only achieved when the three previous factors - truth value, auditability and fittingness - have been attained (Sandelowski, 1986). The 
descriptive synthesis presented in Chapter 5 and Chapter 6 of this thesis bear testimony to my regardfulness of these values with the descriptive research process.

\section{Ethical Considerations}

In conducting any type of research project today, it is imperative to ensure ethical standards are maintained throughout (Streubert Speziale \& Carpenter, 2003). In today's health care, health services are consumer focused and it is with this in mind that ethical considerations are central to the process and success of the research (Fielden, 2000). Principles need to guide the researcher's behaviour and practice throughout the project to ensure that the interests of the participants are promoted and protected (O’Brien, 2001). The key principles are informed consent, privacy and confidentiality, beneficence and justice, and respect (Beanland, Schneider, LoBiondo-Wood \& Haber, 1999; Noble-Adams, 1999; O’Brien, 2001).

Informed consent includes aspects of adequate, comprehensible information, effective communication, absence of coercion, advocacy and the right to withdraw from the study at any time without question (Rogers \& Niven, 1996). All participants will be given an information sheet to introduce and explain this study (Appendix 2). There will be several opportunities for further questions to be answered prior to their consent being gained and before any interviews are undertaken (Appendix 3). An advocate will be available to be present at interviews.

Privacy and confidentiality must be maintained at all times. Data will be kept under lock and key and data will not be stored in the same place as the participants' personal details. All data will be kept for a total of ten years before being destroyed. Pseudonyms will be used throughout the research, to prevent any recognition of participants (O’Brien, 2001). The transcriber will also sign a confidentiality statement, as discussed previously, to protect participants. Beneficence is all about 'doing no harm' and this principle is about protecting the 
participants from undue harm whilst maximizing the possible benefits. All participants will be given the opportunity to have an advocate present during the interviews. Respect is about treating all participants with consideration, equally and fairly throughout the process (Beanland et al., 1999).

Participants of any research are an integral part of the project, and those undertaking research must be aware of the ethical issues around this. Consideration of privacy and confidentiality of participants is very important and ethical standards are necessary for this to occur.

\section{Treaty of Waitangi}

Prior to recruitment of any study, there are certain formalities that a researcher must transgress. An important aspect of the ethics application is the way the intended research process is consistent with the provisions of the Treaty of Waitangi. I needed to implement meetings with members from the Kaumatua Kaunihera Ethics Sub Committee to discuss my project and gain their support for further consultations. 'Equal explanatory power' and concepts of race, culture and ethnicity needed to be understood prior to undertaking this project and further support may be needed from this group. This will be discussed in further depth in the implementation section. The partnership, protection and participation aspects of the Treaty of Waitangi will be incorporated throughout the planning and implementation stages as required.

\section{Implementation}

The planning stage of any research is a very integral part of any project. Done concisely and correctly, this may assist with smoothly running processes and unhindered progress. Prior to recruitment of any study, certain formalities need to be completed. As this study gained data access and used health consumers from a tertiary hospital, formal consent was gained from hospital management. 
During the initial planning period, contact was made with Maori Health, Kaumatua Kaunihera Ethics Sub Committee, to ensure that there were no outstanding issues that needed to be included in the ethics application. Consultation with this group in the tertiary hospital was a compulsory part of the ethics application, as I was about to find out. Initially I was introduced to the Health Equity Assessment Tool (HEAT Tool) (Ministry of Health, 2002) to consider in association with Treaty of Waitangi implications (Appendix 4). The questions incorporated within the HEAT Tool needed to be acknowledged within the application for Maori Health approval. Further in depth consultation with Maori Health was required for Ethics approval. For research involving consumers in the Northern Y Region, Maori Health approval must be gained prior to ethics approval.

The HEAT Tool has been developed to consider how particular inequalities in health have arisen and how effectively to address them. There is considerable evidence of significant health inequalities in New Zealand between ethnic groups, socioeconomic groups, males and females and different geographical regions (Cornwall \& Davey, 2004; Ministry of Health and Public Health Consultancy, 2002). The set of questions initiates some deeper thought into health inequalities and obviously becomes important when dealing with the principles of the Treaty of Waitangi. It ensures that researchers explore these issues and plan research projects to gain data which will assist in the future planning for these inequalities and to have an explicit commitment to implement the Treaty of Waitangi principles of participation, partnership and protection.

'Equal explanatory power' and concepts of race, culture and ethnicity were discussed at length and further readings were suggested for a more meaningful understanding of these in relation to my research (Appendix 5). Nikora (1995) discusses the three concepts of race, culture and ethnicity in relation to social science studies. Race categorises people into groups based on physical and biological characters. However, there are very few who actually belong to 'pure' racial groups today. One cannot assume that behavioural characteristics ascribed to a particular race is biological or genetically determined. It is more likely to be culturally determined. 
However, culture is learned, not something that a person is born with. Socialisation and enculturation processes are instrumental in the individual's development of culture. Nikora (1995) also suggests that no one individual can represent patterns of meaning associated with a whole culture. Culture also refers to a collective group where various facets are interrelated.

To compensate for these drawbacks, ethnicity has been developed to assist with understanding human groups (Nikora, 1995). This enables a reflection on cultural experiences and feelings of a particular group, by acknowledging the primary culture that does not exclude other learned behaviors from other cultures.

This has given me an insight into the differences of these concepts and highlighted the importance of understanding them in relation to research. In the planning and development of this project race, culture and ethnicity were not emphasized as a major consideration. I did not believe that the sample size would be large enough to gain valuable meaningful data in relation to these concepts. There were no exclusion criteria based on race, culture or ethnicity. On reflection, I believe that further studies that are designed with ethnic aspects could provide some very interesting and useful data for analysis. Although the incidence of joint replacements in Maori is still lower than that of New Zealand Pakehas / Europeans (Access Economics, 2005; Manson, 2006), I recognized that some participants may be from any ethnic background including Maori, however, all participants were of European descent in this study.

Having gained consent from Maori Health following a formal meeting with the Kaumatua Kaunihera Ethics Sub Committee, application to the Northern Y Ethics Committee followed. Issues that were initially highlighted by this committee included the importance of clarification of data collected during the second contact, rather than participants being able to add or delete any given data, as this may skew data.

Due to my role as the educator, this highlighted a possible limitation to this study. The involvement and length of this may create a bias. As I am part of a multi disciplinary team who deliver the pre operative education, it was decided to 
acknowledge this as a limitation, but continue, as it was not only the pre operative education that was being explored. The ongoing post operative education and interactions with health professionals were also being explored in relation to the patients' perceived benefits. Prior to the commencement of digitally recording the interview, in depth explanations were given and the opportunity to discuss the issues in regards to my role as an educator. Participants were fully informed that the study was not focused on my role as an educator, but of their experiences of the education they received throughout their joint replacement journey.

It was also advised by the ethics committee that an advocate participate during the interview especially where I had had previous involvement with the participant. This was offered but was not requested by any participants. When this was discussed on the initial contact following the invitation to participate, participants expressed that they felt comfortable and at ease discussing their journey without an advocate being involved. Approval was gained to proceed with this study (Appendix 6).

Information letters were sent out to six purposefully chosen participants following discharge from the tertiary hospital after having their first total joint replacement (Appendix 2). It was decided to initially choose six participants with the ability to increase the numbers as required at a later date. There was a very positive response from all the participants in regard to participating in this research. They were very happy and willing to participate in such a study, and welcomed me into their homes to conduct the interviews. They enjoyed sharing their experiences and the prospects of contributing to a small research. I found this a very fulfilling and rewarding experience, as each one shared some very personal stories and feelings with me. I feel very privileged to be part of their joint replacement journey, both as a researcher for this project and also as an educator in my employment role.

As discussed before, it was decided that six - eight participants would be used for this study. However, due to a participant's unforeseen family crisis at a late stage, this number was reduced to five. With time constraints playing a role, it was impractical to gain a further participant at this late stage. All the interviews were undertaken in the participants' own homes and were digitally recorded. I was 
involved with transcribing the interviews and found that being immersed in the collected data gave me a better insight and meaning into what the participants were saying. Having being involved with the interviews I was able to relive the expressions, mannerisms and atmosphere of the actual interview, as I was transcribing. Follow up phone conversations were completed with two participants to clarify the meanings of some of the data collected.

Analysis of the collected data commenced immediately following the actual interviews. Listening to the recordings initially began to elucidate some meanings and as this occurred, notes were documented. On reflection, the contents and themes began to emerge with ease, by continual revising and highlighting of the data, themes were separated into three groups. Use of the modified version of Burnard's framework, also assisted with the analysis process.

\section{Modified Burnard's Framework}

Stage one is the development of notes and memos that are made after each interview. Following each interview I maintained a journal to reflect back on different issues that arose from the interviews. This included initially how the interview went, the difficulties that I had experienced during this time, ideas that I felt may be important at a later stage and reflections and ideas on some of the topics that were discussed.

Stage two related around the transcribed data and being immersed within its realms. As discussed previously, having transcribed some of the interviews, this also assisted with this stage. As I became more involved with the data, I began to realize the full extent of the participants' experiences and some of the ideas that were emerging.

Stage three involved the definition of the themes emerging and the description of the contents under these themes. This stage identified the major ideas emerging such as communication, advocacy, relationships with health professionals, and pain management, and as I read and reread the transcripts, I was able to pull together the data from each transcript. 
Stage four involved the reduction of themes. This is where I analysed the themes that I had established and put them into broader topics to reduce the number, to produce a manageable, final list. The sub themes were then condensed into three, more manageable groups - communicative, subservient and knowledge partnership.

Stage five was described as inviting two colleagues to generate a list of categories from the transcripts. This was slightly modified, as in this project, my supervisor was utilized to oversee this process. This stage is also useful to enhance the validity and guard against researcher bias (Burnard, 1991). All transcripts were reviewed again to ensure all categories were covered.

Stage six involved the individual process of highlighting each of the categories in each transcript was completed. I found it decidedly easier to have several copies of each transcript and code the sub themes in different highlighted colours. This allowed the transcripts to stay within a theme grouping so as not to confuse when in the process of writing up the findings.

Stage seven was the commencement of the writing process. Having the tape, full copies and also the highlighted copies of the transcripts at hand ensures that the researcher was able to freely refer to the originals as required. This stage was by far the hardest stage to commence. The style of writing needed to be identified at this stage so that progression could occur. This did create a challenge for me as I had identified two different ways of presenting this data. The first was the inclusion of my findings and the linking of data within literature or presenting the data and then utilizing a further chapter for discussion to include the literature data. As my participants varied so greatly it was chosen to include the literature findings into my chapters with my findings. Once this had been established, it became a little easier to focus on the written process. 


\section{Discussion}

Choosing the most appropriate method and design for any research project is very important and can guide the researcher along their journey with ease. Qualitative, exploratory description is a method which is simplistic in nature, but captures rich, revealing data. This assists the researcher to explore topics from the patients' perspectives and to allow their stories to be told about their experiences. Interviewing is the common data collecting method used to initiate this rich data and then analysing the contents and emerging themes. Despite this type of research not being generalisable, it still can provide thought provoking ideas.

My journey through the formalities has been guided by academic and Maori Health team members. A greater appreciation and understanding has been gained for 'equal explanatory power' and concepts of race, culture and ethnicity throughout this research project. It has emphasised the importance of health equality for all New Zealanders, and has provided some provocative, meaningful discussions. Ethical formalities have also been highlighted for the protection of the participants for this research project and a greater understanding of the research process has been gained. Continuation of the journey in the next chapter occurs with the participants' journeys as they proceed with their joint replacement surgery. 


\section{Chapter 5 Participants' Journeys}

An introduction to the five participants involved with this study will be given and their journeys will be explored as they undertake a total joint replacement. This journey commences in pre admission clinic and explores the participants' experiences and perceived benefits of the education they received when undertaking joint surgery in a New Zealand tertiary hospital. Emerging data will be woven together with direct quotations and the contents explored with current supporting literature.

\section{Participants}

Letters of invitation were sent to six patients, who had recently undergone a total joint replacement, inviting them to participate in this study. All six accepted to be part of this study, but one withdrew at the time of the interview, due to family reasons. As discussed in the previous chapter, each participant was happy to share their experiences and discuss their views of the education they received throughout their journey. All participants were of European descent and had been suffering the debilitating effects of osteoarthritis for quite some time. This group of participants included people from the ages of their fifties to their mid eighties. As discussed in the earlier chapters, there is an increase in the incidence of musculo skeletal disease within the elderly age group, however, other factors such as obesity are also becoming a well known risk factor in osteoarthritis. Having the surgery had been a great relief to them all, as they had been trying to manage their symptoms conservatively with very poor results. These participants have welcomed me into their own homes and gave me an insight into their personal and family situations. To them, I am indebted.

As discussed in Chapter Two, the increasing age of the population, high body mass index, sports injuries and social indications can create an increased demand for joint replacement surgery. In the next section, I will introduce the participants, 
for it is their stories that will be told in regard to their journey as they undertake their joint surgery.

Mr M was self employed, living on his own, in his fifties, and was very keen to have his knee replaced so that he could continue to be productive with his work. He had struggled for quite some time to maintain his activity and continue his work for as long as possible, and was taking a cocktail of medications to keep his pain at bay. He had had previous experiences with the public health system for other major health issues and was happy to seek further information or get assistance when he required it. He had recently had a significant weight loss. As discussed earlier, a high body mass index is a serious risk factor for musculoskeletal disease.

Mr K was a retired gentleman in his sixties who lived with his partner, a nurse. He admitted to being quite passive in regard to his health issues and would just do things without questioning. He relied heavily on his partner to seek out assistance.

Mr G lived with his partner and had been actively employed prior to his total hip joint surgery. He was aged in his late fifties and had been suffering with severe pain from both his hips which had debilitating effects on his employment and living activities. He required bilateral joint replacements which were to be done six - eight weeks apart. The interview was completed following his first total hip joint replacement.

Mrs A was an elderly lady in her eighties, living on her own with a very supportive family living near by. This lady had multiple medical problems and surgery was delayed from when she presented in pre admission clinic until her actual admission date, due to these. She also had major disabilities with an amputation of her other leg, so had a prolonged, slower rehabilitation plan following her total knee joint replacement. She was also a retired nurse.

Mrs D was another elderly lady who lived on her own. She too had multiple medical problems prior to having her total knee joint replacement and had 
admitted to feeling very apprehensive on arrival to pre admission clinic. Due to her past medical problems and social circumstances, this lady required complex discharge planning and convalescing care. Mrs D had previous experience in the health care setting as a health care assistant.

These five participants shared their experiences when undertaking a total joint replacement and the trials and tribulations that they experienced along the way. All participants were very quick to point out that their stories were not criticisms about the health care they received or about health professionals that were involved in their care. They were extremely grateful that their joint replacements were undertaken, to relieve the pain and disabilities that they had all suffered prior to their surgery.

\section{The Beginning}

All participants attended the pre admission clinic, with four attending the clinic accompanied by a family member. Mr M who was the youngest of the participants attended on his own. This clinic included an anaesthetic check, health history taking and physical exam, pre operative tests to be carried out, other nursing assessments and health education regarding the pending joint surgery. The health professionals that are involved are: the anaesthetist, Orthopaedic Pre Admission Nurse Specialist, Physiotherapist, Occupational Therapist and clinic nurses. It is a very tiring day and can be between 4-6 hours in duration. As discussed in previous chapters, the pre admission clinic involves interaction with several health professionals for both health assessments and education. For the patients attending this clinic, this is where the formal education regarding their joint replacement surgery and rehabilitation is obtained, by way of video and one on one staff interaction. Literature shows that pre operative clinics are an efficient and effective strategy to provide optimum care and that the different modalities used for education does enhance knowledge retention and reduce the patients' anxiety levels pre operatively (Gammon \& Mulholland, 1996; Maskell \& Wright, 1993). In both these studies, patients' experiences and their perceptions of the given education were not explored. 
On attending this clinic, participants shared their thoughts and feelings. Some were apprehensive regarding their general health status and the risks of anaesthesia, while others commented about their relief as it was getting closer to the actual surgery date. Mrs A spoke of her frustrations of her disability as she described how she "just felt physically handicapped" (Mrs A, line 98) as her family utilised a wheelchair to assist with moving her from room to room.

During the education session, all participants and their support family viewed a video. It was interesting to note that three participants found this a particularly useful tool and remembered it well with reference to their rehabilitation. $\mathrm{Mr} \mathrm{M}$ could not actually remember the contents of the video as it appeared to be some time before that he had viewed it. However, he did comment that "audio visual is better than just audio. There's nothing better than mind's eye” (Mr M, line 145).

Another participant spoke of seeing the video, but had no reflection of its importance in her education as she reflected back to how she was actually feeling that day. "Yes, I saw the video, it was just something, but going to the clinic, I felt handicapped that day. And that did more for me than the whole preparation. I know I saw a film and I knew they would be giving me some exercises to do and that sort of thing, but going to the clinic that day, I supposed it prepared me”. (Mrs A, line 325). This may of been an overriding feeling that may have influenced this lady's retention of knowledge.

All patients are routinely sent a booklet which they can refer to at any time. Mrs D acknowledged “there's the book but you don't always sit down and read it right through" (Mrs D, line 194) and "I'm not a book reader that can sit down and read a book all day. I mean that I skimmed through the whole thing but I didn't read it properly". It was recognised that the video was particularly useful for this participant to reinforce what she had previously reviewed. However she did admit to utilising the booklet again when she was faced with an annoying pain in her knee that affected her at night, eleven weeks post surgery. It appeared that the booklet was something concrete that the participants could refer back to at any time. 
Maskell and Wright (1993) discuss adult learning principles that need to be considered for successful health education. These principles include being selfdirected learners, learning from past experiences, problem-solvers and readiness for learning dependent on developmental tasks and roles. They further discuss that as self-directed learners, adults are able to make their own decisions, be treated respectfully and uniquely as individuals.

The three learning domains also need to be considered with adult teaching: Cognitive, affective and psychomotor, as each adult has different preferred learning styles (Maskell \& Wright, 1993). To facilitate learning, it is necessary to provide varying ways of presenting the information, i.e. visual, audio, verbal and an opportunity to actually do some of the activities. In the pre admission clinic that these participants attended, all of these were accommodated within the education session. This was indicated by comments such as "more or less the drumming into to you” (Mr G, line 216); "the brochures that they gave you, they were all very helpful” (Mrs A, line 106); "with each person you spoke to, each of them were telling and showing you different things, that was good” (Mr K, line 57); "it gets your mind on the job”, (Mr M, line 152), commenting about the booklet; “it was all simple, you couldn't not absorb it” (Mrs A, line 105).

The participants were all very supportive of this clinic as it provided an opportunity for them to pass a 'warrant of fitness' health check and be a little closer to the actual joint replacement surgery that they had all been waiting for. It also gave the participants time to ask any further questions. On further questioning, it was interesting to note that the youngest participant had already done a lot of research into knee joint replacement prior to his clinic appointment. He had actively searched the internet to gain information and to fully prepare himself for his pending surgery. This man has had frequent interactions with health professionals in the past, for other health issues and had previously been very keen to seek information independently. Comparing to his previous health issues he stated, “At the time I couldn't find anyone to help me...so I had to research it for myself. It did become obsessive” ( $M r ~ M$, line 90) The other participant that gained information from the internet was fortunate to have a 
computer-literate partner, who searched the net for further information. This was done following his first specialist appointment, when he was placed on the waiting list for his joint replacement. This was quite some time before his attendance at pre admission clinic.

Two of the participants stated that they had gained knowledge from people who had previously had joint replacements done. However, on questioning them further, it appeared to be broad statements such as "It was a good thing to do and get done" and "I talked to two others and they said they had had a hell of a time" ( $M r M$, lines 164-167). During their attendance at the pre admission clinic, no one could remember talking to any other patients who had previously had a joint replacement done.

The support people who attended pre admission clinic with the participants were all invited to be involved with the whole process during their time at this clinic. It was noted that Mrs D was very apprehensive on coming into clinic on her own and was very relieved when her son availed himself to attend. Mrs D was an elderly lady, who lived on her own, and despite prior experiences with the health profession, still admitted "I was apprehensive, scared, I suppose the plain word is" (line 27) and "I was nervous" (line 493). This was a big boost for Mrs D. Due to her past medical history, there were risks involved which concerned both Mrs $\mathrm{D}$ and her son. Having that time at this clinic, they were able to discuss these and get further questions answered and put their minds at rest. "And by getting him settled that settled me down" (line 471).

Mr K also admitted that having his supportive partner with him at pre admission clinic was very beneficial. He found that he relied on her to explain further about the information given rather than ask the health professionals for further explanations himself. Mr G's wife was also present for the teaching session and became a very valuable team member when $\mathrm{Mr} G$ was discharged home, to maintain the hip precautions to prevent dislocation. "She has caught me once or twice, like I thought I was okay. But she says, "no, you did twist, just slightly" - it wasn't much but it could have been enough to...bang” (line 143). By attending 
pre admission clinic, all participants felt fully prepared for their pending surgery, and had their anxieties relieved and questions answered by the time they left that day. They found the one on one sessions very valuable and were able to discuss individual issues privately and at ease. From pre admission clinic, the next step was admission for surgery. This time did vary slightly, as discussed, with previous medical issues that needed to be attended to.

\section{Admission}

With the facilitation of pre admission clinic, it is often not necessary for patients to be admitted for elective surgery the day before. However, they may be asked to visit the ward the day before to meet the surgeon and anaesthetist and review any further tests that may require repeating. All five of the participants arrived at the designated wards the day before. Only three stayed overnight due to theatre scheduling.

Four were reviewed by their surgeons who went over the procedure and the risks involved. One participant was not seen by the surgeon the day before. It was not until he reached theatre that a very brief meeting occurred. The doctors' visits were all very brief, as stated by the participants, but all appeared satisfied. Erlen (2006) discusses how there may be a non verbal message communicated to the patient that there is limited time available. How many times have we heard patients say “the doctors seem too busy and I don't want to annoy them”.

There was little evidence that the ward nurses involved themselves with reinforcing pre operative education on admission. When participants were asked about reinforcement of educational material, it was common practice to hear that it was predominantly the medical staff that were referred to, regarding further underpinning of knowledge. "One of the young doctors came up ... and told me what was going to happen, all about theatre and that...” (Mrs A, line 181); “The anaesthetist called in to see me...we talked about warfarin, my INR level...” (Mr $M$, line 189). 
In the post operative period, there was evidence that the development of nurse patient relationships with these participants were not always recognised by the participants. Nurses were found to be always busy and had little time to get to know their patients. Little was said regarding the nurses unless specifically probed. Comments were made such as: “the care from nurses I couldn't complain about” (Mrs D, line 100); "To be fair, they were busy” (Mr M, line 208); "Well I know that they had other patients, clients to look after as well” (Mr H, line 189). The participants were all complimentary of the care they received by the ward nurses when probed, but it didn't appear to be of any significance within their joint replacement journey. Reflecting on the lack of acknowledgement of the nurse's role, feelings of confusion and amazement reigned within myself. My own personal impressions and beliefs of the nurse's role interacting with the patient as they began their hospital journey and the importance that I place on this, made me feel very disappointed. I reflect back on my earlier nursing days, whereby the nurse's role was a prominent one within the patient's hospitalisation. Has there been a significant change in the nurse's role as the 21st century progresses?

Christensen (1990) discusses the development of the nursing partnership when the patient is admitted into the ward, and continues until the patient is discharged from the hospital. She goes on to describe the work of both the patient and nurse in stages that involve the settling in period, negotiation of the partnership and going home. Little investigation has been done to reveal how such an intuitive behaviour such as developing a rapport is constructed and developed (Turnbull, 1999). This will be discussed further in the next section within the theme analysis.

As Mrs D states, "If someone... came along and sat down and talked to me, I would of felt at ease and then could ask" (line 324). However, Mrs D describes how the nurses just came in, did their required work and then left, without getting an opportunity to converse with them. How much did the nurses know of how Mrs D was feeling? Mrs D then explained how she had been a health worker for many years and how she had seen many changes in the hospital system. "I was a hospital aide admittedly, but I liked to talk to people and I found that they could relax and talk to me. I found out a lot of their problems...” (line 339). When it was time to mobilise out of bed, $\mathrm{Mr} \mathrm{H}$ was told "right oh, you can get out of bed 
now! " (line 144). The nurses appeared not to have taken the time to find out how $\mathrm{Mr} \mathrm{H}$ was feeling in regard to pain management. As $\mathrm{Mr} \mathrm{H}$ said, "I normally like to do as I'm told, but actually I was quite sore” (line 146).

Relationship is described as "the cement that provides meaning to our work thus meaning to our lives” (McCrea et al., 2003, p.240). It is important for health professionals to develop relationships with the patient so that patient centred care can be initiated to promote health and healing (Hagerty \& Patusky, 2003; Turnbull, 1999; Yamashito, Forchuk, \& Mound, 2005). There is little documentation regarding the strategies to achieve this relationship within the published literature. Titchen (2001) believes that this relationship is founded on three theoretical perspectives which include humanistic existentialism, spiritual and phenomenological aspects. However, little is actually understood of these perspectives and further research is required to support Titchen's work.

Nurses need to use their skills of understanding, listening, exploring and intervening to establish and build the nurse-patient relationship. It is with using such skills effectively that the nurse and patient will connect meaningfully (SteinParbury, 2000).

Mr K was the only participant that recalled the relationship that had developed with one particular ward nurse. "He was bloody fantastic. He was the one that gave me the encouragement... he would spend some time and speak with you... No two ways about it. Whether it was a man to man, or what, I don't know. But everyone spoke very highly of him and so did I” (Mr K, lines 197-201). Listening to someone and being heard are two of the easiest human acts that can also be very healing. To discover the lived human experience and develop healing connections, it is important to initiate conversation and develop a relationship. "Everything exists because it is in relationship with something else. We do not exist in isolation” (McCrea et al., 2003, p.241).

Development of relationships with nurses in the ward appeared to be second nature for Mr M. He explained that "it is up to each individual. You've got to put yourself out there” (line 344). He was very autonomous and due to his previous 
health experiences had gained confidence and self esteem to put himself "out there" (line 313). Developing open lines of communication are all too important in health care. As Mr M states, "I think half the time the health carers are supposed to be mind readers. And that's where it falls down. I think patients need to be more aggressive, and say this is what is actually happening to me. And if it is not working, go back in two or three hours time and tell them again. Instead of saying 'I don't want to bother them'”, (line 315).

One health professional relationship that was developed very early in the post operative period was with the physiotherapist. This relationship was by far the most acknowledged in the post operative period due to the pain involvement, and was constantly reinforced by all the participants. Mrs A describes how the physiotherapy was "disastrous, to me it was disastrous" (line 152). It was the physiotherapists "that were the killing part. They came and they really pushed you. They really did" (line 120). However, when asked if she had benefited from their actions, she stated, "I probably did. But I didn't like it. That was the only thing I didn't like, it was the pressure from the physio" (line 128). Mrs A acknowledged her awareness and knowledge that physiotherapy would play an important part of the post operative period, but felt that she wasn't prepared for the extent and pressure that was involved. "If you had told me about all the awful physiotherapy I would never have gone through the operation” (line 158).

Apprehension was described when the participants laid eyes on the physiotherapist during their stay in hospital. "You watched to see if they were coming to you or not” (Mrs A, line 205). The apprehension regarding the pain that pursued during the physiotherapist's visit played a very important part in the participants' experiences of their journey. When asked, Mrs D acknowledged that it was "how much was it going to hurt" (line 157). An issue that was highlighted during this study was the importance of pain management in the post operative period. “But I knew that my knee was too sore. I didn't want him near me. I did try to accommodate him, but the pain was just too much. Man, it was terrible" (Mr M, line 218). 
It was a familiar remark heard frequently throughout the interviews regarding the amount of pain that participants experienced. "And of course, I didn't expect that much pain, I nearly hit the roof” (Mr G, line 14) as the nurses were turning Mr G for the first time. Mr G went on to explain that the pain he experienced was a different type of pain post his hip joint replacement, however, he still described it “just like dynamite” (line 24).

This raised another significant issue for people having joint replacements initiation of good pain management in the immediate post operative period. All participants had Patient Controlled Analgesia (PCA) connected to their intravenous fluids following their surgery. This is a common way to deliver pain relief controlled by the patient. It is a safe, quick, effective way to manage post operative pain (Waikato Hospital Inpatient Pain Service, 2004). However, participants did not show a good recall of the education they received regarding this type of pain management.

It was acknowledged by all participants that they were reminded to use the PCA pump more frequently. This was by both the nursing and physiotherapy staff. It was recalled that "they growled to me about not using enough morphine on the buzzer” (Mr M, line 122). Mrs D stated that “because I had a lot of pain, I wasn't pressing it enough to get the pain relief. I didn't know how often I was suppose to do it and whether it could be dangerous" (line 167). It became evident that the participants felt their knowledge regarding the PCA pump was inadequate, but when asked if the nurses took the time to explain further, it appeared this was not so or that the participants did not recall them doing so.

Following the removal of the PCA pump, pain was then managed by oral medication. From the participants’ perspectives this was not well managed at all. Mr K spoke of "this is where the system did actually break down...I think that the medication to help alleviate some of the pain was very inconsistent” (line 179). He found that on one occasion he did turn down the offered pain relief, to his detriment, and when he asked a little time later, was told, "Oh no, you refused it!" (line 182). This made him much more cautious in the future, having "learnt it was my own mistake” (line 181). $\mathrm{Mr} \mathrm{M}$ also acknowledged that at times the 
inconsistent administration of pain relief occurred. However, his perspective was "Yeah, it did happen to me a couple of times. But I always blamed myself for not getting on with it” (line 258).

It was interesting to hear $\mathrm{Mr} \mathrm{K}$ state "some of the stuff was going right over my head at times, in this ear and out the other" (line 325). Did Mr K actually want to learn about the differences and understand, or did he seem happy to let his partner take on this role for him? Rankin and Duffy Stallings (1996) describes that even when given all available information and engaging in a full participatory manner, patients may still decide not to change their ways. It is important for nurses to be aware that despite motivational empowerment being used, change or understanding may not always take place.

Another interesting revelation was the perspective of time from the participants' viewpoint, during their stay in hospital. On discussing the use of regular oral pain relief in the rehabilitation period, Mr M stated, “you lose track on time. I don't really know how long the space was. But I know at home, every four hours if I didn't take the tramadol...” (line 263). This may indicate why participants did not request oral medication regularly. It may be that their perception of time was altered.

Mr K had a prolonged stay in hospital due to slow rehabilitation of his knee replacement, and management of pain. This was also complicated by the conflicting advice given to him on his mobilising. Fortunately he discussed this with the physiotherapist, as he was becoming quite confused and sorted the issues out. Confusion also reigned regarding the amount of walking and exercise one must do post operatively. Mr K expressed his concerns of the full on pressure that was placed on him to keep exercising, despite needing to rest periodically during the day. "those that were telling me to get off the bed and go and do something, they weren't even... they hadn't even seen me doing anything” (line 382). Again developing a relationship became an important issue here.

Another frustrating issue for $\mathrm{Mr} \mathrm{K}$ was the lack of equipment available for his rehabilitation. Mr $\mathrm{K}$ was having some difficulties with getting his knee to 
adequately bend following surgery. He complements his partner for being his advocate, as without her repetitive questioning and assisting with his care, he would not have been started on the Continuous Passive Movement machine in the appropriate time frame. He stated that "I would of persevered and been in a hell of a lot of pain, I daresay" (line 340). This machine assists the patient with passive exercises as the patient rests upon their bed. There was not one available for the first few days post operatively. However, following much questioning by his partner, a machine finally became available for Mr K to use. It appeared that advocacy played a very important role, but there was also evidence that knowing the system played a part too. Mr K’s partner had worked in this hospital setting in the past and had the confidence to continually question staff regarding the availability of equipment. Again her prior knowledge also assisted $\mathrm{Mr} \mathrm{K}$ as he dealt with knee swelling post operatively. "We got onto the ice packs, DIY, if you wanted it done" (line 333). "I thought perhaps we should of iced the damn thing straight away" (line 275). His comments indicate that it was initiated and completed by himself and his partner, with little input from health professionals.

This raises an important issue in regard to those patients who do not have the confidence and autonomy to ask for themselves, or do not have a family member/friend to act as an advocate. This became apparent to $\mathrm{Mr} \mathrm{M}$ as he experienced having to be an advocate for another patient in his room, as this elderly man was too embarrassed to ask repeatedly for urinals. "They give him some medication to make him urinate more, but only left one bottle. He had had his hip done and he couldn't get out of bed quick enough to get to the loo" (line 367). Knowing that this man was struggling, $\mathrm{Mr} \mathrm{M}$ had been able to communicate with the nurses and this man's independence was maintained.

\section{Discharge}

The next stage in the participants' rehabilitation was going home. The three men went home with no further health care support, whilst the ladies both had further support from the Home Hospital Service and further convalescing care in a rest home. The Home Hospital Service provided medical and nursing visits daily and 
also visits from the allied health team, including the physiotherapist. One of the men utilised his GP for further support in regard to pain management once discharged, but the other two seemed to manage with their partners support once at home.

Pain management still played a huge role in the participants' rehabilitation, once discharged from hospital. When asked what type of information was given regarding pain management prior to discharge, it was acknowledged this was very minimal. Fortunately for $\mathrm{Mr} \mathrm{K}$, his partner had previous nursing experience and was able to effectively manage his pain once at home. "Once we got onto a routine of getting basically the medication on a much more regular basis, things were a hell of a lot better" (line 309). For Mr M it meant another trip to his general practitioner to assist him with sorting out his pain management post discharge.

For Mrs A, the community based Home Hospital staff played an important role in her pain management, which did at times become quite confusing for her. "you couldn't keep a face on all the people that came and every time somebody would come, I'd have a new prescription. And it really bugged me” (Mrs A, line 239). At times there seemed to be little evidence to show that Mrs A was actually a trained nurse and that she had any previous knowledge regarding medication. "I just took them and I didn't really know what they were for. I just took them" (line 264). During Mrs A's rehabilitation, there was some controversy regarding some swelling in her leg, and the doctor had prescribed an increased dose of frusemide. However, Mrs A felt that the doctor just wasn't listening to her. "I have had a swollen knee ever since I've been nursing. It is a bit more swollen at the moment...” (line 246). There appeared to be some discrepancy regarding her recall of knowledge regarding medication. Previously she had expressed her concerns but then, in this instance, she was well aware of what the increased dose of frusemide would do, and wasn't particularly happy. "I took them for the first week and then I put the other ones down the sink" (line 252).

Being involved with Mrs D's discharge planning did not occur until she was preparing to go home from convalescing care. She was assisted by her family 
which helped with the smooth transition to her home. Having been unwell in the rehabilitation stage, Mrs D found it very helpful having her family involved with the planning. Her knowledge retention was limited and with so much to think about, often she would get confused. Having family members there relieved her anxiety tremendously, and she was able to be discharged knowing that everything was taken care of.

Mr G's discharge went smoothly and he had no issues with the transition from hospital to home. He had a very supportive wife who reinforced issues such as no bending, no crossing or no twisting, as taught in the pre admission teaching. Pain management wasn't as much of an issue for $\mathrm{Mr} \mathrm{G}$, having had his hip joint replaced. From observations in the clinical setting, knee joint replacements often appear to require more input for pain management than hip joint replacements.

Mr M's discharge did not appear to run so smoothly, as he struggled to manage his pain on discharge. He had previously built up a good relationship with his General Practitioner and relied on his assistance. His GP had a big influence on pain management on discharge. Due to the large amount of pain experienced, movement and bending did not progress well, and $\mathrm{Mr} \mathrm{M}$ needed intensive physiotherapy. This did hinder progress and slowed down the return to normal activities quite considerably. An interesting issue that $\mathrm{Mr} \mathrm{M}$ raised during the interview was pre operative preparation of the limb having joint surgery. Unfortunately at pre admission clinic, Mr M did not see a physiotherapist, but was given an information sheet which included pre and post operative exercises. "They gave me a note and stuff. I accepted that....But I was quite happy with all the diagrams and I sort of knew..." (line 35). He admitted that he could have asked more questions, but felt that in hindsight, "I didn't actually listen enough" (line 5).

\section{Life at home}

At the time of the interviews all participants were getting back to their normal every day activities. Mr G was preparing to have further joint surgery on his other 
side, and felt very prepared, as one might imagine. He felt that having being through it before, and knowing what to expect, it may assist with his rate of recovery. His aim was to get back to work when the surgeon allowed him to drive a motor vehicle. Not being allowed to drive for insurance purposes, did pose a problem for some of the participants, particularly those that lived on their own. $\mathrm{Mr} \mathrm{M}$ had decided that he needed to maintain his independence and had driven following his discharge. When asked about his return to driving during the interview his response was, "you shouldn't ask that question... I drove the day I got out of there. I could lift my leg up and down and I went...” (line 445). He was fully aware of the ramifications should anything happen, but chose to drive himself anyway. Mrs D found that the loss of independence once she returned to her own home was quite restrictive. Despite having supportive family who took her out regularly, she still felt quite helpless. For Mr G and $\mathrm{Mr} \mathrm{K}$, this did not appear to be a major problem as their supportive partners were available during their rehabilitation to be the designated chauffeur. It didn’t appear to be a problem for Mrs A, as she only had a mobility scooter. However, she was pleased when she was able to return to the shops to complete her own shopping and get the brands that she likes.

Pain was still an issue for two participants at the time of the interviews, and both were still using regular medication. Mr M was still having active physiotherapy and unfortunately progress was slower for him. Mrs D was still troubled with pain, particularly at night. However, taking regular analgesia has assisted her with managing that pain. She admitted to referring to the written information for further clarification of this pain and also the reassurance of her son. She admitted that she had been told in pre admission clinic that she may still experience some pain from her knee joint replacement several months down the track. With this reassurance, she was able to continue with returning to her routine, everyday chores without too much concern. All the other participants were happy with their progress as they continued to return to their normal everyday activities.

\section{Discussion}

Hearing the participants’ stories as they have experienced their journeys has been 
a very unique experience. Sharing them with you, the reader, has been an important part of this study, and initiating the most appropriate way has been quite a challenge. To continue to acknowledge the richness of the collected data, and to maintain the rigour of this research, interweaving the text with the participants' own words as they share their experiences, has been a very appropriate way to present their stories.

Undertaking these interviews has given me some reassurance about the process of pre operative education that is being carried out within the tertiary hospital where I am currently employed. In my opinion, the process appears to be working well with participants very positive and supportive of their appointment in pre admission clinic. Due to the varying sessions both as a group and as individuals, pre operative education regarding joint replacement appears to be tailored to the individual needs of the patients. Participants reported that the one on one sessions with health professionals were invaluable, and individual planning was able to be commenced within these sessions. It gave them and their families time to discuss individual matters and ask further questions and clarify any outstanding issues.

Despite the pre admission clinic appointment being quite lengthy in time frame, all participants regarded that as of little importance in relation to the knowledge that they gained. When being booked for this, explanations are always given to patients that it can be a long day. However, it appears that patients would prefer one visit to the hospital and have it all done together. All participants appeared to appreciate the session with the anaesthetists, as this does appear to reduce some anxieties that patients have when they have pre existing medical conditions. Mrs A who had pre existing medical problems had to be stabilised prior to surgery, but once she had attended clinic, a plan was initiated to return her back to optimum health. This seemed to reassure her that she wasn't forgotten about and that once stable, surgery would be scheduled.

The structure of pre admission clinic appeared to suit most participants. There was only a little time sitting around as they progressed through the system of blood pressure checks, to health assessments, anaesthetist visits, video viewing and on to the physiotherapist, occupational therapist and specialist nurse visits. They found 
that although some of the information was repeated, this enabled them to understand it better. During the waiting periods, there was interaction with other patients, which at times can create opportunities to discuss their situations. From past clinical experience, this has been found to be beneficial for some patients.

The delivery of health education for joint replacement surgery is varied within this tertiary hospital. Initially a comprehensive booklet was sent to the patient prior to the appointment in pre admission clinic. However, as evident within this study, not all patients availed themselves to read the booklet thoroughly. Unfortunately, health professionals can provide information, but they cannot make patients read it. However, most participants found the booklet very informative and shared it with family members also. The participants that did read the booklet reported that it gave them time to digest the material and be better prepared to ask questions at clinic to clarify information as necessary. When the literature was reviewed, it was found to be beneficial for patients to have the written material prior to attending the clinic (Fielden et al., 2003). This allowed for further clarification if required. If patients were given the written material the same day, there was little time to read and absorb the details, and further clarification is not undertaken (Fielden et al., 2003; Livesley \& Rider, 1993).

Pre operative education sessions enabled participants to establish relationships with health professionals. Not all of the multi disciplinary team involved in pre admission clinic are involved with the participants on admission. As part of my role, I am involved with the follow up of the pre operative tests and also for scheduling patients for surgery. A relationship has already been established in clinic and enables a smooth pathway to be followed for the patients. Further contact can sometimes be required prior to the scheduling of the surgery, and having that developed relationship can assist and reduce patients' anxiety.

An interesting issue to arise from the interviews was how little awareness there was in regard to reinforcement of the pre operative education once the participants were admitted for surgery. On probing this further, it became evident that the physiotherapist was the health professional that was acknowledged to be the main instigator to reinforce the pre operative education. Despite all participants 
expressing how good the nurses were with the care given, limited acknowledgement for further reinforcement of health education regarding their joint replacement surgery was evident. Participants did acknowledge that the nurses were always busy and had little spare time to be able to talk to their patients. This raises further issues whereby participants did not like to bother the nursing staff to ask further questions or clarify issues.

It has been argued that the nurse - patient relationship is a partnership (Christensen 1990), however, this did not appear to be evident within the gathered data. Submissiveness was evident, and this particularly intrigued me as a health professional, with consumer advocacy and rights being more highly publicised in health care today. This will be discussed further within the next chapter.

Overall, the pre operative education given to the participants undergoing a total joint replacement appeared to meet the needs of the consumers. As discussed it became evident that ongoing reinforcement of that education was not always undertaken in a manner that was acknowledged by the participants, and this reinforcement may have provided valuable assistance for the participants in their rehabilitation following their joint replacement surgery. In reflecting on the research question 'what are the patients' experiences and perceived benefits of the given education when undergoing a total joint replacement', these stories tell of those experiences in the participants' own words. Themes that have emerged from the participants' stories will be more closely reviewed within the next chapter. 


\section{Chapter 6 Partnerships}

In the preceding chapter, the participants' stories were told of their journey when undertaking a total joint replacement. Several themes began to emerge as I began to listen as their stories were being told as I worked through the process of analysis as described in the previous chapters. This chapter will identify the themes and how, collectively, they were grouped under the three main headings of 'Communicative Partnership', ‘Submissive Partnership' and 'Knowledge Partnership'. Further discussions will be initiated in regard to the overarching issues in partnership and why this was used as a common theme throughout.

As participants freely talked about their experiences when undertaking a joint replacement, many different ideas started to emerge. Key issues such as those shown in Table 4 appeared to be reoccurring throughout the collected data. These have been collectively grouped, as discussed, and will each be discussed in further detail in the next section.

\begin{tabular}{|ll|}
\hline Communication & Relationships \\
Pain management & Advocacy \\
Autonomy & Submissiveness \\
Knowledge retention & Partnerships \\
\hline
\end{tabular}

Table 4. Reoccurring Sub Themes from data.

\section{Partnerships}

Why partnerships, one might ask? A key insight as I worked with the data was how central partnerships were in the process of the journey that each of the participants took. There are always at least two groups of people associated with nursing, one the 'carer' and the other the 'cared for'. 'Partnership' is described by Christensen as "an alliance between two or more people involved in a shared venture" (1990, p.xiv). With each and every issue that is raised in Table 4, there 
are two groups involved. Communication cannot occur with just one person, relationships are something that occurs between two people, knowledge is shared between health professionals and the patients, submissiveness occurs when one group controls or gives orders over another group. The common denominator was that there are always two persons or groups involved with all these themes, therefore a partnership, as shown in Figure 1, is an appropriate overarching heading to include in each main theme.

Any partnership has active participants, all recognising their rights and obligations and each having a role to play to achieve the best possible outcomes. This is an important aspect of any partnership.

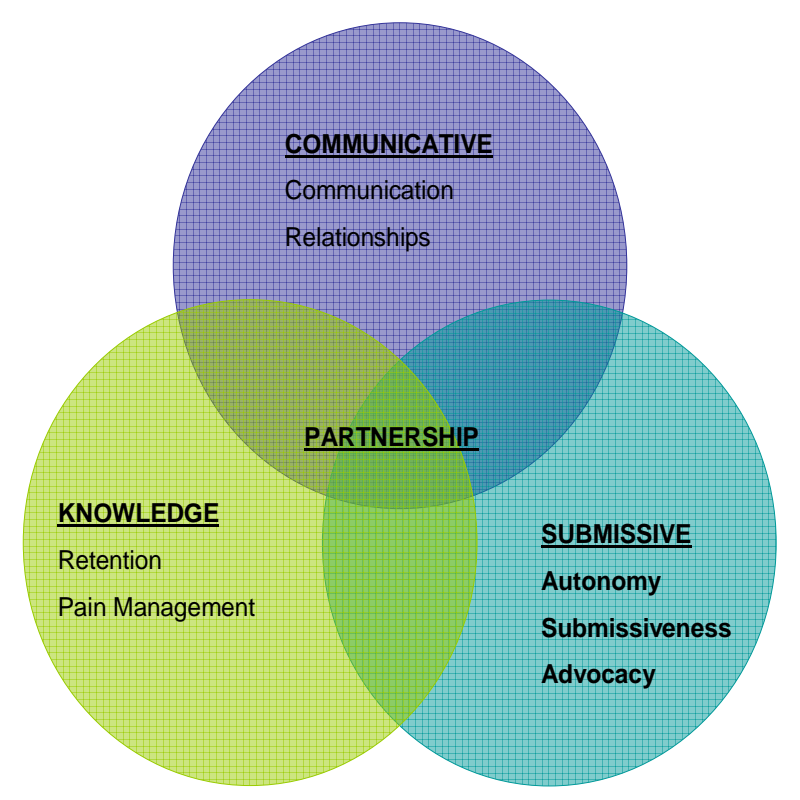

Figure 1. Theme Relationships

Hand in hand with partnership is participation. It is the association of two people or groups in a common endeavour, moving forward together through a process (Meagher, 1996). In this study, it is about the participant moving through their total joint surgery with the assistance of the health professionals to regain their independence and return to their normal daily activities. It is necessary for health professionals to learn about the participant's skills, knowledge, strengths and 
abilities, which are important aspects in gaining mutual growth that is required. Before this can occur a relationship must be developed to enable the transference of this knowledge. This leads on to the Communicative Partnership which will be discussed within the next section.

\section{Communicative Partnership}

This section will examine the sub themes of communication and the development of the nurse-patient relationship in regard to the collected data and literature. "Building rapport with patients is an ability that has become accepted as part of nursing practice” (Turnbull, 1999, p.302). The nurse - patient relationship is considered to be the foundation of nursing care and building the trusting relationship is of utmost importance in health care delivery (Hagerty \& Patusky, 2003; May, 1990; Williams, 2001; Yamashito et al., 2005).

It is suggested that with an increase in technological and scientific change in health and nursing care systems today and the increased pressures that are present, nurses will have little emotional energy left to maximise the therapeutic benefits of the nurse - patient relationship. This may be indicative of this situation already being presented within the collected data. As Mrs D states, “the nurses they didn't really have time... to sort of explain it all. Not that I held anything against them because I thought it was all part and parcel with it" (line 104). And Mr M gave an explanation of "to be fair they are busy..." And Mr K explained that "I sort of felt as though it would of fallen on deaf ears" (line 448). Patients often only expressed dissatisfaction under certain circumstances and often, despite their experiences of the given health care, would still report positive evaluation of the nursing care they received (Coyle \& Williams, 2001).

Christensen (1990) has done extensive study into the nursing partnership over recent years, and describes the nursing partnership in relation to both the patient and the nurse. When a person becomes hospitalised, it is but a brief episode within their lifetime and the nurse's role is to minimise the impact of this. Within the Nursing Partnership framework there are stages that are transgressed to enable 
partnership to develop. These stages involve the beginning, the settling in period, negotiation of the partnership, and going home.

The beginning occurs when a person seeks assistance with a health problem that requires further treatment to be carried out. Preparation is preceded with acquiescence of the suggested planned surgery to achieve beneficial outcomes. Attending pre admission clinic can be part of this beginning process. Settling in occurs when the person is admitted to hospital and the partnership is initiated. It is at this stage that social roles are suspended and self exposure occurs to the medical profession. This is also where the person takes up the patient role, using past experiences to assist them through the many unpleasant, undignified procedures they may have to go through to gain benefits (Christensen, 1990). Accepting the reality of being reliant on expert professionals plays a big part in this process. As $\mathrm{Mr}$ M describes when the anaesthetist discussed the general anaesthetic versus the spinal in regard to his INR levels. "I'd signed a piece of paper to say that it was his decision. He just walked in and said I was having a general...so I stuck my arm out and they stuck a needle in” (line 193).

Christensen (1990) discusses how this submission is often common, but is neither passive or complete. As $\mathrm{Mr} \mathrm{K}$ stated “I normally like to do as I'm told, but actually I was quite sore” (line 146). It is necessary for patients to retain a degree of assertiveness, but also an acceptance to cooperate from the time of admission. It is during this time that the nurse actively seeks information from the patient which is used for comparisons and for the development of care plans.

Collaboration between the nurse and patient is essential for the nursing partnership to continue. From the patient's perspective it is self-centred with the nurse assisting when necessary. The presence of the nurse is vital for this to occur. However, due to work loads and the increased independence of the patient, this becomes sporadic as time progresses. The transition from hospital to home is the completion of that nursing partnership which occurs on discharge of the patient.

To develop a nursing partnership, it is necessary to have good interpersonal communication skills. It assists with the development of personal growth and self 
confidence through self-acceptance (Duldt, Giffin \& Patton, 1984; Edwards, 2003). To create positive outcomes from a health episode, it is necessary to have the development of a high quality interpersonal relationship with good communication. Many nursing theorists, including Roy, Orem, Travelbee, and Newman, have discussed the development of interpersonal communication as being a major concept in the nursing discipline and unique to nursing (Chinn \& Kramer, 1995; Hartweg, 1991; Lutjens, 1991).

May (1990) explores the literature in regard to nurse-patient interaction and finds that verbal interaction is often short in duration. Literature indicates that any interaction that occurs between the nurse and patient is often superficial and task orientated. It is often controlled by the nurse and tactics are frequently used to avoid communication. This is evident in the experiences of Mrs D as the nurses came in and attended to tasks and then left the room as quickly as they had entered. Mrs D expressed that opportunities to express how she was feeling, or clarify information occurred infrequently throughout her hospital stay, which did not allay insecurities or give reinforcement in regard to her rehabilitation.

Crowe (2000) states that "nursing as a discursive practice is produced, negotiated and reshaped via discourse and practice” (p.966). To have an active participation from both the nurse and the patient enables a successful relationship to occur. For the nurse, this means being engaged and interdependent and having the ability to negotiate solutions. It is also having the skills to be reflexive of past experiences and expertise. Nurses need to develop these unique skills and knowledge to enable the nurse-patient relationship to develop to its full potential.

Patient care is not just attending to the physical needs of the patient when hospitalised. It is about facilitating a connectedness with them, and being able to nurture, collaborate and bring purpose and meaning to the nurse-patient relationship. Connection with the patient can facilitate healing (Salmond, 2005). "Caring does not involve specific tasks, instead it involves the creation of a sustained relationship with the other, an ability to reflect on the specifics of that person's history, and an ongoing process of and dialogue through which 
assessments and interventions can be tried, monitored for relevance and adopted or adapted as necessary” (Davis, 1995, p.141).

When listening to the participants' experiences of both the education they received and the care during their hospitalisation, it became evident that participants did not acknowledge the extensive role of the nursing profession. Their physical needs were all met following their joint replacement surgery, however, little was acknowledged by the participants in regard to any further ongoing relationships with the nurses.

The link of passages, as described by Christensen (1990), from the 'beginning' through to 'going home' cannot be transgressed in a linear progression. It is a complex progression which involves both the nurse and the patient working through a matrix of inter-related activities. The patient brings to the relationship the knowledge of 'self' and the nurse brings the professional health knowledge, which is progressed through a number of nursing episodes. This highlights the importance of nurse-patient relationships when patients are recovering from joint replacement surgery. For these participants having their first joint replacement, as in this study, all the experiences were new to them. As $\mathrm{Mr} \mathrm{G}$ stated when discussing the physiotherapy regime, "I got quite a shock there. They wanted me to do a lot of things that I thought I couldn't do" (line 177).

It has become evident that building a therapeutic relationship is very important in any partnership, and mutual respect from all parties must be present to succeed (Yamashito et al., 2005). In clinical practice, this has been an accepted part of nursing practice, however it may differ within the nursing profession. Within Benner's (2001) model of expert to novice, the expert nurse will negotiate differently to the novice nurse, and outcomes may vary. However, no matter what level one practices at, it is imperative that a relationship is established and good communication is present, to assist the person through their journey. For these participants in this study, it is to assist them with their recovery and transition to their normal daily activities following their total joint replacement. 
During the process of analysing the participants' data during this study, it became evident that there was little acknowledgement of this nurse - patient relationship. The raising of several questions made me reflect on my own practice and how I develop this very important aspect within my current nursing role. It also raises questions around patients' expectations of the nursing profession and what can be done to improve this situation. If communication and relationships are improved, would this mean better outcomes for patients? For those having joint replacement surgery, would this have assisted with their rehabilitation process and the transition back to normal, daily activities?

\section{Subservient Partnership}

This section will examine autonomy, submissiveness and the role of advocacy as sub themes that emerged from the collected data. Towards the end of the 20th century, the health service has seen many changes (Hodgson, 2007). The dominance of one professional group, the physicians, has slowly been challenged and created an opportunity for all nurses to advance their practice. Prior to this, healthcare work and thinking has been skewed into a direction of scientific medicine and has delayed the development of nursing as a discipline (Gott, 2000). Again, male dominance within the medical structure was evident, as the predominantly female, nursing workforce remained relatively powerless (Benner \& Wrubel, 1989; Muff, 1988). Indeed the change from apprentice type nursing education to higher educational institutes has raised the status of the nursing profession.

However, this role of subservience is still evident today with the older population. As osteoarthritis does affect a large percentage of the elderly, this submissive role will continue to be apparent. Their experiences and their knowledge of health care often transgress back to the earlier days whereby nurses were the doctors' handmaidens. As in this research project, two of the participants had been health care workers, and ideals from their prior employment were influential in their health care experience. 
Mrs A describes that from her previous health work "it taught me how to behave as a patient" (line 294). She felt this was a very important issue for her when she was hospitalised for her joint surgery. "You really need to learn that” (line 459). She describes how it is just something that was "going to happen to me, I would go to theatre, lie in bed...that sort of thing and then just get over it" (line 185). She didn't feel the need to ask questions about the surgery or rehabilitation, as "it would just happen" (line 113). As her family had been the main instigators for having the knee joint surgery, this showed further subservience by way of someone else knowing the best thing to do.

Mrs D did not acknowledge to staff of her previous nursing aide experience, as she felt this may indiscriminately influence nurses' thoughts about her. "You don't like to sort of say... cos 'she thinks she knows it all'. And you don't, you just keep quiet because that's just the way things go" (line 360). Again, the hierarchal structure from days gone by also was acknowledged by Mrs D. "You don't question what they say. You see, when I was particularly sick this day, I knew there was something wrong, with my chest. Instead of saying, 'you're not listening to me' I just took it" (line 389). And "he was the doctor, he knew just what was going on. You don't question it” (line 396). Qidwai (2005) also acknowledges that the traditional model of medical practice assumes that the doctor knows what is best for his patient, and she suggests that one positive aspect that arises from this issue is the complete trust that consumers put into the medical staff. One may argue that the patient may feel complete powerlessness rather than complete trust.

This type of behaviour shows the lack of autonomy experienced by these participants. It was again evident when discharge planning occurred. For Mrs D, she experienced a feeling of being totally lost, as she didn't know what was happening to her on discharge. "It was all planned for me. It was taken out of my hands" (line 141). For Mr K, there was no consultation and involvement with his discharge either. He was told quite abruptly that he could "go home today" (line 296). This issue was also evident in Loft et al.'s (2003) study, who noted that many acceded to professional care providers' knowledge, status and authority with their questions and needs not attended to. 
On examination of the collected data, it became evident to me, as the researcher, that some participants did not expect to be in partnership with the health providers. There was an expected course of action that was taken, and they appeared happy with this. In direct opposition, Radka (2003) found that consumers in her research asked to be kept informed and be involved with their care. It was noted that open communication was indicated as a key attribute and an essential ingredient in developing the nurse-patient relationship.

Again that made me aware of health consumers and their expectations, and the role of autonomy. What appeared important to me, as a health professional, did not appear to be an important issue for the consumer in this study. Literature supports that autonomy is a value that appears to be of great importance to society today (Rogers \& Niven, 1996; Loft et al., 2003; Zager \& Walker, 2005). But how much significance should be place on this aspect? In years gone by, paternalism was evident with health professionals having control over decision making. However, as consumers become more aware of their rights and expectations, it may be that health professionals may instead need to facilitate the decisionmaking process. But does this have a great meaning to consumers in today's health care? This raises some important issues regarding the consumers' perspectives and may benefit from further study. Despite individual autonomy now being a prominent value in Western medicine and ethics, there still remains much discussion regarding the definition of the concept of health in literature (Varelius, 2005). With varying degrees of autonomy within health care today, are these always valued by everyone?

Advocacy is another issue that has been identified from the participants' stories. The idea of advocacy has been a fundamental aspect of nursing since the beginning of the profession, however, it has evolved from being an intermediary to acting as a custodian of the patient's rights of autonomy and free choice. Much has been written regarding the nurses' role in advocacy, with many inevitably finding themselves placed in untenable situations of conflict between professional roles, employers' role expectations and the potential role of an advocate (Gates, 1994). As in my role during my early days of nursing, as discussed in Chapter One, it often created confusion, and it was necessary to clarify the roles of the 
nurse and of the advocate. Gadow (1983), as cited in Gates, argues that nurses acting as advocates for patients should be based on self-determination and holism principles, and should be achieved through "the unique nature of the nurse/patient interaction" (Gates, 1994, p.10). Again, this brings into the discussion the nurse/patient relationship and the partnership that has been developed. However, in this study there was little evidence of this type of advocacy being present or acknowledged by the participants.

The emergence of advocacy in this study was for self-advocacy and for family to stand in as advocates for the participants. In self-advocacy, people are encouraged to speak up for themselves, thus encouraging the element of self-empowerment. This, in turn, enhances and develops self confidence and self esteem (Gates, 1994). Mr M showed his self determination and self confidence when dealing with the health professionals during his experiences of his total knee joint replacement as he explains, "it is up to the individual. You've got to put yourself out there. Say 'this is where I am at... I think that half the time the health carers are supposed to be mind readers. And that's where it falls down. I think the patients need to be more aggressive and say this is what is actually happening with me. And if it is not working, go back in two or three hours and tell them again” (lines 313-319). Mr M also acknowledged being an advocate for a fellow room mate, acknowledging the fact that the role of advocacy is not only a nursing role or one that a family member may take up.

For participants like Mr K, he was happy to have his partner become his advocate during his stay in hospital. He stated that "I'm not a very good speaker or a very good talker... that's exactly what I did" (line 343). Having a partner with nursing background did assist $\mathrm{Mr} \mathrm{K}$ immensely as she was aware of routines and procedures that $\mathrm{Mr} \mathrm{K}$ was unsure about. She also had quite a strong personality and wasn’t afraid of asking questions. Left for Mr K, he admitted that he would not ask any questions. Having an advocate to assist through the journey has been an incredible help for the likes of Mr K. Family advocacy works on the basis of family loyalty and having the members’ best interests at heart (Meagher, 1996). 
Advocacy is designed to empower others or take action on behalf of others to enable individual goals and objectives to be reached. This is an important issue for those having joint replacements and working towards the goals of independence and returning to normal, daily activities. For the elderly population who may not understand the processes and procedures surrounding hospitalisation and joint replacement surgery, it is imperative that they are empowered as individuals to achieve those same goals, and their rights are considered and protected. As our population increases in age, and an increased number of joint replacements need to be performed, there will be an increased number of patients who may not have supportive family available to advocate for them. For these patients who may be marginalised and/or devalued in society, it is important that choices and opportunities which ultimately affect their lives, be boundless to gain control and responsibility over their lives and gain the best possible outcomes. To gain this empowerment and self confidence during the undertaking of a total joint replacement and the hospitalisation experience, knowledge is the key. This is discussed further in the following section of Knowledge Partnership, relating to the knowledge base, education and retention of this knowledge.

When undergoing total joint replacement surgery, it is important for patients to be involved with decision making during their treatment. Health professionals have the professional knowledge and need to guide patients when making decisions in regard to their care and rehabilitation. Patients need to be empowered with knowledge and have the ability to choose their pathways as they return back to their normal every day activities. Because this health intervention involves both health professionals and patients, it becomes a partnership. As discussed previously, it is a venture that involves two or more people with a shared interest. It is true to say it is a 'joint venture'. Health professionals perform the joint replacement surgery, but then the rest of the rehabilitation is up to the individual.

\section{Knowledge Partnership}

The third and final form of partnership emerging from the research is 'Knowledge Partnership'. As nurses, it is assumed that if we teach patients, they will 
understand. However, it is important to identify the consumers' learning needs to enable nurses to educate them in the best possible manner. It can be a very rewarding activity, but it is not without its challenges and barriers (Crane Cutilli, 2005a; 2005b). As most nurses will discover, educating patients can be a frustrating event when patients chose to follow a different pathway through their journey. Despite any amount of willingness and effort on the health professional's part, it is up to the individual to participate in their own care decisions and care processes (Meagher, 1996; Rankin, Duffy Stallings \& London, 2005). Education is about the process of influencing behaviour, encouraging change in skills, knowledge and attitude for maintenance and improvement of health, however, because it is a process, occurs over a period of time (Loft et al., 2003; Rankin \& Duffy Stallings, 1996; Rankin et al., 2005). Because of this, it is important for all educational material to be reinforced during the patients' journey. Literature shows that pre operative education improves post operative outcomes for patients who are undergoing surgery, (Daltroy, Morlino, Eaton, Poss \& Liang, 1998; Fielden et al., 2003; Maskell \& Wright, 1993), and as discussed in Chapter One, my own clinical practice is very much patient focused. For my practice, it is important for patients to be empowered to allow them to take control of their recovery in the post operative period. This study has allowed a study of patients' experiences and perceived benefits of the given education when undergoing total joint surgery.

Throughout this research project, I needed to reflect on my educator role as I progressed through the interviews and heard what participants were telling me. As I immersed myself in the collected data, I reflected back on my personal knowledge of the process the participants journeyed through. At times I was quite amazed with some of the comments made during these interviews. Being involved in the delivery of education pre operatively, this gave me an insight into patients' perspectives of the importance of education and the retention of this knowledge.

The fastest growing sector in our population is the elderly and joint replacements are more common within the elderly population, as discussed previously. As people grow old, their cognitive efficiency declines (Rankin \& Duffy Stallings, 1996), and it is important that educators take time to deliver the material required. 
Reaching the desired outcome of return of functional abilities requires an involved patient who must have clear expectations of the rehabilitation / recovery process and the knowledge to implement a home regime. The need for the empowered patient with a partnership relationship with the health providers is evident.

Loft et al., 2003, p 43.

It was evident that some participants did not put a big emphasis on pre operative education, as Mrs A states, "the video was something...it was educational I suppose" (line 335). However, most did find it useful for preparing them for their surgery and rehabilitation. Participants recalled very little reinforcement of education by the nursing staff once they were hospitalised. Rankin and Duffy Stallings (1996) state that "providing patient education is central to the role of every nurse providing patient care, regardless of job title or clinical setting” (p. 4). Was the educating role one that didn't seem important for nurses to implement whilst attending to the patients' physical needs? Santavirta et al.’s (1994) study acknowledged similar findings with the physiotherapists' role providing the most relevant information within their teaching module.

Evidence around knowledge of pain management appeared to be a deficit with all participants. They appeared to revert to the submissive practice of relying on the nursing staff to manage their pain. There was evidence that showed that participants had minimal knowledge regarding their PCA pumps and there was little recollection of nursing staff taking the time to educate them regarding this very important issue. Mrs D was told by a physiotherapist that she wasn't using the PCA pump enough, but there was little input from the nursing staff to reinforce this. Little recall was evident regarding the topic of pain and its management in the pre admission clinic. This is one topic which is covered in depth pre operatively, however, it appears that further explaining and reinforcement would be of value to patients to gain an improved outcome. Retention of knowledge is known to decrease with the elderly population, therefore it is imperative that ongoing education is given.

Preparation for discharge in regard to pain management was another area which was not well acknowledged by participants. Being able to manage their pain can 
greatly effect patients' rehabilitation. For Mr M, he had already established a relationship with his GP which enabled him to seek out further assistance. Mr K utilised the nursing knowledge of his partner to manage his pain once discharged. Despite having previous experiences with public health services or prior nursing knowledge, all participants having a total joint replacement were faced with uncertainties regarding their pain management on discharge. Knowing that this is occurring can assist health professionals to seek solutions and improve standards of care. Partnership is yet again revisited for this to occur.

\section{Discussion}

The revisiting of partnership is imperative as health professionals go about providing health care today. For the participants involved with this study, the ideal partnership has not always been evident or acknowledged. This has been shown in many different ways as we hear the participants' stories being told about their experiences when undergoing a total joint replacement. This study initially started out looking at the education and the benefits of the education that participants received when undertaking a total joint replacement. However, it has highlighted the importance of partnership, which may be something that many may take for granted and assume occurs automatically once the patient enters into the public health system. To have some control and be given support to assist with the transition back to everyday living must give the patients self confidence and build up their self esteem.

In the busy world of health care today, frontline health professionals must be made aware of the importance of such things as partnership. For without partnership, there will be no communication, no effective nurse-patient relationships, no empowerment, no transferring of knowledge and advice to assist patients back to normal lives following not just total joint replacements, but any elective surgery. Partnership is the key to any practice in the health profession.

Exploring the patients' health educational experiences and their preparedness for their joint replacement and rehabilitation was one of the main aims of this project. As discussed, it is important for patients to be fully prepared for this major 
surgery and the implications it can have on their everyday lives. It appears that the participants involved with this study were well prepared for the surgery but further reinforcement of the health education would have assisted them more during their rehabilitation period both in hospital and at home. Listening to the participants' stories gave an insight into the important issues that arose during the time of preparing and being admitted for joint replacement surgery. Allaying anxieties and clarifying information in the pre operative stage gave the participants a better understanding of what was expected in the post operative period. This study has also given some insights into the needs and expectations that patients and their families have when undertaking a joint replacement.

This study has highlighted that partnership is, indeed, a very essential part in any health treatment. For patients that undergo total joint replacements, it is especially important that partnership occurs so that they can gain the best optimal outcomes in their journeys. As discussed, health professionals provide the professional expertise and knowledge around the joint replacement, however, the patient brings their 'self'. They are responsible for the continuation of their rehabilitation programmes once they are discharged back into their own homes and it is their hard work that gains the best outcomes. But without a partnership, this will not occur. As I often quote to patients undertaking joint replacement surgery, "it’s a joint effort. We put the joint in, but then you must make it work”.

Partnerships will not occur when partners are not equal. It is imperative that patients realise that they are an integral part of the process and that they have responsibilities. However, for this to occur, relationships must be developed between health professionals and the consumers of health care. For the participants in this study, as discussed, there was little recognition of the ever important nurse-patient relationship. This could possibly affect the outcomes of those patients undertaking joint replacements.

Empowering patients with knowledge of the joint replacement surgery and enabling them to speak out is another important aspect that has been highlighted within this study. Patients can make informed choices and decisions regarding their health care and rehabilitation and be proactive with their care. As previously 
discussed, there are several different learning styles that need to be considered within the education delivery. Reinforcement is a continual process that needs to be carried out by all health professionals, as retention of this knowledge can vary amongst patients. This study has highlighted the common theme of 'Partnership' that emerged from the gathered data. For me as a health professional, I strongly believe that this is the essential piece of any quilter's patchwork that intertwines all the pieces together. 


\section{Chapter 7 What Now?}

This project was initiated to find out about the patients' experiences of the education they received when undertaking a total joint replacement and the usefulness and benefits of this health education in the rehabilitation period. During this journey I was interested in such things as how easy the education was to understand, the appropriateness of written material, preparedness for surgery and discharge, and other issues that were not covered well by the education? As discussed in the introduction, the aim for all patients undergoing a total joint replacement is to reach the desired outcomes of return of functional abilities. To do this, the patients need to have clear expectations of the recovery process and the knowledge to continue with the rehabilitation plan in their own home.

During this study, several issues arose that were rather surprising. As discussed, this study initially focused on the given education when undertaking a joint replacement, but when the data was analysed, it became evident that other important issues arose. These could relate to any person finding themselves hospitalised for treatment within any public health setting. Because the rehabilitation is patient-dependent in total joint replacements, knowledge and ability to understand the given education relies on the partnership, nurse-patient relationship, knowledge retention, communication and empowerment of the patient. These are very important issues that need to be present in every day care.

The ever important partnership was not always apparent or acknowledged when the participants were hospitalised or following their joint replacement surgery. This lead on to the nurse-patient relationship which was not always well developed throughout their stay, which in turn did affect the communication between the nursing staff and the participants. Another issue that became apparent was the loss of autonomy and the submissiveness that developed as participants were inpatients in the public health system. For some of the participants this was not an issue. It appeared that partnership did not appear to be a high priority for them. They were happy to put their faith and trust in the medical professional 
without question. These participants were of the elderly age group who had been brought up in the hierarchical era whereby patients did not ask but did as they were told.

At the near completion of this study another relevant article was published. Sjoling, Norbergh, Malker and Asplund (2006) explored the information needs of patients awaiting total joint replacement surgery. It looked at the way patients gained the information that they needed and what the patients want. Interestingly it was acknowledged that communication played an important role within this study. It was found that the "way the information is given and whether the respondent is confirmed as a human being, taken seriously and believed by staff in the mutual process of communicating information is more important” (p.11). This furthers the indication to provide evidence to explore patients' experiences of health education when undertaking total joint replacements.

All participants were happy with their pre operative education and all stated that they felt fully prepared for the pending surgery. Written material was also praised as being a very useful, informative tool which participants could read at their leisure and share with family members. It was shown to be resourced throughout the journey, even three months post operatively. It was following the surgery which was of some concern. This study reveals little evidence of the given pre operative education being reinforced by nursing staff while patients were in hospital. Participants had developed a relationship with the physiotherapists, and repetitive reinforcement was given in regard to the physiotherapy aspects, however, little input was given by nurses. It also appeared that the physiotherapists, when treating the participants, reinforced issues regarding pain management. Yes, nurses do appear to be busy, but they should not be too busy as to not reinforce education and give ongoing education regarding pain management and rehabilitation once the patient has been discharged to their home environment.

On discharge planning, at the tertiary hospital where the study took place, there is a Discharge Coordinator who coordinates the more complex patients. This does relieve the clinical nurses from some of this responsibility of discharge planning, however, as part of the nursing partnership that Christensen (1990) describes, the 
final 'going home' part is still important to complete in this model of care. It seemed that the participants did not appear to be fully acknowledged by the nursing staff who cared for them.

\section{Implications for Practice}

From any research there is always a discussion on the 'so whats' of the project. What has the project uncovered or highlighted that shows relevance to clinical practice? Have the initial questions been answered? If so, what implications does this have for clinical practice? If not, what can be done to get answers to those questions? How does one disseminate the knowledge gained? How do you initiate the findings into the clinical practice?

The importance of this research is to consider evidence generated by the participants who were consumers of health education during their joint journey and to enable relevant findings to be utilised within clinical practice as appropriate. It is becoming increasingly expected that health professionals will use appropriate evidence from research to inform their clinical practice (Thompson et al., 2001).

Qualitative research is not generalisable to the wider population, but it can still be utilised within similar clinical settings. Reflection on current practice in similar settings can be undertaken and nurses can be encouraged to replicate studies to compare findings within their clinical environment. Having undertaken this research, it has given me great insight into a process that I had believed worked well within this tertiary hospital setting that I am currently working in. It has highlighted to me that 'everything isn't as it seems' and further research could be undertaken to get an enhanced understanding. Health education for consumers can be very challenging and rewarding, but there is no guarantee that the consumer will take everything 'on board'.

There are also two different perspectives that need to be considered. It has been an enlightening experience to discover during this project that what may seem 
important from the health professional's view, may not always hold a high level of concern from the consumers' perspective. For the participants involved in this study, many had been waiting for a long time for their elective surgery. Living with the pain and debilitation that arthritis can create is a major issue on its own and these participants were only too happy for the surgery to be undertaken, so they could then get on with life. Reflecting on this issue, I question just how important does this health education appear to patients? Yes, all the participants received some varying degree of benefits from the given education. However, compare this with the elderly patient who has been unfortunate in fracturing a hip and requires an acute total hip joint replacement. How does this patient manage rehabilitation with limited or no pre operative education?

The experience in interviewing health consumers has also been an informative experience. For these participants, it was a great relief that surgery was undertaken and that all participants did not want to appear to be critical of the health care they received. I also learned that often health consumers need probing into areas which don't appear to be an important aspect of their journey. Participants often made a generalised comment about the health education they received, but did not hold much relevance to it. Mrs A stated that "yes, I saw the video. It was just something ... but, it was educational, I suppose” (line 336). And Mrs D said in relation to the written booklet, "I skimmed through the whole thing but I didn’t actually read it properly” (line 232).

The ever increasing pressure of providing more health care to the New Zealand population has put continual stress on the district health boards in recent years. With the population aging as projected, even more pressure will be placed on health professionals. For orthopaedic services it is highly likely that pressure will arise from the osteo arthritic effects that debilitate the elderly age group and increase the clinical need for joint replacements to be undertaken. Care needs to be evaluated carefully and consumers' voices need to inform health service practices. Far too often patient satisfaction surveys focus on organisational outcomes and little is understood from the consumers’ perspective. 
This study has highlighted the importance of partnership in health care and the need to return back to the basics in nursing by evaluating how well nurses develop the nurse-patient relationship and open these communication channels. For without these two important ingredients, there is no partnership. Over the past decades, nursing has changed, with new theories, new models and new systems in education. These changes place more emphasis on the patient-centred care. Morrison and Burnard (1997) discuss how through this time of change, two things remain unchanged - the need to care and the need to communicate. The way nurses do this has changed due to the accountability, the Bill of Rights and the general public education regarding health care. However it is still the basis of any nursing partnership.

The need to support and empower patients in the attainment of self confidence and self esteem is another important finding from this study in relation to preparedness for total joint replacement. Patients need to participate within the health partnership and be able to make choices throughout their journey when undertaking a total joint replacement. Nurses are the facilitators and can assist by guiding them in the most appropriate choices to help rehabilitate them back to their normal daily activities once surgery has been undertaken. The nurse-patient relationship is again highlighted as an important part of this process. As discussed, no partnership is achieved without this relationship being developed.

Enabling patients to question the health care they are receiving and gain further knowledge on expected outcomes following joint replacement surgery will decrease the feeling of "learning to behave as a patient" (line 294) as described by Mrs A during her interview. It will enable patients to actively participate in their care and be part of the decision making, rather than being told by medical, nursing and allied health staff what is going to happen. Giving them the encouragement and the skills to actively participate will reduce the submissive atmosphere that some of these participants' experienced throughout their journeys.

It is now the twenty first century and times have changed. It is important that the population takes charge of their own health and show some responsibility towards 
it. The above issues of partnership, empowerment, and communication are all essential piece works that need to be developed for this to occur. Knowledge regarding one's health is an important aspect and health education will play a larger role in the future. With education and knowledge, people will be able to better manage their illness and have realistic goals for treatment. As the number of joint replacement increases in the future, it is imperative that people are well educated and are well prepared for their joint surgery and the expected rehabilitation. This, in turn, will assist with patient satisfaction, rehabilitation, return to normal daily activities and also may reduce the length of hospital stay. Thus reducing the burden on an already struggling health system.

\section{Limitations of this Study}

During this research project it became apparent that good interviewing skills are essential in qualitative research. Interview skills are used in my clinical practice, however, as a new comer to research, I needed to acknowledge my inexperience. The questions of how much probing does one do, is it relevant to the topic, or has important data not been collected that could be relevant? As the interviews progressed, I gained more confidence and skills, and found that I could probe and question consumers more clearly. This evolving level of confidence did raise some issues in regard to rigour. There is no doubt in my mind that participants interviewed early in the study were interviewed less well. However, in working with the participants texts and overall findings I have attempted to minimise the impact of this.

Using the participants' words when telling their stories was utilised in Chapter 5 to enable the 'truth' values to be evident to the reader. This gives an indication of the experiences that the participants experienced during their journeys when undertaking joint replacement surgery.

The prior interaction with the participants in my educator role which was acknowledged during the ethics application process did not seem to bias the data collected from the participants. As all participants declined the presence of an 
advocate during the interviews, seemingly they felt no prior threats to their wellbeing. This did, however, raise some issues from the health perspective view. As discussed prior, issues that I felt were important for patients to understand, did not seem to appear to be important issues for them as the patients. Some patients were happy 'becoming patients' and letting things just happen.

\section{Reflections}

In the health setting that I am currently employed, I have always had great faith in the holistic care that is given to patients. However, for me, this study has highlighted that sometimes this care is not individualised and ongoing reinforcement of education and rehabilitation planning does not always take place as it should. My initial preconceived expectations of what this study may highlight has initiated further thoughts around the health care delivered today for patients undergoing joint replacement surgery.

An imperative part of nursing for me, personally, is the art of caring. Davis (1995) describes the meaning of caring as "attending, physically, mentally and emotionally to the needs of another and giving a commitment to the nurturance, growth and healing of that other” (p.141). For this to occur as discussed previously, the development of the nurse-patient relationship is imperative. An aspect that has been highlighted within this project is the lack of recognition and acknowledgement of this relationship occurring within the participants’ journeys. Does the work of the nurse appear to be 'invisible' to patients? Are they just there to attend to the physical cares that are needed? How do nurses feel about the lack of acknowledgment within the joint journey? This raises several issues that would indeed be interesting topics to research further in the future.

The development of this nurse - patient relationship, I believe, is imperative to nursing. But how can this be instilled in the nursing profession today? Is it an attribute that just occurs within nurses, or is it a learned process? Does the nursing education cover this clearly important aspect within the curriculum? What are the thoughts of the nurses working in clinical areas regarding the development of this 
relationship? Is there time in today's health world to be able to initiate it? This again raises issues that would benefit further research.

In conjunction with the nurse-patient relationship development, is the nurses' ongoing involvement in patient education in respect to the 'joint journey'. Again, there appeared to be little evidence showing that reinforcement of education was occurring once the patient had been admitted into hospital. Knowledge retention is not necessarily going to be evident if reinforcement of material does not take place. Influencing behaviour and changing practice to improve one's health will not occur if reinforcement of education is not repeatedly attended to. For the patient's empowerment and autonomy, knowledge needs to be given. As our population continually grows older, that knowledge needs to be delivered in a manner that patients can understand. Again, some serious issues are raised as per the reasons why the ward nurses are either not reinforcing the health education or appear not to be doing so? What do nurses need to do to raise the profile of their chosen profession?

Nurses' involvement again appears not to be acknowledged within the discharge planning process. Again, it comes back to the acknowledgement of the imperative nurse - patient relationship for this to occur. Within this process is the ever important pain management that is required for joint surgery. In this study and from clinical experience, pain is a major issue for patients having total knee joint replacements. This needs to be managed well for rehabilitation to progress. A majority of patients have limited knowledge regarding this and rely on health professionals to guide them. For those who have recently had surgery, this creates a further issue to effectively cope with the transition to being discharged home and also managing the pain.

This study has raised several questions which remain unanswered. It has been a very interesting journey and the findings have been intriguing. As a researcher I had to be mindful not to become protective of the hospital where I work and impose a belief that patients receive the best possible care. Rather I had to avoid such assumptions and be open to the patients' experiences as they were told and 
as I listened. But until the patients' stories and experiences are heard, I can only assume.

\section{Methodological Reflections}

The qualitative, descriptive methodology that was used in this study proved to be appropriate to explore patients' experiences and perspectives of the health education they received when undertaking a total joint replacement. This method is particularly useful for the researcher who is wanting to know the "who, what, and where of events” (Sandelowski, 2000, p.339), when there is little known about the topic. This gave me the opportunity to give a descriptive summary of how patients perceived the health education they received and how helpful it was in preparing them for total joint replacement surgery and the following rehabilitation period. I am in complete agreement with Sandelowski (2000) when she discusses how this descriptive method is no easier, nor less valuable, nor less scientific than other methods. It has enabled me to present a comprehensive summary of findings of this study in everyday language, which has not utilised philosophical, conceptual or highly theoretical frameworks. The journey has been informative and comprehensive, and by no means, easy.

The use of an 'aide memoire' was particularly useful, as I transgressed through the interviewing process. I became more skilled and confident with each open ended interview and found myself probing further into participants' experiences to gain more valuable data. This method allowed me to gain rich data from the perspective of the consumer as they journeyed through the pathway of joint replacement surgery.

Using this descriptive method of research and reporting will support clinical staff to understand the patients' perspectives of the health education they received when they are undertaking joint surgery. It is often heard in the clinical setting that nurses struggle to understand much research as it is too highly academic for them to understand. The reader of this research can follow through the processes 
and have an understanding of patients' perspectives without needing to filter through different theoretical lenses.

\section{My Reflections}

Undertaking this study has been a great learning curve, not only about the research process but also from the clinical aspect in hearing the patients' experiences when undertaking a total joint replacement first hand. My own personal learning and growth has been tremendous and this will be a great assistance in my clinical practice. As discussed, the pre operative education given to these participants was found to be very beneficial, however, further development of patient empowerment, autonomy and knowledge retention may be beneficial.

On reflection through my journey, I have gained much experience with my interviewing skills. However, there is always room for improvement with further attention and focus on the types of questions which may lead to the collection of a higher quality of data. The use of open ended questions can sometimes be a challenge for the novice researcher, but these skills can also be utilised within the clinical setting.

What changes would I make to current practice? The realisation of what patients perceive as being important compared to health professionals, is an important issue, and hearing their stories has enabled me to re evaluate this. The pre operative education process that is currently being undertaken appears to be meeting the needs of the consumers well. The written pamphlets and the video material will continue to be updated regularly. Another beneficial development will be the dissemination of my findings to the clinical staff who are currently employed in the tertiary hospital where this study was undertaken, and also to other orthopaedic nurses involved with caring for patients having total joint replacements. To get the patients' stories and experiences heard by health professionals so they can gain some insights into how they can assist them during 
their journey when undertaking a total joint replacement, will be beneficial to all involved.

For myself in my own clinical practice, I strive to improve the delivery of health education with patients undertaking a total joint replacement. My aim is that patients will become an active member of the partnership and participate with decisions regarding their health care. To raise their awareness of autonomy and self empowerment will encourage them to become part of the partnership so that they can assist with their transition back to normal daily life activities as soon as possible following their joint replacement surgery. Regularly re evaluating the pre operative education process which I am currently involved with, will be an ongoing process with changes implemented as required.

Looking back on my initial aim for this study of exploring patients' health educational experiences and their preparedness for joint surgery and rehabilitation, it appears that all patients were prepared for their actual joint surgery. However, some were not so prepared for the rehabilitation process including the intense physiotherapy that was required post operatively. As health professionals, we need to explore this further and find ways in which to assist patients to better address this need.

Chapter 5 gives a detailed insight into how the participants perceived the benefits of the health education they received, both pre operatively and in the rehabilitation period. Using the participants' quotes enables the story to be more authentic and captures the second aim of this study. I wish to thank the participants who took part in this study, who shared their experiences so willingly. What they had to say was meaningful and it captured consumers' voices so that other health professionals can be aware of their experiences. It is their stories that have given me an insight into their perspectives of the health education they received when they were undertaking joint replacement surgery, and has given me the drive to improve the delivery of health education and care in the future.

To understand the needs and expectations of patients following total joint replacement was another aim that I set out to discover. It was revealed that these 
will not always be the same for every patient having a total joint replacement and that individual care planning must be undertaken by health professionals, to produce the best possible patient outcomes. For this to occur, a relationship must be established to gain important, imperative data from the patients.

My last aim for this study was to explore concepts that may improve the structure, type and method of delivery in patient education when undertaking joint replacement surgery. This venture revealed that the structure currently in place for pre operative health education did meet the needs of the patients and further changes were not necessitated. However, further exploration into changing the type and method of delivery may be beneficial for better patient outcomes when undergoing total joint replacement surgery.

Through this project I have developed an insight into the practicalities of research practices and realities. It has given me an opportunity to make a scholarly contribution to orthopaedic nursing, by being able to develop, implement and evaluate my own research project. Once again, I am indebted to the participants who so willingly participated in this study - 'Patient experience of joint replacement education: A joint venture'. 


\section{Appendices}

\section{Appendix 1 Transcriber's Statement of Confidentiality.}

This is to certify that I

Of

fully understand that the information contained in these tapes and transcripts is confidential. I also agree not to discuss their content with anyone other than the researcher, Sheree Gare, at any time.

Signature:

Date: 


\title{
Appendix 2 Information Sheet
}

\author{
VICTORIA UNIVERSITY OF WELLINGTON \\ Te Whare Wananga o te Upoko o te Ika a Maui
}

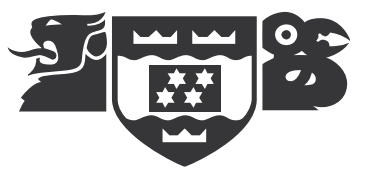

\section{INFORMATION SHEET FOR PARTICIPANTS.}

\section{Joint Venture: Educational experiences and the effects on rehabilitation post} joint replacement - patients' perspectives.

Hello. My name is Sheree Gare. I am currently undertaking my final year of my Masters in Nursing (Clinical), through Victoria University of Wellington. For my research I wish to hear from former patients who have undergone their first joint replacement and explore their journey in relation to the health education they received. I would like to hear their experiences and how they perceived this education to assist them throughout the journey of surgery and their recuperation

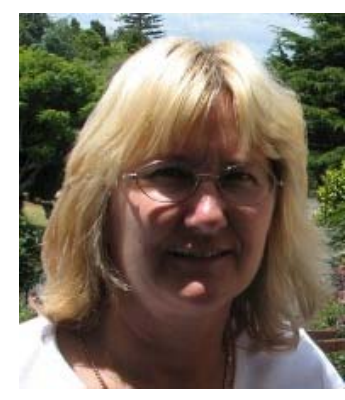
period.

To do this I need your help. I am looking for six to eight people who have recently had a total joint replacement who will share their experiences with me.

I have an extensive nursing background, having commenced my training in 1980 . I have worked at Waikato Hospital for the last 26 years. Over the past few years I have been involved with patients who need total joint replacements and have actively participated in the pre operative teaching of patients who are about to proceed with joint surgery. I am interested in the type of education given and how well it is portrayed and understood by patients like yourself.

You may recognise me from the above photo as being involved with your pre operative care. My aim of this study is not about my role in your care, but about the health education you received through your entire journey for your joint replacement.

I would like to meet with you on two occasions for approximately one hour each (or longer if required). On the first occasion I would like to interview you to hear your story and experiences about your joint surgery and the health education that was offered to you. This conversation will be audio taped to assist me to remember exactly what has been said. I will have the tape transcribed to assist 
with my exploration. I plan to look generally at trends across all participants. On the second occasion, information will be clarified.

I would be happy to have these meetings in your own home or at a mutually arranged place.

The information that is gained from this project may be of benefit to patients and health professionals and on completion it will be published and used in educational presentations. I will give my assurance that the information that you give will be kept confidential and no material which could personally identify you will be used in any reports of this study. All the transcripts will be kept in a safe place during this project and on completion will be stored for a further ten years prior to being destroyed. A summary of the research findings will be sent to you at the completion of the project, if you request.

I am happy to provide further information and answer any further questions you may have about this study. I can be contacted at home on 078236681 during the evenings and weekends, or my mobile 021721897 during work hours. You can gain further information about myself and my aims for this project from my supervisor, Cheryle Moss, Associate Professor, at the Graduate School of Nursing and Midwifery at Victoria University of Wellington. Phone 044636141.

This study has been approved by the Northern Y Regional Ethics Committee.

If you have any concerns during or after this study that you wish to discuss with other than the primary researcher, you may contact the Health and Disability Consumer Advocacy Service, 078343960.

Your participation is entirely voluntary. You do not have to take part in this study and if you choose not to, you will not be disadvantaged with your health care. Should you agree to participate in this project, please contact me within the next two weeks and express your interest at being involved with this study.

Thank you for your assistance and help with my project.

Yours sincerely,

Sheree Gare.

Post Graduate Student.

Graduate School of Nursing and Midwifery. 


\title{
Appendix 3 Consent Form
}

\author{
VICTORIA UNIVERSITY OF WELLINGTON \\ Te Whare Wananga o te Upoko o te Ika a Maui
}

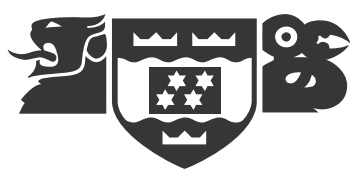

Joint Venture: Educational experiences and the effects on rehabilitation post joint replacement - patients' perspectives.

- I have been given and have understood an explanation of this research project.

- I have had an opportunity to ask questions and have had them answered to my satisfaction.

- I am aware that my participation is completely voluntary and the choice to participate or not participate will not affect my future health care or treatment that I may need.

- I understand that I may withdraw at any time from this study and may withdraw any information given without giving any reason and without any penalties.

- I understand that my name will not appear in any report of the research findings or presentations and that the information I share will remain anonymous.

- I understand that all interviews will be taped and transcribed.

- I understand that at the end of the project the researcher will keep the transcripts for a period of ten years and then destroy them.

- I am aware that this project has been approved by the Northern Y Regional Ethics Committee.

- I am aware that for any further concerns or questions that may arise, I may contact the main researcher, Sheree Gare, Phone 078236681 or Cheryle Moss, Associate Professor (Supervisor) on Phone 044636141. 
- I understand that I can contact the Health and Disability Consumer Advocacy Service, 07 8343960, if I have any concerns or issues during this study.

- I agree to take part in this research project.

I wish to have an advocate present during the interview.

I wish to be given a written report on completion of this study.

Signed:

Date:

Name of Participant: (please print clearly)

Statement by Researcher:

I have discussed the aims and procedures of this project with (the participant) and in my opinion consent was given freely and with understanding.

Signed:

Date:

Researcher’s name: Sheree Gare 


\section{Appendix 4 A Health Equity Assessment Tool (HEAT)}

The following set of questions have been developed to assist to consider how particular inequalities in health have come about, and where the effective intervention points are to tackle them.

1. What health issue is the policy/programme trying to address?

2. What inequalities exist in this health area?

3. Who is most advantaged and how?

4. How did the inequality occur? (What are the mechanisms by which this inequality was created, is maintained or increased?)

5. What are the determinants of this inequality?

6. How will you address the Treaty of Waitangi in the context of the New Zealand Public Health and Disability Act 2000?

7. Where/how will you intervene to tackle this issue? Use the Ministry of Health Intervention Framework to guide your thinking.

8. How could this intervention affect health inequalities?

9. Who will benefit most?

10. What might the unintended consequences be?

11. What will you do to make sure it does reduce/eliminate inequalities?

12. How will you know if inequalities have been reduced/eliminated? 


\section{Appendix 5 Maori Health Approval}

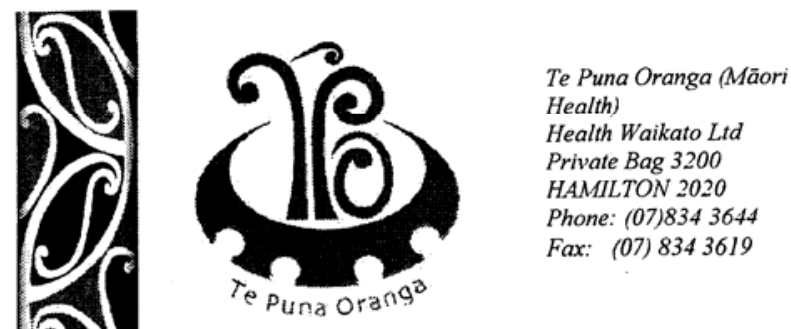

Sheree Gare

Orthopaedic Pre Admission Nurse Specialist/Research student VUW

196 Main Road

Ohaupo

Tena koe Sheree,

Re: "Joint venture: Relevance and helpfulness of education in rehabilitation following primary unilateral total joint replacement - patients' perspectives."

Thank you for submitting research material to the Kaumatua Kaunihera Ethics Subcommittee for comment. The Sub-committee read and discussed your research proposal and is pleased to have the opportunity to provide feedback.

The Sub-committee wish to reiterate a pivotal Maori research point that has been discussed and explained. We refer to discussions on ethnicity and research and the concept of 'Equal Explanatory Power'. We feel it is important to provide you with extra material to support your understanding of these concepts. We also encourage you to dedicate some time to understanding distinctions between race, culture and ethnicity as a way of understanding this specific piece of research advice.

Equal Explanatory Power refers to researcher's efforts to ensure that numbers of Maori participants support meaningful analysis by ethnicity. Ethnicity is therefore a primary variable and this is quite different from studies that are dedicated to examining aspects of. culture. The attached reading by Nikora (1995) is designed to clearly explain the concept of ethnicity (along with race and culture). We are not encouraging researchers to explore culture within research projects that are not specifically designed to do so. Again we are encouraging Equal Explanatory Power as opposed to cultural investigation.

We also recommend that you read the methodology section of the study cited below. The study is qualitative, achieves Equal Explanatory Power and asks the same qualitative questions of all participants regardless of ethnicity.

Reference: Lapsley, H., Nikora, L., Black, R.(2002). Kia Mauri Tau: Narratives of Recovery from Disabling Mental Health Problems.

In addition to considering the benefits of Equal Explanatory Power, we suggest that you develop relationships with Hospital Kaitiaki (Maori Patient Advocates) in an effort to recruit Maori participants. 


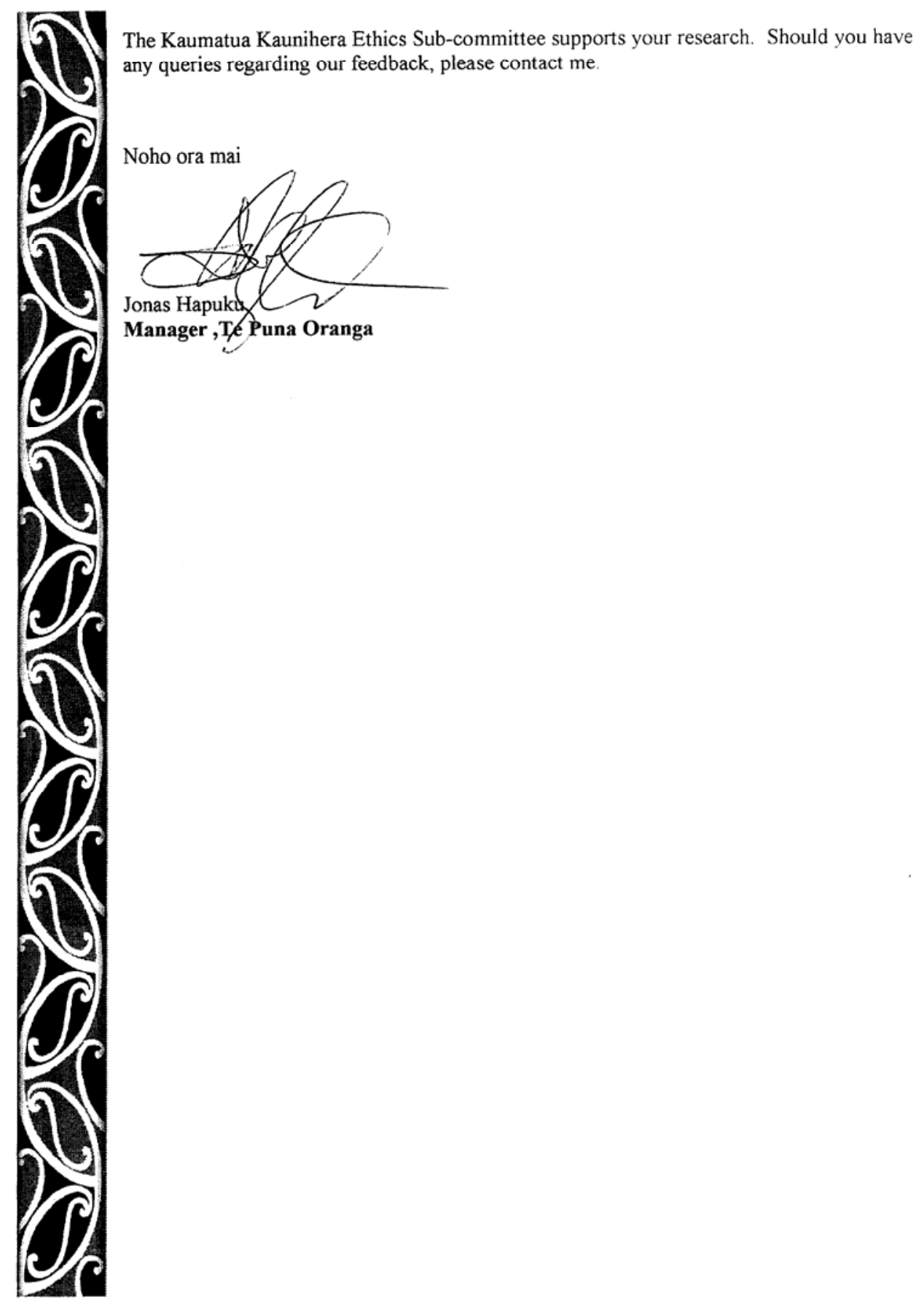




\section{Appendix 6 Northern Y Ethics Committee Approval}

Health
and
Disability
Ethics
Committees

25 July 2006

Ms Sheree Gare

196 Main Road

Ohaupo, Waikato

\author{
Northern Y Regional Ethics Committee \\ Ministry of Health

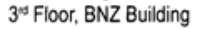 \\ 354 Victoria Street \\ PO Box 1031 \\ Phone (07) 8587021 \\ $\operatorname{Fax}(07) 8587070$
}

Dear Sheree

Joint Venture: Relevance and helpfulness of education in rehabilitation following primary unilateral total joint replacement - patients' experiences.

Investigators: Sheree Gare.

Ethics ref: NTY/06/05/040

Locations: Participants homes.

The above study has been given ethical approval by the Northern $Y$ Regional Ethics Committee.

Approved Documents

Information sheet and consent form- Joint Venture: Pre operative educational experiences and the effects on rehabilitation post joint replacement- patients' perspectives.

Transcribers Statement of Confidentiality

Accreditation

The Committee involved in the approval of this study is accredited by the Health Research Council and is constituted and operates in accordance with the Operational Standard for Ethics Committees, March 2002.

Final Report

The study is approved until 28 February 2007. A final report is required at the end of the study and a form to assist with this is available from the Administrator. If the study will not be completed as advised, please forward a progress report and an application for extension of ethical approval one month before the above date. Report forms are available from the administrator.

Amendments

It is also a condition of approval that the Committee is advised of any adverse events, if the study does not commence, or the study is altered in any way, including all documentation eg advertisements, letters to prospective participants.

Please quote the above ethics committee reference number in all correspondence.

It should be noted that Ethics Committee approval does not imply any resource commitment or administrative facilitation by any healthcare provider within whose facility the research is to be carried out. Where applicable, authority for this must be obtained separately from the appropriate manager within the organisation.

Yours sincerely

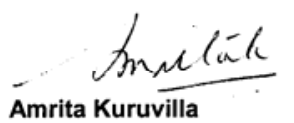

Northern Y Ethics Committee Administrator

Email: amrita_kuruvilla@moh.govt.nz 


\section{References}

Access Economics. (2005). Economic cost of arthritis in New Zealand. Retrieved on February 23, 2006, from http://www.arthritis.org.nz/index.php?section=news\&id=18

American Academy of Orthopaedic Surgeons. (2006a). Total Hip Replacement. Retrieved December 8, 2006, from http://orthoinfo.aaos.org/fact/thr_report.cfm?Thread_ID=504\&topcategory=Hip

American Academy of Orthopaedic Surgeons. (2006b). Total Knee Replacement. Retrieved December 8, 2006, from http://orthoinfo.aaos.org/fact/thr_report.cfm?Thread_ID=513\&topcategory=Knee

Armitage, S.K. \& Kavanagh, K.M. (1998). Consumer- orientated outcomes in discharge planning: A pilot study. Journal of Clinical Nursing, 7(1), 67-74.

Arthritis New Zealand. (n.d.). Types of arthritis. Retrieved July 31, 2005, from http://www.arthritis.org.nz/types/index.html

Babbie, E. (1979). The practice of social research. $3^{\text {rd }}$ Ed. California: Wadsworth.

Baldwin, M.A. (2003). Patient advocacy: A concept analysis. Nursing Standard, 17(21), 33-39.

Bandura Quotable Quotes. (2005). Retrieved April 30, 2005 from http://www.emory.edu/EDUCATION/mfp/banquotes.html

Bauman, Z. (2000). Liquid society. Cambridge: Polity.

Beanland, L., Schneider, Z., LoBiondo-Wood, G. \& Haber, J. (1999). Nursing research: Methods, critical appraisal and utilisation. Sydney: Mosby.

Beck, C.T. (1994). Phenomenology: Its use in nursing research. International Journal of Nursing Studies, 31(6), 499-510.

Berg, B.L. (1989). Qualitative research methods for the social sciences. New York: Allyn and Bacon.

Benner, P. (2001). From novice to expert: Excellence and power in clinical nursing practice. New Jersey: Prentice Hall Health.

Benner, P \& Wrubel, J. (1989). The primacy of caring. Stress and coping in health and illness. California: Addison-Wesley Publishing Company.

Bone and Joint Decade Joint Motion 2000-2010. Retrieved 15 August, 2006 from http://www.boneandjointdecade.org 
Breslow, L. \& Gale, T. (Eds) (2002). Alma-Ata Declaration. Encyclopedia of Public Health. Retrieved 14 January, 2007 from http://health.enotes.com/public-healthencyclopedia/alma-ata-declaration

Brooks, B.A. (2001). Using the internet for patient education. In J.M. Fielden, S. Scott \& J.G. Horne. An investigation of patient satisfaction following discharge after total hip replacement surgery. Orthopaedic Nursing, 22(6), 429-436.

Burnard, P. (1991). A method of analyzing interview transcripts in qualitative research. Nurse Education Today, 11(6), 461-466.

Butler, G.S., Hurley, C.A., Buchanan, K.l. \& Smith-Van Horne, J. (1996). Pre hospital education: Effectiveness with total hip replacement surgery patients. Patient Education and Counseling, 29(2), 189-197.

Chinn, P.L. \& Kramer, M.K. (1995). Theory and nursing - a systematic approach. $4^{\text {th }}$ Ed. Missouri: Mosby-Year Book Inc.

Christensen, J. (1990). Nursing partnership: A model for nursing practice. Wellington: Daphne Brasell Associates Press.

Cornwall, J. \& Davey, J.A. (2004). Impact of population ageing in New Zealand on the demand for health and disability support services, workforce implications. A background paper completed for the Ministry of Health in June 2003 by the New Zealand Institute for Research on Ageing (NZiRA) and the Health Services Research Centre (HSRC), Victoria University of Wellington. Wellington: Ministry of Health.

Coyle, J. \& Williams, B. (2001). Valuing people as individuals: Development of an instrument through a survey of person-centredness in secondary care. Journal of Advanced Nursing, 36(3), 450-459.

Crane Cutilli, C. (2005a). Do your patients understand? Determining your patients' health literacy skills. Orthopaedic Nursing, 24(5), 372-377.

Crane Cutilli, C. (2005b). Health Literacy. What you need to know. Orthopaedic Nursing, 24(3), 227-231.

Crowe, M. (2000). The nurse-patient relationship: A consideration of its discursive context. Journal of Advanced Nursing, 31(4), 962-967.

Daltroy, L., Morlino, C., Eaton, H., Poss, R. \& Liang, M. (1998). Pre operative education for total hip and knee replacement patients. Arthritis Care Research, 11(6), 469478.

Davis, C. (1995). Gender and the professional predicament in nursing. Buckingham: Open University Press.

Denzin, N.K. \& Lincoln, Y.S. (Eds) (1994). Handbook of Qualitative Research. Thousand Oaks, CA: Sage Publications. 
Denzin, N.K. \& Lincoln, Y.S. (Eds) (2005). The Sage Handbook of Qualitative Research. $3^{\text {rd }}$ Ed. Thousand Oaks, CA: Sage Publications.

Donovan, J., Dingwall, I. \& McChesney, S. (2006). Weight change 1 year following total knee or hip arthroplasty. ANZ Journal of Surgery, 76, 222-225.

Duldt, B.W., Giffin, K. \& Patton, B.R. (1984). Interpersonal communication in nursing. Philadelphia: Davis Company.

Edwards, C. (2003). Exploration of the orthopaedic patient's 'need to know'. Journal of Orthopaedic Nursing, 7, 18-25.

Emden, C. \& Sandelowski, M. (1998). The good, the bad and the relative, Part one: Conceptions of goodness in qualitative research. International Journal of Nursing Practice, 4, 206-212.

Emden, C. \& Sandelowski, M. (1999). The good, the bad and the relative, Part two: Goodness and the criterion problem in qualitative research. International Journal of Nursing Practice, 5, 2-7.

Erlen, J.A. (2006). Who speaks for the vulnerable? Orthopaedic Nursing, 25(2), 133-136.

Fellows, H., Lucas, B., Burgess, L., Abbott, D., Clare, A. \& Barlow, K. (1999). Orthopaedic pre-admission assessment clinics: Part 2. Journal of Orthopaedic Nursing, 3, 60-66.

Fellows, H., Lucas, B., Burgess, L., Abbott, D., Clare, A. \& Barlow, K. (1998). Orthopaedic pre-admission assessment clinics: Part 1. Journal of Orthopaedic Nursing, 2, 209-218.

Fielden, J. (2000). The Lifeworlds of Grief: Illuminating the lived experience of family members after a loved one has completed suicide. Unpublished Thesis: Victoria University of Wellington.

Fielden, J.M., Scott, S. \& Horne, J.G. (2003). An investigation of patient satisfaction following discharge after total hip replacement surgery. Orthopaedic Nursing, 22(6), 429-436.

Fox, D.J. (1982). Fundamentals of research in nursing. $4^{\text {th }}$ ed. New Jersey: AppletonCentury-Crofts.

French, B. (1995). The role of outcomes in the management of nursing. Nursing Researcher, 2(4), 5-13.

Gadow, S. (1983). Existential advocacy: Philosophical foundation in nursing. In Gates, B. (1994). Advocacy: A nurses’ guide. London: Scutari Press.

Gahlmer, J.E., Forsythe, E., Domhildt, E., Lewis, M.N., Corbin, K.E. \& Rosier, T. (1996). A retrospective study on the effectiveness of pre-operative patient 
education on post operative outcomes and efficiency of care in patients undergoing total hip arthroplasty. Issues on Aging, 19(1), 10-13.

Gammon, J. \& Mulholland, C.W. (1996). Effect of preparatory information prior to elective total hip replacement on post-operative physical coping outcomes. International. Journal of Nursing Studies, 33(6), 589-604.

Gates, B. (1994). Advocacy: A nurses’ guide. London: Scutari Press.

Giddens, A. (1991). Modernity and self-identity. Cambridge: Polity.

Gill, T., Taylor, A., Chittleborough, C. \& Dal Grande, E. (2003). “Is there a relationship between obesity and chronic conditions? Using surveillance data over a 10 year period”. Population Research and Outcomes Studies Unit, South Australian Dept of Human Services, Adelaide. Retrieved February 23, 2006, from http://www.dh.sa.gov.au/pehs/PROS/obesity-chron-cond-cond03.ppt

Glaser, B.G. \& Strauss, A.L. (1967). The discovery of grounded theory. New York: Aldine.

Gott, M. Ed. (2000). Nursing practice, policy and change. Oxon: Radcliffe Medical Press.

Grbich, C. (1999). Qualitative research in health: An introduction. St Leonards: Allen \& Unwin.

Guba, E.G. \& Lincoln, Y.S. (2005). Paradigmatic controversies, contraindications and emerging confluences. In N.K. Denzin \& Y.S. Lincoln (Eds.). The Sage Handbook of Qualitative Research. (pp 191 - 215). Thousand Oaks, CA: Sage Publications.

Guba, E.G. \& Lincoln, Y.S. (1981). Effective evaluation. San Francisco: Jossey-Bass. In M. Sandelowski. (1986). The problem of rigour in qualitative research. Advances in Nursing Science, 8(3), 27-37.

Hagerty, B.M. \& Patusky, K.L. (2003). Reconceptualising the nurse-patient relationship. Journal of Nursing Scholarship, 35(2), 145-150.

Hartweg, D.L. (1991). Dorothea Orem - Self-care deficit theory. California: Sage Publications.

Health of Older People Strategy. (2002). Retrieved August 18, 2006, from http://www.moh.govt.nz/publications/hops

Health Promotion Forum of New Zealand. (n.d.). Retrieved July 26, 2005, from http://www.hpforum.org.nz/page.php?7

Heartfield, J. (2004). Zombie anti-imperialists v's the 'Empire'. Retrieved on 20 June, 2006, from http://www.spiked-online.com/articles/0000000CA6BA.htm 
Higgs, J. \& Bithell, C. (2001). Professional expertise. In J. Higgs and A. Titchen (Eds.). Practice Knowledge \& Expertise in the health professions. (pp 58-68). Oxford: Butterworth-Heinemann.

Hilton, A. (2001). Should we evaluate qualitative studies - if so, how? Research Column. International Cancer Nursing News, 13(2), 2.

Hodgson, P. (2007). Building quality into our health system. Retrieved on 26 March, 2007, from www.beehive.govt.nz/Print/PrintDocument.aspx?DocumentID=28773

Holloway, I. \& Wheeler, S. (1996). Qualitative research for nurses. Oxford: Blackwell Science.

Hope, T. (1995). Evidence based medicine and ethics. Journal of Medical Ethics, 21, 259-260.

King, A. (2004). Implementing the New Zealand Health Strategy 2004. Retrieved on 20 March, 2005, from http://www.beehive.govt.nz/Print/PrintDocument.aspx?DocumentID=21766

Kinsella, K. \& Velkoff, V.A. (2001). An aging world: 2001, U.S. Government Printing Office, Washington, DC. Retrieved on 16 November, 2005, from http://www.census/gov/prod/2001pubs/p95-01-1.pdf

Krueger, R.A. (1994). Focus Groups: A practical guide for applied research. ( $2^{\text {nd }}$ ed.). California: Sage Publications.

Labovitch, R.S., Bozic, K.J. \& Hansen, E. (2006). An evaluation of information available on the internet regarding minimally invasive hip arthroplasty. The Journal of Arthroplasty, 21(1), 1-5.

Langford, R.W. (2001). Navigating the maze of nursing research - An interactive learning adventure. Missourri: Mosby.

Lewis, C., Gunta, K. \& Wong, D. (2002). Patient knowledge, behaviour and satisfaction with the use of a pre-operative DVD. Orthopaedic Nursing, 21(6), 41-49.

Lichtenstein, R., Semaan, S. \& Marmar, E.C. (1993). Development and impact of a hospital-based perioperative patient education program in a joint replacement centre. Orthopaedic Nursing, 12(6), 17-25.

Lin, P.C., Lin, L.C. \& Lin, J.J. (1997). Comparing the effectiveness of different education programmes for patients with total hip arthroplasty. Orthopaedic Nursing, 16(5), 43-49.

Livesley, P.J. \& Rider, M.A. (1993). Joint replacement and patient education. International Orthopaedics, 17, 34-36.

Loft, M., McWilliam, C. \& Ward-Griffin, C. (2003). Patient empowerment after total hip and knee replacement. Orthopaedic Nursing, 22(1), 42-47. 
Lutjens, L.R.J. (1991). Callista Roy - An adaptation model. California: Sage Publications.

Malkin, K.F. (2000). Patients' perceptions of a pre-admission clinic. Retrieved on 7 March, 2003, from http://web3.epnet.com/citation.asp?tb=1\&_ua=bo+S\%5F+1st+Advances++in++N ursin...

Manson, J. (2006). Primary total hip arthroplasy audit 2002-2004. Presentation given in Orthopaedic Dept, Waikato Hospital, Tuesday, July 112006.

Marcinkowski, K., Wong, V.G. \& Dignam, D. (2005). Getting back to the future. A grounded theory study of the patient perspective of total knee joint arthroplasty. Orthopaedic Nursing, 24(3), 202-209.

Maskell, M. \& Wright, J. (1993). Pre-operative preparation for patients undergoing total joint replacement. CONA, 15(1), 12-15.

May, C. (1990). Research on nurse-patient relationships: Problems of theory, problems of practice. Journal of Advanced Nursing, 15(3), 307-315.

McCrea, M.A., Atkinson, M., Bloom, T., Merkh, K., Najera, I.L., Merkh, K. \& Smith, C. (2003). The healing energy of relationships. Nursing Administration Quarterly, 27(3), 240-248.

McDaniel, R.W. \& Bach, C.A. (1996). Focus group research: The question of scientific rigor. Rehabilitation Nursing Research, 5(2), 53-59.

McDonald, S., Green, S.E. \& Hetrick, S. (2004). Pre operative education for hip or knee replacements. The Cochrane Systematic Reviews 2004, Issue 1. Retrieved 15 March, 2005, from Art. No.:CD003526. DOI:10.1002/14651858.CD003526.pub2.

Meagher, J. (1996). Partnership or pretence. Surrey Hills: Psychiatric Rehabilitation Ass.

Messer, B. (1998). Reducing lengths of stays in the total joint replacement population. Orthopaedic Nursing, March/April Supplement, 23-25.

Middleton, S. \& Lumby, J. (1998). Exploring the precursors of outcome evaluation in Australia: Linking structure, process and outcome by peer review. International Journal of Nursing Practice, 4, 151-155.

Minichiello, V., Avoni, R., Timewell, E \& Alexander, L. (1990). In-depth interviewing: Researching people. Melbourne: Longman Cheshire Pty Ltd.

Ministry of Health and Public Health Consultancy, Te Roopu Rangahau Hauora a Eru Pomare. (2002). A Health Equity Assessment Tool. Department of Public Health, University of Otago and Ministry of Health.

Ministry of Health. (2002). Reducing Inequalities in Health. Wellington: Ministry of Health. 
Morgan, D.L. (1993). Focus Groups as Qualitative Research. California: Sage Publications.

Morrison, P. \& Burnard, P. (1997). Caring and communication. The interpersonal relationship in nursing. London: Macmillan Press Ltd.

Morse, J.M. \& Field, P.A. (1996). Nursing research: The application of qualitative approaches. $2^{\text {nd }}$ ed. London: Chapman \& Hall.

Muff, J. (1988). Of images and ideals: A look at socialization and sexism in nursing. In A. Hudson Jones. Ed. Images of nurses: Perspectives from history, art and literature. Philadelphia: University of Pennsylvania Press.

New Zealand Orthopaedic Association. (2006). New Zealand National Joint Register. Retrieved 12 August, 2006 from http://www.cdhb.govt.nz/njr/figures.htm

New Zealand Orthopaedic Association. (2005). New Zealand Joint Replacement Data Revealed. Retrieved 12 August, 2006 from http://www.nzoa.org.nz/page.php?page=81\&expandfldr=3

New Zealand Orthopaedic Association. (2003). The aging of New Zealand. An epidemic with major impact on musculo-skeletal disease. Wellington: NZ Orthopaedic Association.

Nikora, L.W. (1995). Race, culture and ethnicity-organisation of Maori social groups. A working paper. Hamilton: University of Waikato, Psychology Dept.

Noble-Adams, R. (1999). Ethics and nursing research 2: Examination of the research process. British Journal of Nursing, 8(14), 956-960.

O’Brien, M. (2001). Doing ethical research legally: Research ethics and the law. In M. Tolich, (Ed.). Research Ethics in Aotearoa New Zealand (pp.25-34), Auckland: Pearson Education.

Oregon Department of Human Services, (2004). Arthritis in Oregon, 2002 Data Report, DHS Health Services. Health Promotion and Chronic Disease Prevention Programme. Retrieved on July 26, 2005, from www.dhs.state.or.us/publichealth/arthritis/rpt2002/rpt2002.pdf

Parse, R.R., Coyne, A.B. \& Smith, M.J. (1985). Nursing research: Qualitative Methods. Marylands: Brady Communications Company.

Parsons, M. \& Greenwood, J. (2000). A guide to the use of focus groups in health care research: Part 1. Comtemporary Nurse, 9(2), 169-180.

Pellino, T., Tluczek, A., Collins, M., Trimborn, S., Norwick, H., Engelke, Z.K. \& Broad, J. (1998). Increasing self efficacy through empowerment: Pre operative education for Orthopaedic patients. Orthopaedic Nursing, July/August 48-59. 
Polit, D.F.B. \& Beck, C.T. (2004). Nursing research: Principles and methods. $7^{\text {th }}$ Ed. Philadelphia: Lippincott Williams \& Wilkins.

Poutasi, K.O. (2004). Annual report for the year ended 30 June, 2004. Retrieved on July 24, 2006, from http://www.moh.govt.nz/moh.nsf/UnidPrint/MH3518?OpenDocument

Plummer, K. (2005). Critical humanism and queer theory: Living with the tensions. In N.K. Denzin \& Y.S. Lincoln (Eds.). The Sage Handbook of Qualitative Research. (pp 191 - 215). Thousand Oaks, CA: Sage Publications.

Pointin, D.J. \& Webb, C. (1995). Assessing patient satisfaction, Part 1: The research process. Journal of Clinical Nursing, 4, 383-389.

Qidwai, W. (2005). Patient autonomy: Reflections from a developing country. Letters to the Editor. American Family Physician, 71(7), p 1261.

Radka, I.M. (2003). Handover and the consumer voice: The importance of knowing the whole, full story. Unpublished thesis. A thesis submitted to the Victoria University of Wellington in fulfillment of the requirements for the degree of Master of Arts in Nursing.

Rankin, S.H. \& Duffy Stallings, K. (1996). Patient education: Issues, principles, practices. $3^{\text {rd }}$ Ed. Philadelphia: Lippincott.

Rankin, S.H., Duffy Stallings, K., \& London, F. (2005). Patient education in health and illness. $5^{\text {th }}$ Ed. Philadelphia: Lippincott Williams \& Wilkins.

Roach, J.A., Tremblay, L.M. \& Bowers, D.L. (1995). A pre operative assessment and education programme: Implementation and outcomes. Patient Education and Counselling, 25, 83-88.

Rogers, J. \& Niven, E. (1996). Ethics - A guide for New Zealand Nurses. Auckland: Addison Wesley Longman.

Rolfe, G. (1996). Choosing the theory - practice gap: A new paradigm for nursing. Oxford: Butterworth-Heinemann.

Sackett, D. L., Richardson, W.S., Rosenberg, W., \& Hayes, R.B. (1997). Evidence-based medicine: How to practice and teach EBM. New York: Pearson Professional.

Salmond, S.W. (2005). Time for a humanity check. Nurses connecting...Nurses making a difference. Orthopaedic Nursing, 24(5), 311-312.

Sandelowski, M. (2000). Focus on research methods: Whatever happened to qualitative description? Research in Nursing and Health, 23, 334-340.

Sandelowski, M. (1995). Focus on qualitative research. Sample size in qualitative research. Research in Nursing and Health, 18(2), 179-183. 
Sandelowski, M. (1986). The problem of rigor in qualitative research. Advances in Nursing Science, 8(3), 27-37.

Sandelowski, M. \& Barroso, J. (2002). Finding the findings in qualitative research. Journal of Nursing Scholarship, 34(3), 213-219.

Santavirta, N., Lillqvist, G., Sarvimaki, A., Honkanen, V., Konttinen, Y. \& Santaqvirta, S. (1994). Teaching of patients undergoing total hip replacement surgery. International Journal of Nursing Studies, 31(2), 135-142.

Showalter, A., Burger, S. \& Salyer, J. (2000). Patients and their spouses' needs after total joint arthroplasty. Orthopaedic Nursing, 19(1), p 49-62.

Simons, J. \& Ewing, R. (2001). Using practical knowledge of the creative arts to foster learning. In J. Higgs \& A. Titchen (Eds.) Practice Knowledge \& Expertise in the Health Professions. (pp 186-191). Oxford: Butterworth-Heinemann.

Sjoling, M., Norbergh, K.G., Malker, H. \& Asplund, K. (2006). What information do patients waiting for and undergoing arthroplastic surgery want? Their side of the story. Journal of Orthopaedic Nursing, 10, 5-10.

Spalding, N.J. (1995). A comparative study on the effectiveness of a pre operative education programme for total hip replacement patients. British Journal of Occupational Therapy, 58(12),526-531.

Stein-Parbury, J. (2000). Patient and person. Developing interpersonal skills in nursing. $2^{\text {nd }}$ Ed. Marrickville: Harcourt Australia Pty Ltd.

Street, A. (2001). Professional knowledge and power relationships. In J. Higgs \& A. Titchen (Eds.) Practice Knowledge \& Expertise in the Health Professions. (pp 207-212). Oxford: Butterworth-Heinemann.

Streubert Speziale, H.J. \& Carpenter, D.R. (2003). Qualitative research in nursing: Advancing the humanistic imperative. 3rd ed. Philadelphia: Lippincott Williams \& Wilkins.

Tak, S.H. (2006). An insider perspective of daily stress and coping in elders with arthritis. Orthopaedic Nursing, 25(2), 127-132.

Tak, S.H. \& Hong, S.H. (2005). Use of the internet for health information by older adults with arthritis. Orthopaedic Nursing, 24(2), 134-138.

Thomas, K., Burton, D., Withrow, L. \& Adkisson, B. (2004). Impact of a pre operative education programme via interactive telehealth network for rural patients having total joint replacements. Orthopaedic Nursing, 23(1), 39-44.

Thompson, C., McCaughan, D., Cullum, N., Sheldon, T.A., Mulhall, A., \& Thompson, D.R. (2001). Research information in nurses' clinical decision making: what is useful? Journal of Advanced Nursing, 36(3), 376-388. 
Thorne, S.E. (1997). The art (and science) of critiquing qualitative research. Qualitative research: Issues for application. In J.M. Morse (Ed). Completing a qualitative project: Details and dialogue. (pp 117-132). Thousand Oaks, California.

Titchen, A. (2001). Skilled companionship in professional practice. In J. Higgs \& A. Titchen (Eds.) Practice Knowledge \& Expertise in the Health Professions. (pp 6979). Oxford: Butterworth-Heinemann.

Tobias, M. \& Howden-Chapman, P. (Eds.) (2000). Social inequalities in health, New Zealand 1999: A summary. Wellington: Ministry of Health.

Turnbull, G.I. (1994). Dialogue, educating tomorrow's colleagues: The physiotherapist in the university system. Physiotherapy Canada, 46(1), 9-14.

Turnbull, J. (1999). Intuition in nursing relationships: the result of 'skills' or 'qualities'? British Journal of Nursing, 8(5), 302-306.

Urry, J. (2000). Sociology beyond societies: Mobilities for the twenty-first century. London: Routldge.

Van Manen, M. (1990). Researching lived experience: Human science for an action sensitive pedagogy. Albany, NY: State University of New York Press.

Varelius, J. (2005). Health and autonomy. Medicine, Health Care and Philosophy, 8, 221-230.

Vermont Department of Health. (1999). “Chronic disease in Vermont: Arthritis”. Disease Control Bulletin, Vol 1:3, Retrieved on February 23, 2006, from www.state.vt.us/health/_hs/epidemiology/arthritis/arthritis/.htm

Waikato Hospital Inpatient Pain Service. (2004). Patient Controlled Analgesia Pamphlet. Waikato Hospital.

Webb, C. \& Kevern, J. (2001). Focus group as a research method: A critique of some aspects of their use in nursing research. Journal of Advanced Nursing, 33(6), 798805.

Williams, A. (2001). A literature review on the concept of intimacy in nursing. Journal of Advanced Nursing, 33(5), 660-667.

World Health Organisation. (n.d.). Declaration of Alma-Ata. Retrieved July 19, 2005, from http://www.euro.who.int/About WHO/Policy/20010827_1

World Health Organisation and the Bone and Joint Decade. (2001). The global economic and healthcare burden of muscular disease. Retrieved August 14, 2005, from http://www.ota/download/bjdExecSum.pdf

Yamashito, M., Forchuk, C. \& Mound, B. (2005). Nurse case management: Negotiating care together within a developing relationship. Perspectives in Psychiatric Care, 41(2), 62-70). 
Zager, L.R. \& Walker, E.C. (2005). One vision, one voice. Orthopaedic Nursing, 24(2), $130-133$. 